\title{
FLOWSHEET FOR RECOVERY OF CURIUM FROM POWER REACTOR FUEL REPROCESSING PLANT WASTE
}

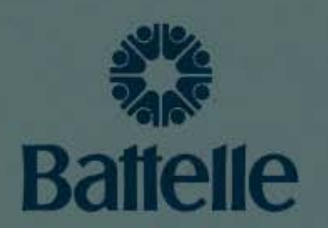

Pacific Northwest Laboratories

Richland, Washington 99352

\section{MAY 1974}

Prepared for the U.S. Atomic Energy Commission under Contract AT(45-1):1830 


\section{NOTICE}

The report was prepared as an account of work sponsored by the United States Government. Neither the United States nor the United States Atomic Energy Commission, nor any of their employees, nor any of their contractors, subcontractors, or their employees, makes any warranty, express or implied, or assumes any legal liability or responsibility for the accuracy, completeness or usefulness of any information, apparatus, product or process disclosed, or represents that its use would not infringe privately owned rights.

s.

\section{PACIFIC NORTHWEST LABORATORY operated by BATTELLE \\ for the \\ U.S. ATOMIC ENERGY COMMISSION \\ Under Contract AT(45-1)-1830}

Printed in the United States of America Available from

National Technical information Service U.S. Department of Commerce

5285 Port Royal Road

Springfield, Virginia 22151

Price: Printed Copy \$5.45; Microfiche \$1.45 


\section{2}

\section{FLOWSHEET FOR RECOVERY OF CURIUM FROM POWER REACTOR FUEL REPROCESSING \\ PLANT WASTE}
E. J. Wheelwright
L. A. Bray
H. H. Van Tuy 1
H. T. Fullam

May 1974

\section{BATTELLE}

PACIFIC NORTHWEST LABORATORY

RICHLAND, WASHINGTON 99352 
I. SUMMARY . . . . . . . . . . . . . . . . . . . 1

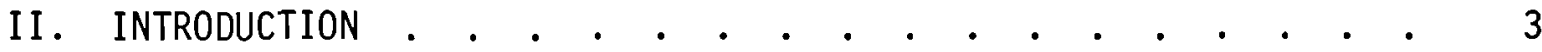

Identification of Need . . . . . . . . . . . . . . 3

Program Objectives . . . . . . . . . . . . . . . 4

Flowsheet Criteria . . . . . . . . . . . . . . . 4

Division of Responsibility . . . . . . . . . . . . 5

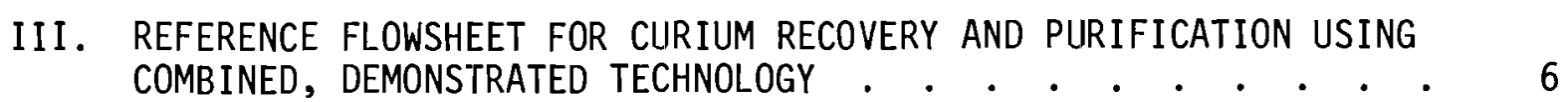

Integrated Flowsheet . . • . . . . . . . . . . . 6

Waste Disposal. . . . . . . . . . . . . . . . . 23

Discussion and Justification . . . . . . . . . . . 26

Development Work Required in Support of Plant Construction

and Operation. . . . . . . . . . . . . . 34

IV. IMPROVED FLOWSHEET FOR CURIUM RECOVERY AND PURIFICATION USING

NEW TECHNOLOGY. . . . . . . . . . . . . . . . . 36

Improved Flowsheet . . . . . . . . . . . . . . . 36

Isolation of the Lanthanide/Actinide Fraction . . . . . . 38

Separation of the Actinides from Lanthanides . . . . . . 38

Separation of Curium from Americium. . . . . . . . . . 39

Research and Development Requirements. . . . . . . . 40

V. NEPTUNIUM RECOVERY . . . . . . . . . . . . . . . 43

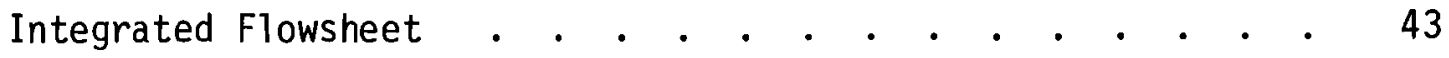

Neptunium Feed . . . . . . . . . . . . . . . . 43

REFERENCES . . . . . . . . . . . . . . . . . . . . 49

ACKNOWLEDGMENTS . . . . . . . . . . . . . . . . . . . 51

APPENDIX A - Alternate Methods for Curium Purification . . . . . A-1

APPENDIX B - Process Stream Flows and Compositions. . . . . . . B-1

DISTRIBUTION . . . . . . . . . . . . . . . . . . . Distr-1 


\section{$\underline{\text { LIST OF FIGURES }}$}

1 Flow Diagrain for Curium Recovery . . . . . . . . . . 7

2 Flowsheet for Solvent-Extraction Removal of Pu, Np and U from Clarified HLLW . . . . . . . . . . . . . . 12

3 Organic Solvent Cleanup Circuit . . . . . . . . . . . 13

4 Denitration and Clarification of Ion-Exchange Feed Solution . . . . . . . . . . . . . . . . . 15

5 Cation-Exchange Purification Flowsheet . . . . . . . . . 17

6 Ion-Exchange Flowsheet Time Cycles . . . . . . . . . . 18

7 Idealized Product Elution Curve . . . . . . . . . . . 22

8 Advanced Flowsheet for Curium Recovery and Purification . . . 37

9 Phase I - Concentration. . . . . . . . . . . . . . 45

10 Phase II - Decontamination . . . . . . . . . . . . . 46

11 Phase III - Neptunium Removal Cycle . . . . . . . . . . 47

12 Phase IV - Ion-Exchange Purification. . . . . . . . . . 48

A-1 The Karlsruhe Flowsheet . . . . . . . . . . . . . . A-2

A-2 The ORNL Flowsheet . . . . . . . . . . . . . . . A-5

A-3 Curium - Low Acid Process . . . . . . . . . . . . . A-6

A-4 Curium - High Acid Process . . . . . . . . . . . . . A-7

A-5 Curium - Final Processing . . . . . . . . . . . . . A-8

A-6 Anion-Exchange Flowsheet for Pu and Np Separation . . . . A-10

A-7 Time Cycle - Anion-Exchange Flowsheet . . . . . . . . . A-11

B-1 Flowsheet for Solvent Extraction Removal of Pu, $U$ and . . . B-3

B-2 Flowsheet for Sugar Denitration of Aqueous Curium Feed. . . B-15

B-3 Flow Diagram for Ion-Exchange Recovery and Purification
of Curium . . . . . . . . . . . B-23 


\section{$\underline{\text { LIST OF TABLES }}$}

1 Properties of Curium-244 . . . . . . . . . . . . . . 3

2 Barnwe11 HLLW Composition after 3-Year Cooling Period . . . . 9

3 Radiolytic Heat Output of Barnwell HLLW after 3-Year Cooling Period . . . . . . . . . . . . . . . . . 10

4 Cation-Exchange Flowsheet Resin-Bed Sizes . . . . . . . . 16

5 Displacement of the Actinide/Lanthanide Absorbed Band Down the Elution Columns . . . . . . . . . . . . . . 20

6 Data for Resin Bed Stripping. . . . . . . . . . . . . 24

7 Data for Resin Bed Regeneration. . . . . . . . . . . . 24

8 The Effect of Curium Recovery on BNFP Waste Management . . . . 25

9 Comparison of Operating Parameters. . . . . . . . . . . 32

10 Concentration of Actinides and Lanthanides in HLLW . . . . . 40

11 TBP Partition Coefficients as a Function of $\mathrm{HNO}_{3}$ Concentration. . . . . . . . . . . . . . . . 41

A-1 Karlsruhe Flowsheet - Stream Flows and Compositions . . . . . A-3

B-1 Basis for Design of Extraction and Stripping Columns . . . . B-4 


\section{SUMMARY}

Curium-244 has the potential of providing an inexpensive source of power for radioisotope thermoelectric generators. Flowsheets for the recovery of curium from spent-power-reactor fuels were studied and two selected flowsheets were recommended for further development as part of a program sponsored by the USAEC Division of Space Nuclear Systems with General Atomic Co. as principal contractor and BNW as subcontractor for process chemistry. The flowsheets were designed to process al1 of the high-level liquid waste from the Barnwell Nuclear Fuel Plant (5 tonnes of fuel per day) with the waste being aged 3 years before processing. Recovery of at 1 east $80 \%$ of the curium was desired with a product purity of over $97 \%$. Flowsheets were evaluated with respect to technical feasibility, time of curium availability, relative cost, and impact on waste management. $A$ secondary objective was to include neptunium recovery in the flowsheet.

Two flowsheets are described which merit continued development work: 1) a reference flowsheet consisting of solvent-extraction and ion-exchange steps, and 2) an improved flowsheet using only solvent extraction, but based on incomplete laboratory data. Other flowsheets were considered but rejected as inferior to the above flowsheets.

The reference flowsheet consists of the following steps: 1) feed clarification by centrifugation, 2) removal of $\mathrm{Pu}, \mathrm{Np}$ and $U$ by solvent extraction, 3) acid destruction by reaction with sugar, 4) a second clarification by centrifugation, 5) purification by ion exchange, and 6) waste disposal. The principal advantage of the reference flowsheet is that little additional process development is required, so that early curium availability is possible, while the principal disadvantage is the adverse impact on waste management.

The improved flowsheet consists of the same operations for the first four steps, followed by a solvent-extraction process to separate curium from the rare earths, other fission products, and process reagents. A final 
separation of curium from americium might require a small-scale ion-exchange operation. This flowsheet has the advantages of low cost and minimum inipact on wastes, but has the disadvantage of longer lead time before curium availability.

Each flowsheet is compatible with a neptunium recovery process demonstrated at the Hanford Purex Plant. Effluent from Step 2 ( $\mathrm{Pu}, \mathrm{Np}, \mathrm{U}$ removal) is concentrated, neptunium is further concentrated by solvent extraction, and on a compaign basis it is purified by ion exchange.

Additional research and development work is recommended on each of the two curium flowsheets so that options can be kept open for either early recovery of curium or recovery of curium at lowest cost. 


\section{INTRODUCTION}

\section{IDENTIFICATION OF NEED}

Some of the properties of curium-244 that pertain to this study are summarized in Table 1. These properties make ${ }^{244} \mathrm{Cm}_{2} \mathrm{O}_{3}$ attractive as a radioisotopic heat source in electrical power generators for a number of space applications. Preliminary estimates $(1)$ indicate that the cost per watt of power can be substantially lower from ${ }^{244} \mathrm{Cm}_{2} \mathrm{O}_{3}$ than from ${ }^{238} \mathrm{PuO}_{2}$ when the curium is recovered from high-level waste that has been accumulated during the reprocessing of spent nuclear fuel discharged from power reactors.

\section{TABLE 1. Properties of Curium-244}
Half-life
Specific Power (100\% Basis)
Melting Point of $\mathrm{Cm}_{2} \mathrm{O}_{3}$
Specific Power of $\mathrm{Cm}_{2} \mathrm{O}_{3}$
Compound Power Density (a)
Major Types of Radiation
Spontaneous Fission Half-life
$18.1 \mathrm{yr}$
$2.84 \mathrm{~W} / \mathrm{g}$
$2230^{\circ} \mathrm{C}$
$2.59 \mathrm{~W} / \mathrm{g}$
$29.4 \mathrm{~W} / \mathrm{cm}^{3}$
Alpha and Neutron
$1.4 \times 10^{7} \mathrm{yr}$
(a) This power density assumes an isotopic purity of $97 \%$ and a compound density of $90 \%$ of theoretical density.

The Division of Space Nuclear Systems, USAEC, initiated this program to develop accurate data on the recovery of curium from wastes generated by the Barnwell Nuclear Fuel Plant. The total amount of curium available from this source may be required for space use late in this decade or early in the next one. 


\section{PROGRAM OBJECTIVES}

The primary objectives of this study are to determine the time and capital investments necessary to develop a ful1-scale curium-244 recovery, processing, and encapsulation facility at the Barnwell Nuclear Fuel Plant (BNFP) as well as to estimate the quantity, quality, and cost of the curium-244 product recovered from the high-level liquid waste (HLLW). A secondary objective is to determine similar information for the recovery, processing, and encapsulation of neptunium-237 from the BNFP high-leve1 liquid waste.

\section{FLOWSHEET CRITERIA}

Discussions were held with cognizant scientists and engineers at Battelle Pacific Northwest Laboratories (PNL) September 21, 1973, Oak Ridge Nationa1 Laboratory (ORIVL) November 7, 1973, Savannah River Laboratory (SRL) November 8, 1973, and the BNFP November 8, 1973 to review state-of-the-art processing and to establish criteria for flowsheet selection. The criteria chosen to guide flowsheet selection and development are:

- High probability of technical feasibility (minimum economic risk)

- $100 \%$ of Barnwe11 HLLW to be processed (35 tonne spent fue1/week)

- HLLW aged approximately 3 years prior to processing

- Curium content assumed to be $25 \mathrm{gm} /$ tonne of fue 1 processed

- Minimum curium recovery is $80 \%$

- Minimum product purity is $97 \%$ (ORNL fuel characterization specification)

- Curium/neptunium facility to be adjunct but separate from BNFP

- Minimum impact on waste management - less than $20 \%$ additional nonvolatile solids if possible

- Minimum cost - capital costs should generally be minimized in favor of slightly increased operating costs

- Early availability of curium product.

The flowsheet can be applied to plutonium recycle fuels, in which the curium content will be increased by 30 to 100-fold. This will not significantly affect the size or operation of the curium recovery plant, but will decrease the unit cost of curium by a corresponding amount. Also, it can be applied to larger or smaller total throughputs by proper sizing of equipment. 


\section{DIVISION OF RESPONSIBILITY}

The curium/neptunium recovery study was performed by General Atomic Company as the prime contractor with technical assistance from the following subcontractors: Battelle, Bechtel, Inc., and Donald W. Douglas Laboratories (DWDL). The individual task assignments are listed below.

\section{General Atomic}

- Manage the program

- Integrate subcontractor tasks

- Develop operating cost data

- Interface with BNFP

Battelle

- Survey existing technology

- Develop process flowsheets based on existing technology for recovery and purification of curium-244 and neptunium-237 from BNFP high-level liquid waste

- Recommend follow-on R\&D

Bechtel

- Design and layout the processing equipment and physical plant in sufficient detail to make appropriate cost estimates for construction DWDL

- Develop procedures and specifications for manufacturing curium-244 heat sources and neptunium-237 irradiation targets from the purified materials

This final report summarizes the work performed by Battelle in completing the task assignments indicated above. 
III. REFERENCE FLOWSHEET FOR CURIUM RECOVERY AND PURIFICATION USING COMBINED, DEMONSTRATED TECHNOLOGY

Unit operations potentially applicable to curium recovery are acid destruction, thermal concentration, solution clarification, selective precipitation, solvent extraction, and ion exchange. Curium purification flowsheets employing combinations of these unit processes have been proposed by the Karlsruhe Nuclear Research Center ${ }^{(2)}$ and the Oak Ridge National Laboratory $(3,4)$ and are discussed in Appendix A. A combination flowsheet employing a cation-exchange final purification step was used at Hanford for the first recovery of curium from irradiated power-reactor fuel. $(5,6)$ This Hanford ion-exchange purification technique was subsequently modified at the Savannah River Laboratory by using micron-size resin in high-pressure columns at faster flow rates for the purification of curium from highly irradiated plutonium. ${ }^{(7,8)}$ Finally, in completing a state-of-the-art review, both a11-ion-exchange and al1-solvent-extraction flowsheets were developed and examined; see Appendix $A$ for details and a comparative review of these flowsheets.

\section{INTEGRATED FLOWSHEET}

The proposed reference flowsheet for curium recovery and purification from the BNFP HLLW is given in Figure 1. The individual processing steps are discussed in the following subsections and appropriate engineering data in support of the flowsheet are provided in Appendix B.

Barnwe11 HLLW

In the Barnwel1 Nuclear Fuel P1ant, spent power-reactor fuel will be dissolved and processed by solvent extraction at a rate of 5 tonnes/day to recover separate plutonium and uranium products. Small but significant amounts of plutonium and uranium, plus curium, americium, neptunium, a 11 fission products, gadolinium previously added to the dissolver as a soluble poison, and some non-radioactive metal salts will be discharged as a 
- Numbers indicate aVerage flows in gallons per day

- ion-exchange processing is batch operation

- all other operations are continUOUS

- each ION-EXCHANGE batch is 3.5 days flow

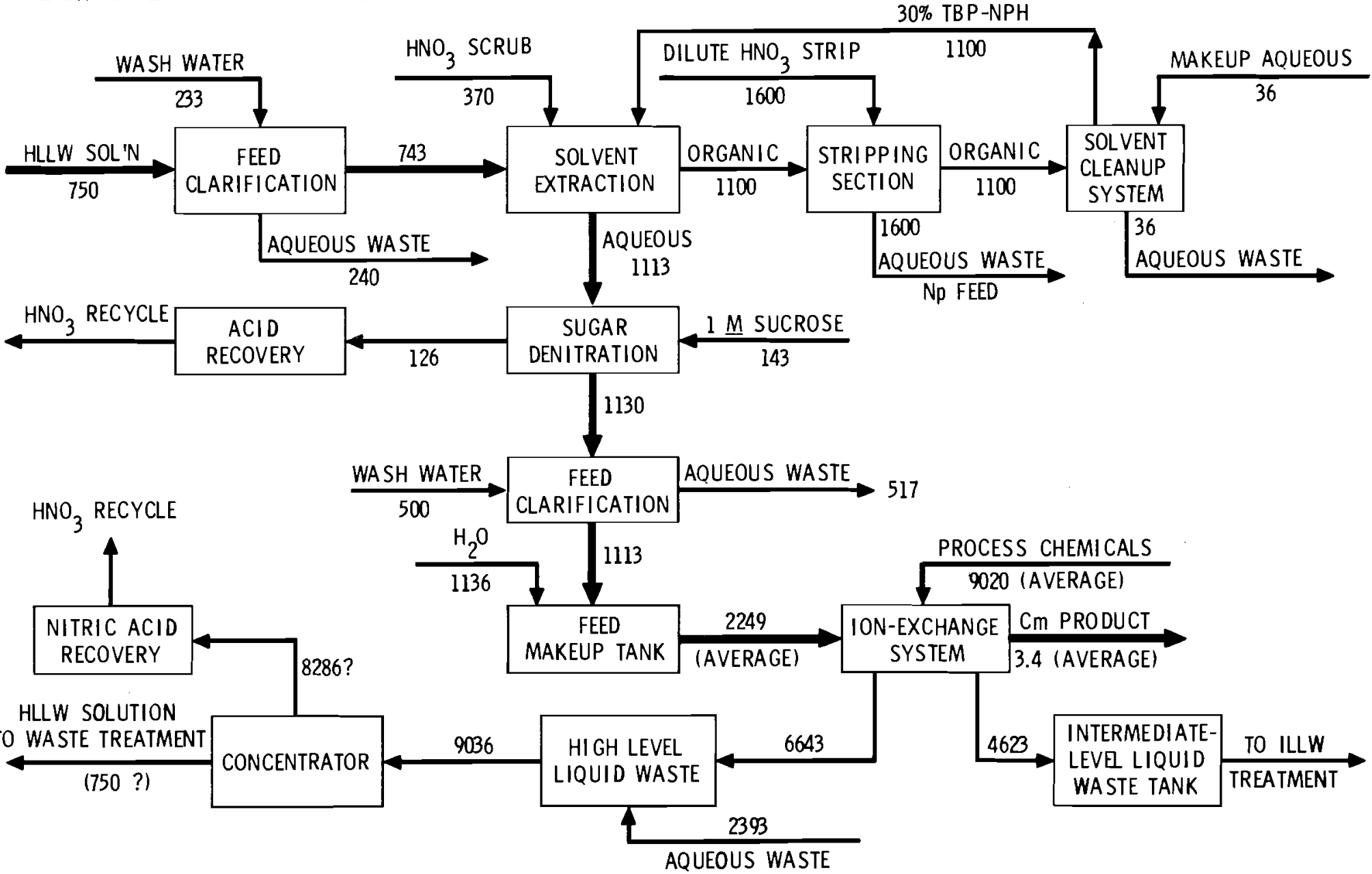

FIGURE 1. Flow Diagram for Curium Recovery 
high-level 1 iquid waste at a rate of $300 \mathrm{ga} 1 /$ tonne of processed fuel. By the end of a 3-year interim storage period, the heat generation rate will have decreased sufficiently to allow the waste to concentrate to a volume of $150 \mathrm{gal} /$ tonne of fuel. The composition of the HLLW at the end of the 3-year cooling period is given in Table 2 and the radiolytic heat output in Table 3. This then becomes the feed for the curium/neptunium recovery plant.

\section{Feed Clarification}

When discharged from the reprocessing plant, the HLLW will contain a significant quantity of suspended solids: principally zirconium, molybdenum, the noble metals and insoluble phosphates. The storage tanks are designed with mixing devices to keep these solids suspended. The HLLW composition is assumed to be $1 \%$ settled solids (by volume). The solidphase composition is assumed to be $35 \%$ solid material and $65 \%$ entrained aqueous phase. Because solids cause operational difficulties in solventextraction columns and severe plugging in ion-exchange resin beds, the initial processing step involves the removal of such solids by centrifugation. The only curium or neptunium losses anticipated at this step will be due to entrained aqueous phase in the separated solid phase. Such losses are expected to be less than $1 \%$ if the solids are not washed and less than $0.1 \%$ if the solids are washed and the wash solution returned to the aqueous stream.

Solvent Extraction

Table 2 shows that up to $100 \mathrm{~g}$ of Pu/tonne of processed fue 1 will be discharged in the HLLW. However, in the ion-exchange purification step, HLLW equivalent to 17.5 tonnes of fue 1 will be processed per batch in non-critically-safe equipment. Because the possibility of accumulating $1750 \mathrm{~g}$ of plutonium in a non-critically-safe geometry exists, a prior plutonium removal step is mandatory. The plutonium could be removed by anion exchange and such a process (see Appendix A) was carefully examined and then rejected. 
TABLE 2. Barnwe11 HLLW Composition after 3-Year Cooling Period

\begin{tabular}{|c|c|c|c|}
\hline Element & $\mathrm{g}$ /tonne & $\mathrm{Kg} /$ day & $\begin{array}{l}\text { Concentration } \\
\text { in Waste, M }\end{array}$ \\
\hline$H$ & 2,600 & 13.0 & 4.58 \\
\hline $\mathrm{Na}$ & 5,000 & 25.0 & 0.383 \\
\hline $\mathrm{Fe}$ & 20,000 & 100.0 & 0.631 \\
\hline $\mathrm{Cr}$ & 200 & 1.0 & 0.0067 \\
\hline $\mathrm{Ni}$ & 80 & 0.4 & 0.0025 \\
\hline $\mathrm{Se}$ & 14.4 & 0.072 & 0.0003 \\
\hline $\mathrm{Br}$ & 13.7 & 0.069 & 0.0003 \\
\hline $\mathrm{Rb}$ & 347 & 1.74 & 0.0071 \\
\hline $\mathrm{Sr}$ & 828 & 4.14 & 0.0163 \\
\hline Y & 416 & 2.08 & 0.0082 \\
\hline $\mathrm{Zr}$ & 3,710 & 18.55 & 0.0701 \\
\hline Mo & 3,560 & 17.80 & 0.0643 \\
\hline Tc & 822 & 4.11 & 0.0146 \\
\hline $\mathrm{Ru}$ & 2,330 & 11.65 & 0.0402 \\
\hline $\mathrm{Rh}$ & 505 & 2.53 & 0.0086 \\
\hline$P d$ & 1,520 & 7.60 & 0.0254 \\
\hline $\mathrm{Ag}$ & 82 & 0.41 & 0.0013 \\
\hline$c \mathrm{~d}$ & 136 & 0.68 & 0.0021 \\
\hline In & 1.6 & 0.008 & \\
\hline Sn & 25.7 & 0.13 & 0.0004 \\
\hline $\mathrm{Sb}$ & 10.8 & 0.054 & 0.0002 \\
\hline $\mathrm{Te}$ & 535 & 2.68 & 0.0073 \\
\hline Cs & 2,600 & 13.00 & 0.0340 \\
\hline $\mathrm{Ba}$ & 1,750 & 8.75 & 0.0224 \\
\hline La & 1,320 & 6.60 & 0.0167 \\
\hline $\mathrm{Ce}$ & 2,540 & 12.70 & 0.0317 \\
\hline $\mathrm{Pr}$ & 1,280 & 6.40 & 0.0160 \\
\hline $\mathrm{Nd}$ & 4,180 & 20.90 & 0.0507 \\
\hline $\mathrm{Pm}$ & 35.6 & 0.18 & 0.0004 \\
\hline $\mathrm{Sm}$ & 1,010 & 5.05 & 0.0119 \\
\hline Eu & 174 & 0.87 & 0.0020 \\
\hline Gd & 9,122 & 45.61 & 0.1021 \\
\hline $\mathrm{Tb}$ & 1.3 & 0.006 & \\
\hline $\mathrm{Hg}$ & 10 & 0.050 & 0.0001 \\
\hline $\mathrm{Np}$ & 482 & 2.41 & 0.0036 \\
\hline u & 10,000 & 50.00 & 0.0740 \\
\hline $\mathrm{Pu}$ & 100 & 0.50 & 0.0007 \\
\hline Am & 525 & 2.63 & 0.0038 \\
\hline & 25 & 0.125 & 0.0002 \\
\hline $\mathrm{NO} \overline{3}$ & 288,945 & $1,444.75$ & 8.21 \\
\hline $\mathrm{PO}_{4}^{-3}$ & 2000 & 10.0 & $\underline{0.0372}$ \\
\hline & 368,837 & $1,844.23$ & \\
\hline
\end{tabular}


TABLE 3. Radiolytic Heat Output of Barnwe11 HLLW after 3-Year Cooling Period(a)

\begin{tabular}{|c|c|c|c|}
\hline \multirow[b]{2}{*}{ Isotope } & \multicolumn{3}{|c|}{ Watts } \\
\hline & $\begin{array}{l}\text { per tonne of } \\
\text { fuel processed } \\
\end{array}$ & $\begin{array}{l}\text { per } 17.5 \text { tonne } \\
\text { of fuel processed }\end{array}$ & $\begin{array}{l}\text { per gallon } \\
\text { of solution }\end{array}$ \\
\hline${ }^{90} S r$ & 460 & 8,050 & 3.066 \\
\hline${ }^{106} \mathrm{Ru}$ & 540 & 9,450 & 3.600 \\
\hline${ }^{134} \mathrm{Cs}$ & 610 & 10,675 & 4.065 \\
\hline${ }^{137} \mathrm{Cs}$ & 440 & 7,700 & 2.933 \\
\hline${ }^{144} \mathrm{Ce}$ & 500 & 8,750 & 3.335 \\
\hline${ }^{147} \mathrm{Pm}$ & 12 & 210 & 0.079 \\
\hline${ }^{154} \mathrm{Eu}$ & 42 & 735 & 0.280 \\
\hline${ }^{155} \mathrm{Eu}$ & 2 & 35 & 0.008 \\
\hline${ }^{241} \mathrm{Am}$ & 40 & 700 & 0.265 \\
\hline${ }^{242} \mathrm{Cm}$ & 20 & 350 & 0.132 \\
\hline${ }^{244} \mathrm{Cm}$ & 65 & 1,138 & 0.431 \\
\hline Other & 10 & 175 & 0.068 \\
\hline & 2,741 & 47,968 & 18.26 \\
\hline
\end{tabular}

(a) The ion-exchange process is a batch operation and each batch of feed solution contains the waste from 17.5 tonne of fuel. 
A solvent-extraction system which uses pulse-column contactors and $30 \%$ tri-n-butylphosphate (TBP) in a normal paraffin hydrocarbon diluent (NPH) is proposed as the plutonium removal step for the following reasons:

- The technology is firmly established,

- The same system is employed in the BNFP which could simplify operator training and solvent handling,

- In addition to plutonium, both uranium and neptunium are extracted and can be recovered at this point.

Details of the extraction and stripping cycles are included in the flowsheet shown in Figure 2. Engineering data and distribution coefficients are given in Appendix B. A properly designed and operated system will provide for the removal of $99 \%$ of the plutonium and $98 \%$ of the uranium and neptunium from the HLLW. The curium losses from the HLLW will be less than $1 \%$. The aqueous acid strip of the TBP-NPH solvent becomes the feed solution for the neptunium concentration and purification cycle described in Section IV.

The used $30 \%$ TBP-NPH solvent will require a cleanup cycle similar to that used at BNFP prior to re-use. The used solvent is washed with an aqueous phase containing approximately $0.2 \mathrm{M}$ sodium carbonate (and possibly some potassium permanganate). Aqueous make-up is added as needed to maintain the carbonate concentration. Figure 3 gives the details of the solvent cleanup cycle.

\section{Sugar Denitration}

The nitric acid concentration of the aqueous raffinate from the solventextraction process must be reduced from approximately 3 molar to a value in the range of 0.5 to 0.75 molar to permit efficient absorption of curium by the ion-exchange resin used for final purification. Direct neutralization with caustic cannot be considered because the enormous quantity of sodium required would adversely affect final waste solidification and also seriously interfere with curium absorption by the resin. Acid destruction with formaldehyde or formic acid has been used, but the reaction is exothermic and difficult to control. $(9,10)$ Denitration of the aqueous raffinate down to $1.0 \mathrm{M} \mathrm{HNO}$ with $1 \mathrm{M}$ sucrose at $100^{\circ} \mathrm{C}$ has been demonstrated to be a safe, 
- NUMBERS INDICATE AVERAGE

flOWS IN GALLONS PER DAY

$\bullet=$ INDICATES CURIUM PATH

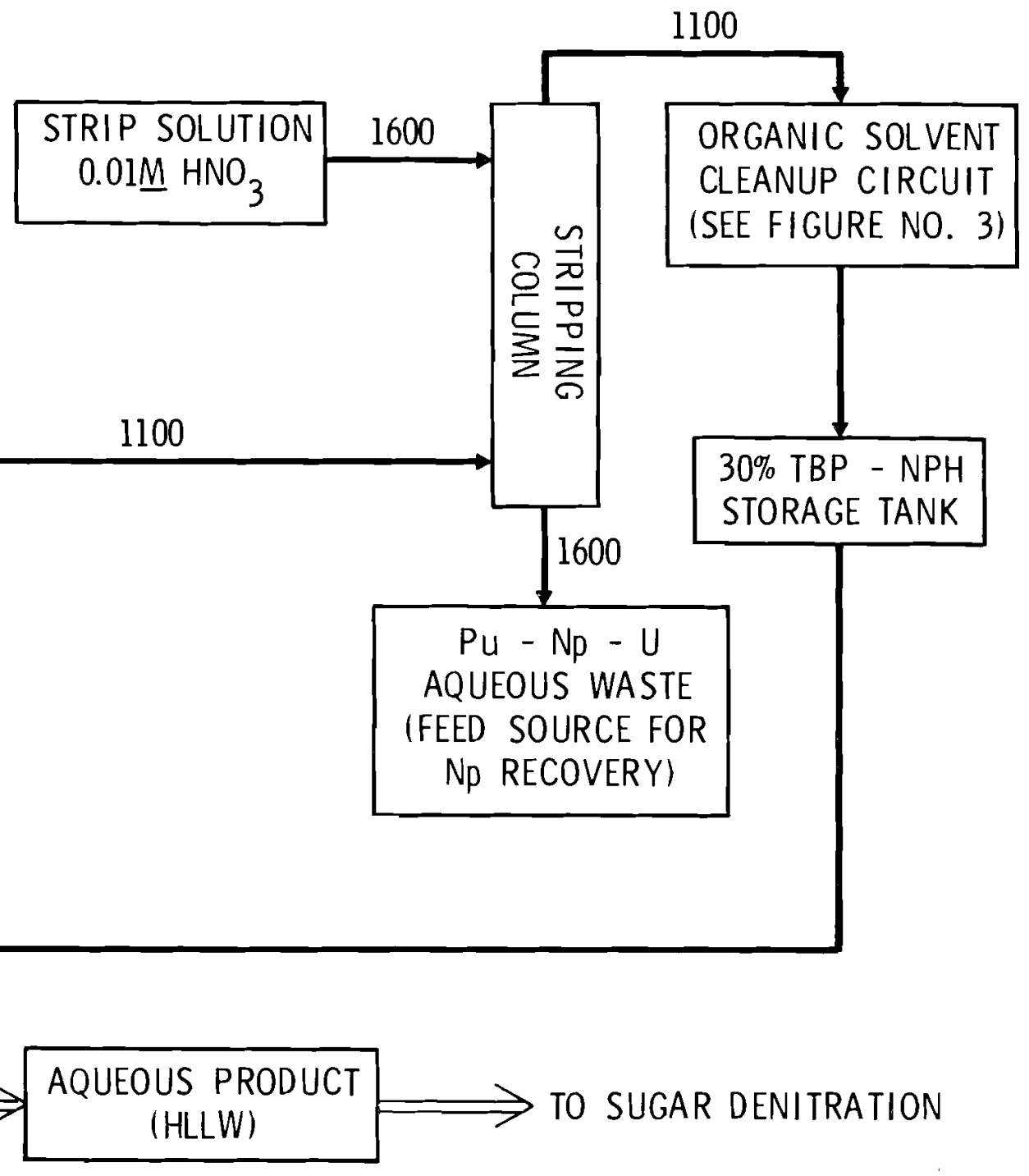

FIGURE 2. Flowsheet for Solvent-Extraction Removal of Pu, Np and $U$ from Clarified HLLW 


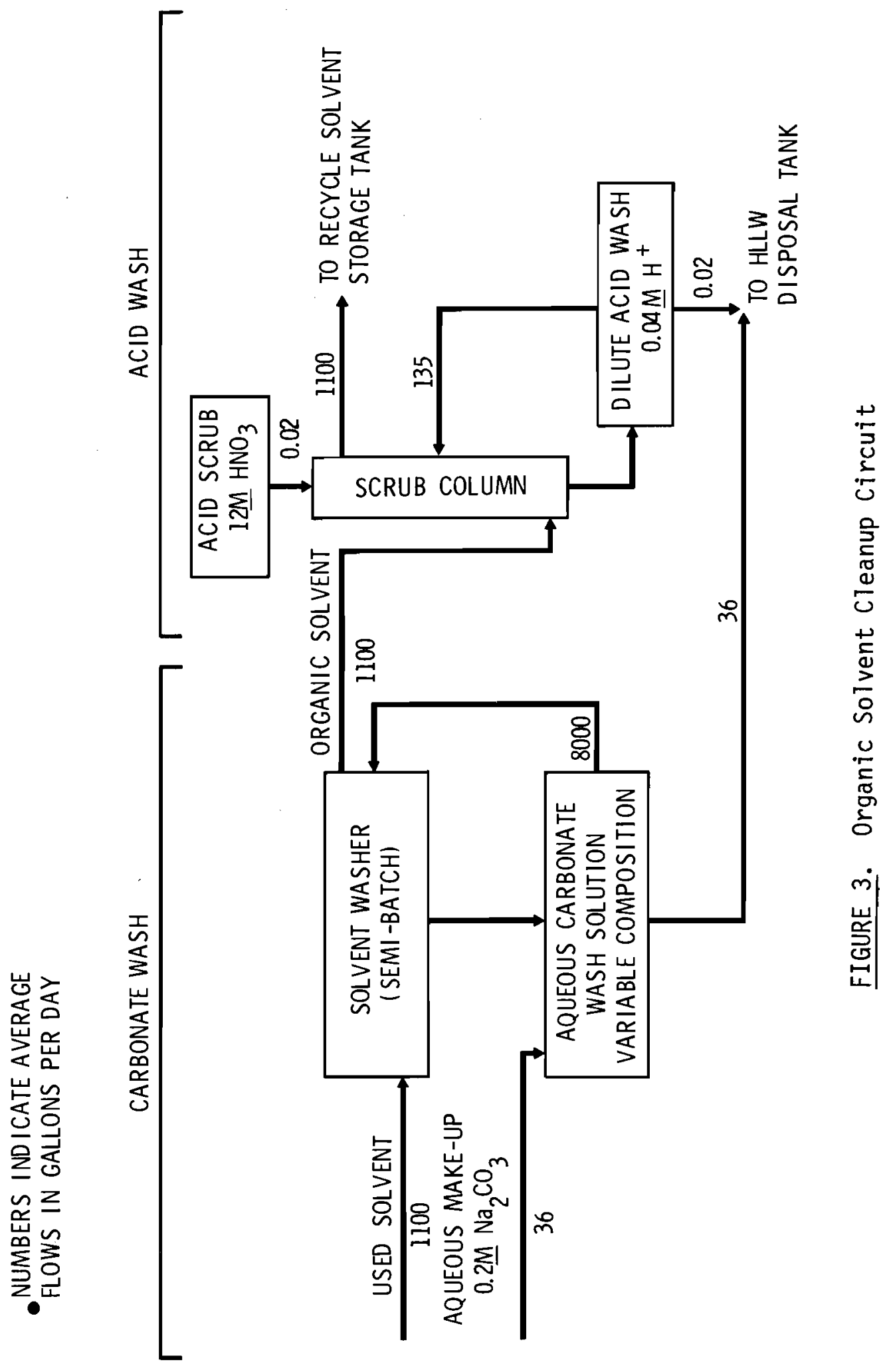


reliable process $(11)$ and is recommended for this acid destruction step. The denitration is terminated at $1 . \mathrm{OM}^{\mathrm{HNO}} \mathrm{H}_{3}$ to avoid the formation of excessive amounts of solids.

Details of the sugar denitration step are given in Figure 4 and Appendix B. Some water will evaporate during the denitration step; this has been assumed to be $10 \%$ of the water entering the denitration reactor. The system used to recover oxides of nitrogen from the sugar denitration step can be similar to that used in the BNFP and must be capable of handling at least 8700 gram moles of $\mathrm{NO}_{x}$ per day.

Feed Clarification

As the acid concentration is reduced by sugar denitration, additional solids (mostly noble metals) will be formed which must be removed from solution prior to the ion-exchange feed absorption step. This is functionaliy similar to the initial feed clarification step and could be performed in similar equipment.

Ion-Exchange Purification

The final processing step in the integrated flowsheet (Figure 1) separates curium from all other impurities in the treated HLLW by a "banddisplacement" cation-exchange process. This process, which is a batch operation, processes two batches per week under normal conditions and the amount of feed solution processed per batch corresponds to the HLLW accumulated from reprocessing 17.5 tonnes of spent fuel.

The ion-exchange purification process can be subdivided into seven steps or functions:

- Feed solution preparation

- Feed absorption

- Water wash of the saturated resin bed

- Elution of absorbed band down a sequence of smaller-sized resin beds

- Curium product and recycle collection

- Resin bed stripping

- Resin bed regeneration and/or replacement. 


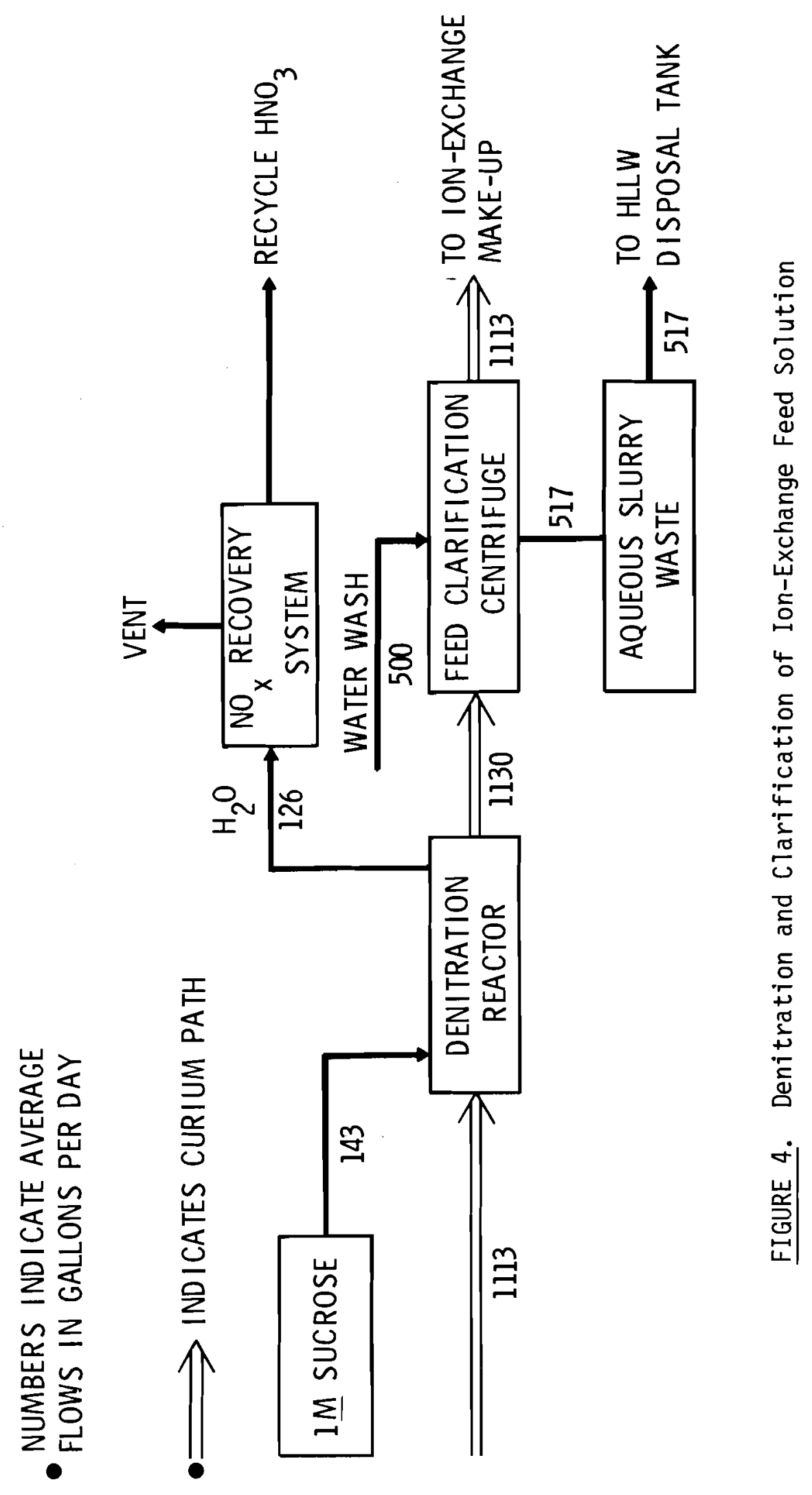


These processing steps are correlated in the cation-exchange purification flowsheet (Figure 5) and are discussed individually in the paragraphs that follow. For purposes of simplification, Figure 5 shows one column representing the feed absorption column and a second column representing the seven elution columns. The size and size ratio of each of the eight ion-exchange resin beds in this plant are given in Table 4, while the projected time cycle for these sequential steps is given in Figure 6.

The influent solutions and ion-exchange columns are heated by thermalexchange with thermostated water so that the resin beds are maintained at 60 to $70^{\circ} \mathrm{C}$ during the elution step. The recommended ion-exchange resin is Dowex 50W, X-8 (100 to 200 mesh) or its equivalent. To minimize the pressure drop through each bed, the resin will be hydrostatically graded into 3 or 4 particle size ranges and the individual columns filled with resin from the same particle size range. In general the larger particle size resin will be used in the larger columns and the smaller particle size resin will be used in the smaller columns. The specified complexing agent is diethylenetriaminepentaacetic acid (DTPA). The eluting solutions are prepared by slurrying DTPA in demineralized water and adding ammonium hydroxide until the desired solution $\mathrm{pH}$ is reached.

TABLE 4. Cation-Exchange Flowsheet Resin-Bed Sizes

\begin{tabular}{|c|c|c|c|c|c|}
\hline $\begin{array}{l}\text { Column } \\
\text { Number }\end{array}$ & Column Function & $\begin{array}{c}\begin{array}{c}\text { Volume, } \\
\text { gal }\end{array} \\
\end{array}$ & $\begin{array}{l}\text { Diameter, } \\
\text { in. }\end{array}$ & $\begin{array}{l}\text { Height, } \\
\mathrm{ft} \\
\end{array}$ & $\begin{array}{r}\mathrm{H} / \mathrm{D} \\
\text { Ratio } \\
\end{array}$ \\
\hline 1 & Feed Absorption & 1700 & 48.0 & 18.1 & 4.5 \\
\hline 2 & Elution & 565 & 28.0 & 17.7 & 7.6 \\
\hline 3 & Elution & 212 & 19.0 & 14.4 & 9.1 \\
\hline 4 & Elution & 79.3 & 12.0 & 13.5 & 13.5 \\
\hline 5 & Elution & 29.6 & 7.63 & 12.5 & 19.7 \\
\hline 6 & Elution & 11.1 & 4.81 & 11.8 & 29 \\
\hline 7 & Elution & 4.20 & 2.91 & 12.2 & 50 \\
\hline 8 & Elution & 1.06 & 1.94 & 6.80 & 42 \\
\hline
\end{tabular}




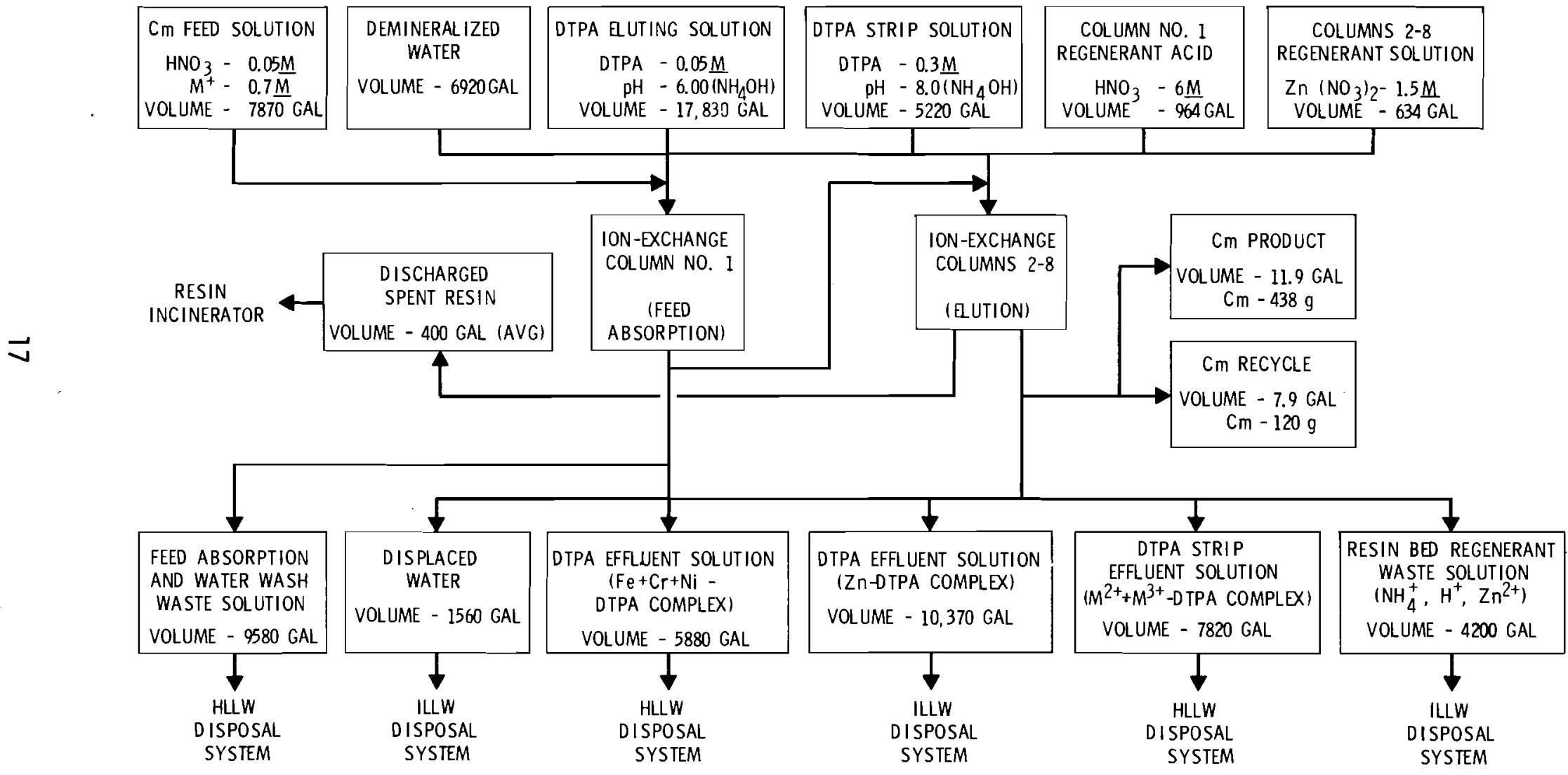

FIGURE 5. Cation-Exchange Purification Flowsheet 
HOURS

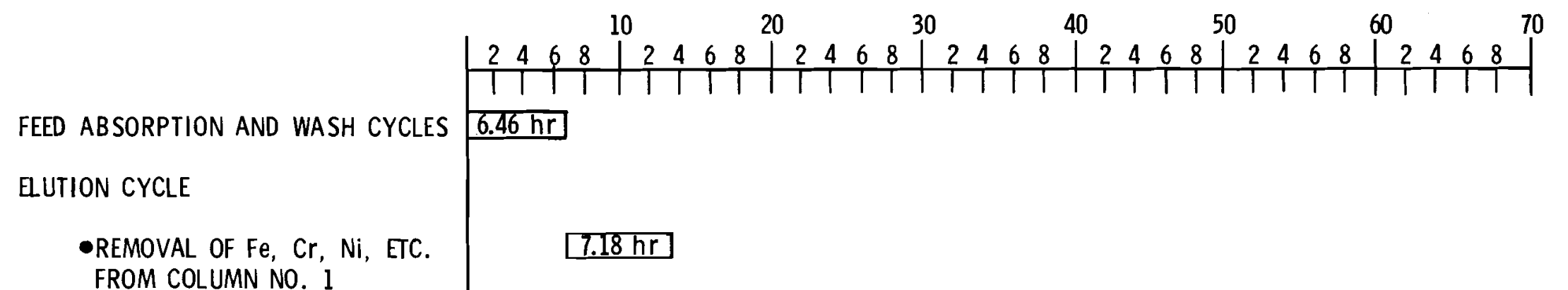
FROM COLUMN NO. 1

-DISPLACEMENT OF Zn FROM ELUTION COLUMNS

-PRODUCT AND REWORK COLLECTION

RESIN STRIP CYCLE

RESIN REGENERATION CYCLE

$32.5 \mathrm{hr}$

$4.10 \mathrm{hr}$

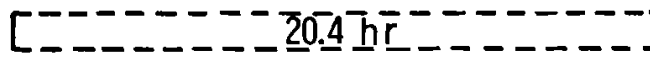

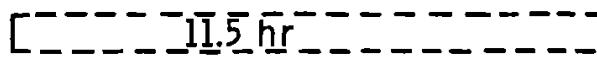

FIGURE 6. Ion-Exchange Flowsheet Time Cycles 
In the description of a separation cycle which follows, Column 1 initially contains the specified volume of resin in the $\mathrm{H}^{+}$cycle, re-settled in demineralized water. The elution columns are assumed to contain the specified volumes of the same resin, but then converted to the $\mathrm{Zn}^{2+}$ cycle and re-settled in demineralized water.

\section{Feed Solution Preparation}

The monovalent-ion concentration of the denitrated and clarified HLLW is too high for efficient absorption of curium and the other actinide/ lanthanide ions by the resin in the feed absorption column. However, a one-fold dilution with demineralized water irmediately before or during the feed absorption step is sufficient to correct this problem.

\section{Feed Absorption}

The feed absorption cycle is accomplished in 5.31 hours by pumping $7,870 \mathrm{ga} 1$ of the feed solution down-flow through Column 1 at a rate of $24.7 \mathrm{gpm}\left(8 \mathrm{ml} / \mathrm{min}-\mathrm{cm}^{2}\right)$.

\section{Water Wash of Saturated Resin Bed}

At the conclusion of the feed absorption cycle, Column 1 contains approximately $800 \mathrm{gal}$ of feed solution, and some resin at the bottom of the column has not reached an equilibrium loading of curium. The bed is then washed with $1700 \mathrm{gal}$ of demineralized water at a rate of $24.7 \mathrm{gpm}$ $\left(8 \mathrm{ml} / \mathrm{min}-\mathrm{cm}^{2}\right)$ to displace all unabsorbed feed solution and to increase the loading of the resin at the bottom of the column. The wash cycle requires $1.15 \mathrm{hr}$.

\section{Elution Cycle}

The elution cycle is initiated by connecting columns 1 and 2 in series and pumping the DTPA eluting solution through the system at a rate of $16.8 \mathrm{gpm}$ (corresponding to a flow rate of $16 \mathrm{ml} / \mathrm{min}-\mathrm{cm}^{2}$ through Column 2). The water is displaced from the two columns in about $1.35 \mathrm{hr}$ (1360 gal of solution). Then $\mathrm{Fe}^{3+}, \mathrm{Cr}^{3+}, \mathrm{Ni}^{2+}, \mathrm{Pu}^{4+}, \mathrm{Th}^{4+}$ and 
other absorbed ions which form complexes with DTPA that are stronger than the $\mathrm{Zn}^{2+}$-DTPA complex are removed from Column 1 and passed through Column 2 without any significant exchange. Approximately $5.83 \mathrm{hr}$ at the same flowrate $(5,880$ gal of effluent solution) are required to complete the removal to waste of these impurities, after which the remaining ions in the absorbed band on Column 1 start to elute down and displace the $\mathrm{Zn}^{2+}$ from the resin in Column 2 as the $\mathrm{Zn}^{2+}$-DTPA complex. At these specified conditions the rate of advance of the front edge of the absorbed lanthanide/actinide band is close to $33 \mathrm{in.} / \mathrm{hr}$ and the rate of volumetric displacement is $0.087 \mathrm{gal}$ of resin/gal of effluent solution collected.

As separation takes place, the ions of interest in the absorbed band start to collect into adjacent sub-bands in the order $\mathrm{Zn}, \mathrm{Cm}, \mathrm{Am}, \mathrm{Tb}, \mathrm{Gd}-\mathrm{Eu}$, $\mathrm{Sm}$, etc. When the front edge of the absorbed band reaches a point about $2 / 3$ of the distance down Column 2, Column 3 should be valved into the system so that the eluting solution then passes in sequence through Columns 1, 2 and 3 . The flow rate is held constant until an in-line gamma detector on the solution line between columns 2 and 3 indicates that curium activity is moving from Column 2 to Column 3. At that time the flow rate is reduced to $7.74 \mathrm{gpm}$ which corresponds to a flow rate of $16 \mathrm{ml} / \mathrm{min}-\mathrm{cm}^{2}$ through Column 3 . In a similar manner the remaining five columns are added ahead of the advancing absorbed band. Data concerning the advance of the absorbed band down the seven elution columns is given in Table 5 .

TABLE 5. Displacement of the Actinide/Lanthanide Absorbed Band Down the Elution Columns

\begin{tabular}{cccc}
$\begin{array}{c}\text { Column } \\
\text { Number }\end{array}$ & $\begin{array}{c}\text { Eluting Solution } \\
\text { Flow Rate, } \\
\text { gpm }\end{array}$ & $\begin{array}{c}\text { Effluent Solution } \\
\text { Required for } \\
\text { Bed Displacement, } \\
\text { gal }\end{array}$ & $\begin{array}{c}\text { Elution Time } \\
\text { Required for } \\
\text { Bed Displacement, } \\
\text { hr }\end{array}$ \\
\cline { 2 - 3 } 3 & 16.8 & 6500 & 6.45 \\
4 & 7.73 & 2430 & 5.24 \\
5 & 3.08 & 913 & 4.94 \\
6 & 1.25 & 340 & 4.53 \\
7 & 0.495 & 128 & 4.31 \\
8 & 0.180 & 48.4 & 4.48 \\
& 0.081 & 12.2 & 2.51 \\
\hline
\end{tabular}


As the front edge of the absorbed band moves onto successively smaller columins and the flow rate is reduced, the back edge moves at a progressively slower rate. Because the separation factors between curium and those ions which concentrate toward the back of the absorbed band is very large, curium is rapidly removed from that part of the band that elutes behind gadolinium. Therefore, when the inline detectors indicate that there is no more curium moving from Column 1 onto Column 2, Column 1 is valved out of the sequence. This should take place when or before Column 4 is added so that there are never more than three columns in the system at any one time. Other columns are removed in a like manner as the elution proceeds.

\section{Curium Product and Recycle Collection}

By the time the front edge of the absorbed band reaches the bottom of Column 8, curium and americium will have separated from all other impurities and from each other as shown in the elution curve in Figure 7. Most of the gadolinium and all ions which elute behind gadolinium will have been removed on trailing columns valved out of the elution column system. As the absorbed band elutes from the bottom of Column 8, the operator will divert the stream to collect the zinc-curium binary solution in the re-work tank, the pure curium fraction in the product tank, and then the curiumamericium binary fraction in the re-work tank. This fractionation can be done on the basis of information from a gamma detector-spectrometer on the product line. If desired, pure americium could be collected at no additional cost up to this point in the separation process.

\section{Resin Bed Stripping}

Each resin bed that is valved out of the elution sequence will be at least partially saturated with ions absorbed from the treated HLLW during the feed absorption step. Since these include ${ }^{90} \mathrm{Sr}$ and ${ }^{144} \mathrm{Ce}$, which generate substantial energy on decay, each resin bed must be immediately 


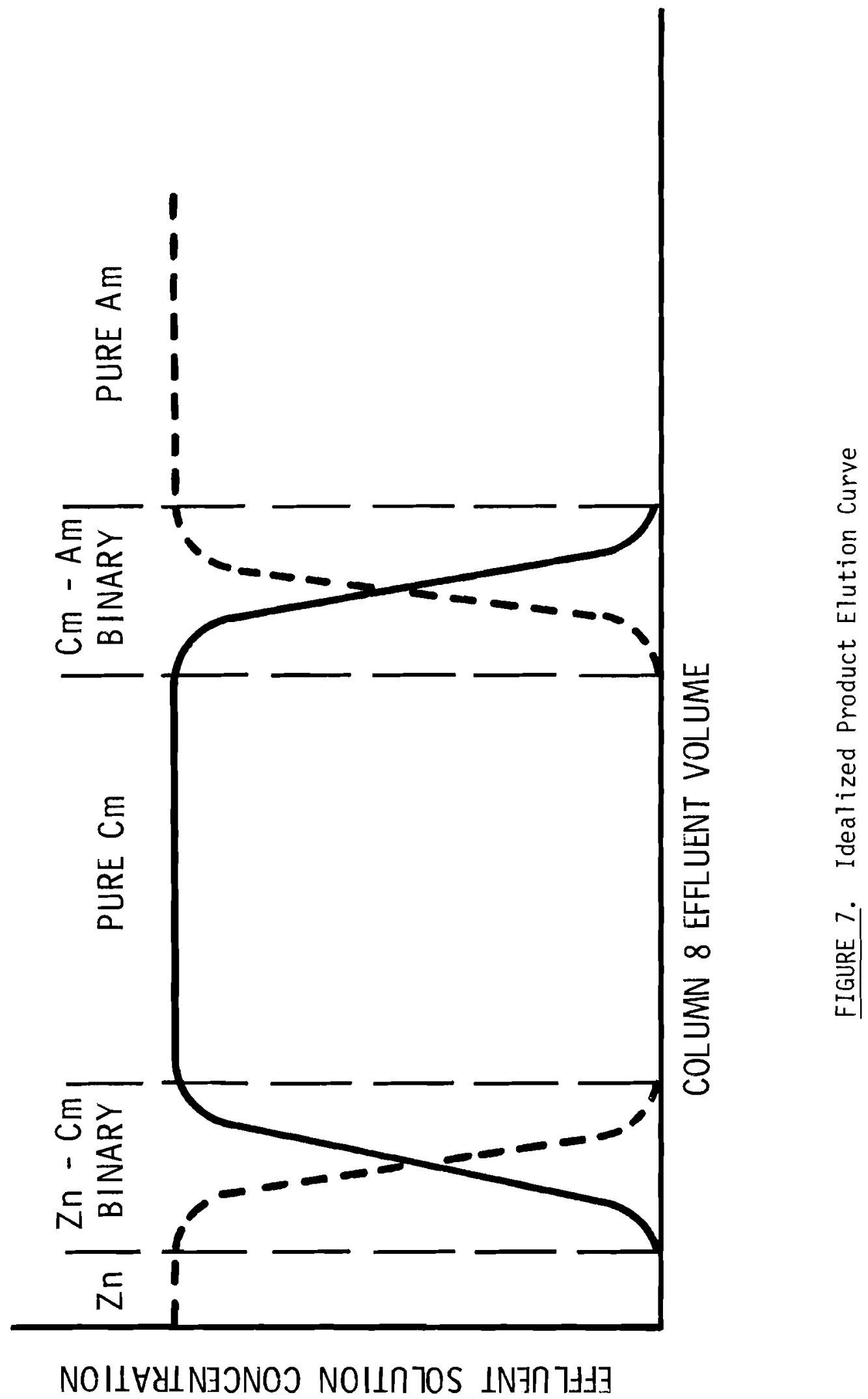


stripped free of such materials with the 0.3M DTPA stripping solution and then be water washed to minimize resin damage and prevent self-heating of the resin beds. Solution volumes, flow rates and time cycles for these steps are given in Table 6.

\section{Resin Bed Regeneration}

Each resin bed must be regenerated to complete the ion-exchange cycle. When the resin beds are stripped, the resin is left in the $\mathrm{NH}_{4}^{+}$cycle. Column 1 is converted to the $\mathrm{H}^{+}$cycle with $\mathrm{HNO}_{3}$ to avoid the massive addition of ammonium ion to the HLLW during the subsequent feed absorption cycle. The remaining beds are converted to the $\mathrm{Zn}^{2+}$ cycle as a prerequisite for the next elution cycle. A11 waste produced during the regeneration should be of intermediate level activity. The conditions for the regeneration are given in Table 7. After each bed has been regenerated and water washed, the bed is re-settled by pumping a small volume of water up-flow through the bed.

The resin will degrade as a result of accumulative radiation damage. The rate of degradation increases with exposure time and the concentration of higher specific power isotopes absorbed on the resin. Thus, the need for replacement will vary from four to six times/yr for the largest columns down to weekly for the final columns where the curium band is concentrated. When resin is changed in a given column, all the resin will be removed and replaced at one time. In the purification cycle, resin should be changed out after it has been stripped, but before it is regenerated. The average resin replacement rate is estimated to be 400 gal/purification run.

\section{WASTE DISPOSAL}

A waste disposal designation is assigned to each of the ion-exchange effluent solutions in Figure 5 . The ion-exchange purification process increases the volume of the HLLW stream from 7790 to $46,600 \mathrm{gal} /$ week and produces an additional 32,300 gal of ILLW/week. The solvent extraction and centrifugation steps adds an additional 16,800 gal of high-level waste per week. The effect of the curium recovery reference flowsheet on the BNFP waste disposal operation is shown in Table 8 . Both the high-level 
TABLE 6. Data for Resin Bed Stripping

\begin{tabular}{|c|c|c|c|c|c|c|}
\hline \multirow[b]{2}{*}{$\begin{array}{l}\text { Column } \\
\text { Number } \\
\end{array}$} & \multicolumn{3}{|c|}{ DTPA Stripping Solution } & \multicolumn{3}{|c|}{ Water Wash } \\
\hline & $\begin{array}{l}\text { Volume, } \\
\text { gal }\end{array}$ & $\begin{array}{c}\text { Flow Rate, } \\
\mathrm{gpm}\end{array}$ & $\begin{array}{l}\text { Time, } \\
\mathrm{hr}\end{array}$ & $\begin{array}{c}\text { Volume, } \\
\text { gal } \\
\end{array}$ & $\begin{array}{c}\text { Flow Rate, } \\
\mathrm{gpm}\end{array}$ & $\begin{array}{l}\text { Time, } \\
\mathrm{hr}\end{array}$ \\
\hline 1 & 3410 & 24.7 & 2.30 & 1700 & 24.7 & 1.15 \\
\hline 2 & 1130 & 8.40 & 2.24 & 565 & 8.40 & 1.12 \\
\hline 3 & 423 & 3.86 & 1.83 & 212 & 3.86 & 0.92 \\
\hline 4 & 159 & 1.54 & 1.72 & 79.3 & 1.54 & 0.86 \\
\hline 5 & 59.4 & 0.624 & 1.59 & 29.6 & 0.624 & 0.79 \\
\hline 6 & 22.5 & 0.248 & 1.51 & 11.2 & 0.248 & 0.75 \\
\hline 7 & 8.45 & 0.090 & 1.56 & 4.20 & 0.090 & 0.78 \\
\hline 8 & 2.11 & 0.040 & 0.88 & 1.06 & 0.040 & 0.44 \\
\hline
\end{tabular}

TABLE 7. Data for Resin Bed Regeneration

\begin{tabular}{|c|c|c|c|c|c|c|}
\hline \multirow[b]{2}{*}{$\begin{array}{l}\text { Column } \\
\text { Number }\end{array}$} & \multicolumn{3}{|c|}{$\mathrm{HNO}_{3}$ Conversion } & \multicolumn{3}{|c|}{ Water Wash } \\
\hline & $\begin{array}{c}\text { Volume, } \\
\text { gal }\end{array}$ & $\begin{array}{c}\text { Flow Rate, } \\
\text { gpm }\end{array}$ & $\begin{array}{l}\text { Time, } \\
\mathrm{hr}\end{array}$ & $\begin{array}{c}\begin{array}{c}\text { Volume, } \\
\text { gal }\end{array} \\
\end{array}$ & $\begin{array}{c}\text { Flow Rate, } \\
\text { gpm }\end{array}$ & $\begin{array}{l}\text { Time, } \\
\mathrm{hr}\end{array}$ \\
\hline 1 & 964 & 24.7 & 0.65 & 1700 & 24.7 & 1.15 \\
\hline \multicolumn{7}{|c|}{$\left[\mathrm{Zn}\left(\mathrm{NO}_{3}\right)_{2}\right.$ Conversion $]$} \\
\hline 2 & 397 & 8.40 & 0.79 & 565 & 8.40 & 1.12 \\
\hline 3 & 149 & 3.86 & 0.64 & 212 & 3.86 & 0.92 \\
\hline 4 & 55.7 & 1.54 & 0.60 & 79.3 & 1.54 & 0.86 \\
\hline 5 & 20.9 & 0.624 & 0.56 & 29.6 & 0.624 & 0.79 \\
\hline 6 & 7.93 & 0.248 & 0.53 & 11.2 & 0.248 & 0.75 \\
\hline 7 & 3.04 & 0.090 & 0.56 & 4.20 & 0.090 & 0.78 \\
\hline 8 & 0.793 & 0.040 & 0.33 & 1.06 & 0.040 & 0.44 \\
\hline
\end{tabular}


TABLE 8. The Effect of Curium Recovery on BNFP Waste Management Basis: Waste load from processing 17.5 tonnes of fuel (3.5 days)

\begin{tabular}{|c|c|c|c|c|}
\hline & & Barnwe 11 & Curium Pro & sing Waste \\
\hline & & HLLW & HLLW & ILLW \\
\hline Volume & (gallons) & 2,625 & $31,625^{(a)}$ & $16,180^{(a)}$ \\
\hline $\mathrm{H}^{+}$ & (gram-moles) & 45,500 & 36,135 & 10,940 \\
\hline $\mathrm{Na}^{+}$ & (gram-moles) & 3,805 & 4,032 & \\
\hline $\mathrm{NO}_{3}^{-}$ & (gram-moles) & 81,500 & 61,250 & 29,100 \\
\hline $\mathrm{PO}_{4}^{3+}$ & (gram-moles) & 371 & $>371^{(b)}$ & \\
\hline $\mathrm{Fe}-\mathrm{Ni}-\mathrm{Cr}$ & (gram-moles) & 6,356 & $>6,356^{(c)}$ & \\
\hline RE's & (gram-moles) & 2,303 & 2,303 & \\
\hline FP's & (gram-moles) & 3,213 & 3,213 & \\
\hline Actinides & (gram-moles) & 818 & 816 & \\
\hline $\mathrm{Zn}^{2+}$ & (gram-moles) & 0 & & 3,600 \\
\hline $\mathrm{NH}_{4}^{+}$ & (gram-moles) & 0 & 14,015 & 16,848 \\
\hline DTPA & (gram-moles) & 0 & $7,338^{(d)}$ & 1,963 \\
\hline Resin & (ga11ons) & 0 & & \\
\hline
\end{tabular}
(a) Before thermal concentration
(b) Depends on solvent degradation in solvent extraction circuit
(c) Depends on corrosion in curium recovery plant
(d) Initial Leve 1 - will decrease as DTPA is destroyed 
and intermediate-level waste streams are concentrated prior to return to the BNFP for solidification. Engineering details of the waste disposal are provided in Appendix B.

The spent resin can be decomposed in $\mathrm{HNO}_{3}-\mathrm{H}_{2} \mathrm{O}_{2}$ or can be incinerated. Direct incineration is proposed because the aqueous decomposition waste would require further treatment prior to final disposal.

\section{DISCUSSION AND JUSTIFICATION}

\section{Feed Clarification}

The need for an initial feed clarification step is firmly established. The HLLW wil1 contain solids which must be removed before curium recovery and purification is attempted. Centrifugation of such solutions is an established engineering practice and needs no amplification.

The requirements for the second clarification step are not as firmly defined. Solids will form during the sugar denitration, but the quantity and physical characteristics of these solids depend upon process variables including time and temperature. The reference flowsheet specifies continuous denitration to $1 \underline{\mathrm{M}} \mathrm{HNO}_{3}$ followed by centrifugation and then accumulation in a feed make-up tank. The final preparation step is a one-fold dilution to $0.5 \mathrm{M} \mathrm{HNO}_{3}$. It is possible that solids could form in the make-up tank during the accumulation period or as a result of the water dilution to $0.5 \mathrm{M} \mathrm{HNO}_{3}$. A study should be made of the solids formation in this stream as a function of time, temperature, and solution composition. This investigation would define the need for hold-up storage following the denitration or dilution steps and the correct sequence for the final centrifugation before or after the dilution to $0.5 \mathrm{M} \mathrm{HNO}_{3}$.

Solvent Extraction

As previously stated, plutonium must be removed from the HLLW prior to the final ion-exchange purification of curium to comply with criticality safety requirements. A secondary objective of the reference flowsheet 
is the recovery and purification of neptunium. Both objectives can be achieved by the recommended solvent extraction flowsheet or the anionexchange flowsheet described in Appendix A. Each system has advantages over the alternate.

The prime reason for recommending solvent extraction is the well established technology. It is used in other plants, including BNFP, for processing solution of similar composition and heat load. Some interchange of solvent, solvent clean-up, and plant operators with BNFP is possible. Anion exchange has not been used on a plant scale for the recovery of plutonium or neptunium from solutions containing the level of activity or concentration of fission products found in the HLLW. If anion exchange were to be used, the effects of resin damage from radiolysis and the presence of such fission products as technetium upon the process would have to be determined experimentally before a firm flowsheet could be proposed.

Both processes provide for the removal of plutonium and neptunium from the HLLW. Uranium is also removed by solvent extraction, but not by anion exchange. The relatively large amount of uranium in the HLLW decreases the curium capacity of a given volume of cation-exchange resin; therefore the prior removal of uranium is an advantage in subsequent processing of the HLLW. One of the advantages of anion exchange is that plutonium and neptunium can be separated from each other in the same equipment used for removal from the HLLW as part of a normal operational cycle. Separate, additional concentration and purification cycles are required in either system to obtain sufficient decontamination of plutonium or neptunium from fission products.

Final waste management is a little more complicated with anion exchange. A moderately large amount of degraded anion-exchange resin must be changed out frequently and properly discarded. The cost of new resin is substantial and the resin incinerator would have to be enlarged to accept the increased load. In addition, the nitric acid concentration of the HLLW must be increased from $4.5 \mathrm{M}$ to $6.5 \mathrm{M}$ prior to plutonium and neptunium absorption 
on the anion-exchange resin bed. This increases the solution volume by $30 \%$ and increases the amount of acid that must be destroyed before the final cation-exchange process. In contrast, degraded TBP-NPH is removed during the solvent washing cycle and discarded as a modest addition to the final high-level waste disposal.

The second advantage of anion exchange is that the curium plant could be designed with a single type of unit operation. There would be no organic solvent or solvent washing facility required. The cost benefit of this could be determined only after significant design work on both systems.

After reviewing the relative advantages of the two alternate systems, solvent extraction was chosen for the reference flowsheet because of proven technology which obviates the need for development work.

\section{Sugar Denitration}

The destruction of nitric acid with sugar at elevated temperature has been extensively investigated and has been used on a plant scale with highactivity solutions. The operating parameters and chemistry of the reactions are known, but the rate of consumption of sugar is a function of the kind and concentration of several metal ions which catalyze the reaction. A modest development effort is recommended to more accurately determine the rate of sugar consumption in denitration of a solution of this composition.

\section{Ion-Exchange Purification}

The three potential separations processes that might be used to purify curium from the broad spectrum of impurities shown in Table 2 are selective precipitation, solvent extraction and ion exchange. Band-displacement cationexchange chromatography is the only separations process that has been demonstrated to be effective for this task on a plant or pilot-plant scale of operation. There are strong indications that solvent extraction could be developed into an effective separations method for this specific task, but the technology for its use has not been developed. Some of the attempts to develop and implement these and other separations methods have been reviewed by Wheelwright and Roberts. (6) 
The ion-exchange process proposed for the reference flowsheet is an extension of demonstrated technology, but only in the operating conditions that are proposed, the size of the facility, and differences in the composition of the feed solution. These are most usefully discussed by comparing the reference flowsheet with the ion-exchange purifications performed at $\operatorname{SRL}(7,8)$ and PNL. $(6)$

The SRL curium purification facility was developed to recover and purify curium from irradiated plutonium. After the irradiated targets were dissolved, solvent extraction was used to remove plutonium and to provide a curium feed solution for ion-exchange processing that was predominantly americium, curium and the lanthanide fission products. The lanthanide/actinide ratio in the feed solutions processed ranged from $5 / 1$ to $17 / 1$ and the curium/americium ratio was $\geq 1$. The SRL ion-exchange feed solution was a much easier feed to process than the HLLW and the resin in the feed absorption column could be loaded to a much higher curium content during the feed absorption cycle.

The SRL facility used a relatively narrow size range of resin particles, hydrostatically graded from Dowex 50W, X-8 (200 to 400 mesh) resin, in 4-, 3-, 2- and 1-in. diameter columns that were $5 \mathrm{ft}$ high. The steel columns were water jacketed and heated to 70 to $80^{\circ} \mathrm{C}$. Separation was achieved by eluting the absorbed band of mixed ions down successively smaller columns of $\mathrm{Zn}^{2+}$-cycle resin with $0.05 \mathrm{M}$ DTPA buffered to a specific $\mathrm{pH}$ in the range of 3.0 to 6.0 with ammonium hydroxide. The improvement in kinetics achieved by using very small sized resin particles permitted rapid separation with elution flow rates up to $36 \mathrm{ml} / \mathrm{min}-\mathrm{cm}^{2}$. Because of the small particle size of the resin, the pressure drop through the resin bed was high and required pressures up to $2000 \mathrm{psi}$ to maintain the desired flow rate through the $5-\mathrm{ft}$ high resin beds.

In the single curium purification campaign at PNL, Dowex 50W, $X-8$ (50 to 100 mesh) resin was used in a column facility containing 14-, 10-, 8-, 6-, 4-, 3-, 2-, and 1-in. diameter columns that were $9 \mathrm{ft}$ high. The initial separation of curium and americium from all other impurities was 
performed by elution down $\mathrm{Zn}^{2+}$ - cycle resin with $0.05 \mathrm{M}$ DTPA buffered to $\mathrm{pH} 6.5$ with ammonium hydroxide at a solution flow rate of $4 \mathrm{ml} / \mathrm{min}-\mathrm{cm}^{2}$. The final separation of curium from americium was achieved in a similar elution with 0.1M nitrilotriacetic acid (NTA) buffered to $\mathrm{pH} 6.5$ at a flow rate of $6 \mathrm{ml} / \mathrm{min}-\mathrm{cm}^{2}$. The elutions were performed at $60^{\circ} \mathrm{C}$ and at column pressures of less than $25 \mathrm{psi}$. In subsequent kilogram-scale purifications of promethium and americium, using the same kind of resin in the same equipment, very good purification has been obtained at elution flow rates of $8 \mathrm{ml} / \mathrm{min}-\mathrm{cm}^{2}$.

The five principal areas of technical uncertainty in the ion-exchange part of the reference flowsheet are enumerated below and discussed in following paragraphs.

- The curium capacity of the resin bed during the feed absorption cycle.

- The effect of resin particle size, elution flow rate, elution distance, and resin bed height/diameter ratio upon curium purification.

- The possible effect of feed-solution impurities upon the separation process and the purity of the product.

- The rate of resin radiolysis and its effect upon the purification process.

- Alternative eluting agents.

One of the requirements of the reference flowsheet is that the plant should have the capacity to process all of the HLLW from BNFP. The amount of treated HLLW that can be pumped through a given volume of resin, without significant loss of curium to the waste effluent solution, determines the size of the feed absorption column needed for a chosen batch size. This capacity is difficult to calculate because the resin absorption coefficients are different for each ion and the capacity cannot be inferred from the work performed at SRL or previously at PNL. Because of the vital importance of this value, a loading capacity experiment was performed using a 100-m1 bed of Dowex 50W, X-8 (100 to 200 mesh) resin in the $\mathrm{H}^{+}$cycle and a feed solution simulating the treated HLLW. Americium was used to simulate both americium and curium, but non-radioactive compounds were used for each of 
the other constituents of the feed solution. Solids were formed during the preparation of this feed solution and were removed by filtration prior to the addition of americium. The feed solution flow rate was $4 \mathrm{ml} / \mathrm{min}-\mathrm{cm}^{2}$. The normal resin capacity is 1.7 to 1.9 equivalents/liter of settled resin. In this experiment, the total americium loss in the column effluent was $5 \%$ of the americium in the feed solution processed to $50 \%$ instantaneous americium breakthrough, and $67 \%$ of the resin bed capacity was occupied by americium and lanthanide ions. At 100\% instantaneous americium breakthrough the total americium loss was increased to $15 \%$ and the americium/lanthanide loading was increased to $78 \%$. The size of the feed absorption column in the reference flowsheet is calculated from the $50 \%$ breakthrough data. Because of the importance of this resin bed capacity number, this experiment should be repeated on a five-fold larger scale with two or three separate feed solution make-ups and at the specified feed solution flow rate. Separate feed make-ups are suggested because of the difficulty of exactly simulating the waste solution in any single attempt.

Changes in resin particle size, eluting agent, eluting solution $\mathrm{pH}$, eluting solution flow rate, elution distance and the resin bed height/diameter ratio have independent and collective effects upon the separation efficiency that can be achieved; one example will illustrate this point. Assuming no adverse effects from radiolysis or decay heat, if the elution flow rate is $0.5 \mathrm{ml} / \mathrm{min}-\mathrm{cm}^{2}$ and the other conditions are optimum, good separation could be achieved with 20 to 50,50 to 100,100 to 200 or 200 to 400 mesh size resin, but the time required would be very long. If the elution rate is increased to $35 \mathrm{ml} / \mathrm{min}-\mathrm{cm}^{2}$ the elution time will be decreased seventy-fold, but good separation can be obtained only if 200 to 400 mesh resin is used and the price for the much faster process is a pressure system that can withstand the 1000 to 2000 psi required to force the solution through the smaller resin particles at the high flow rate. A complicating factor in curium processing is that radiolysis effects cannot be ignored. 
The ion-exchange facility in the reference flowsheet represents a compromise in several parameters between the SRL and PNL facilities (i) Tustrated in Table 9).

\section{TABLE 9. Comparison of Operating Parameters}

\begin{tabular}{|c|c|c|c|}
\hline & SRL & $\begin{array}{l}\text { Reference } \\
\text { Flowsheet }\end{array}$ & PNL \\
\hline $\begin{array}{l}\text { Resin particle size } \\
\text { (mesh) }\end{array}$ & 200 to 400 & 100 to 200 & 50 to 100 \\
\hline $\begin{array}{l}\text { Eluting solution flow rate } \\
\left(\mathrm{m} 7 / \mathrm{min}-\mathrm{cm}^{2}\right)\end{array}$ & 36 & 16 & 6 to 8 \\
\hline $\begin{array}{l}\text { Maximum Pressure drop } \\
\text { (psi) }\end{array}$ & 2000 & 250 & 25 \\
\hline
\end{tabular}

The compromise is necessary to provide the necessary capacity and avoid either large-sized, high-pressure column systems, multi-parallel column systems or both.

These compromises are reasonable for the purposes of this report. However, before a very expensive shielded facility is designed and built, a development program should be conducted on a 5 to $10 \%$ size scale using a non-radioactive feed which simulates the treated HLLW. Tracers of ${ }^{241} \mathrm{Am},{ }^{154} \mathrm{Eu},{ }^{144} \mathrm{Ce}$, etc. could be added to the feed solution to aid in controlling the experiments and providing analytical results. The major objective of this experimental work would be to verify the separation efficiency of the specified column system using the specified resin, eluting solution andflow rate. A secondary objective would be to determine if the elution distance could be shortened, thereby eliminating one or more of the columns or shortening the plarined columns.

Pressure drop experiments were performed at PNL with Dowex 50W, $X-8$ (100 to 200 mesh) resin to provide a guide for the design of the ion-exchange columns. In water at $25^{\circ} \mathrm{C}$ the pressure drop was found to vary in a 1 inear manner between 2 and $20 \mathrm{ml} / \mathrm{min}-\mathrm{cm}^{2}$ and to be $0.73 \mathrm{psi} / \mathrm{ft}$ of bed depth/ml/min- $\mathrm{cm}^{2}$. The pressure drop across Column 2 at the specified elution flowrate would be 207 psi. 
No problems are foreseen from impurities in the HLLW feed solution. The experimental program outlined in the previous paragraph should identify any problems if they exist.

The exact effect of radiolysis upon the separation process cannot be simulated, but must be determined from plant experience. Resin degradation rates and other radiolysis problems have been considered in the design of the reference flowsheet.

The curium work at PNL ${ }^{(6)}$ demonstrated that NTA is a better eluting agent than DTPA for separating curium from americium. Very little work has been done on the use of NTA for the separation of curium from other impurities in the HLLW. This lack of information on NTA prompted the recommendation of DTPA in the reference flowsheet, but some development work with NTA might prove $i$ ts superiority. In any event, if needed, NTA could be directly substituted for DTPA during the elution down the last 2 or 3 columns by simply providing a second, much smaller make-up system. Waste Treatment and Disposal

In the absence of a curium recovery program, HLLW from the BNFP wi 11 be stored for an appropriate period of time, converted to a solid by continuous direct calcination, then packaged and disposed of in a manner prescribed by governmental regulations. This waste management concept may be perturbed by the addition to the waste of the materials required for curium recovery and purification shown in Table 8 . In the reference flowsheet three kinds of waste (HLLW, ILLW, and degraded resin) are accumulated and must be prepared by separate processes for final disposal.

The HLLW will require an approximate twelve-fold thermal concentration followed by calcination. The large amounts of ammonium ions, zinc, and DTPA, which are added during the purification, will probably affect the size, design and mode of operation of both the concentrator and the waste calciner. Major problems are not anticipated, but a development program is recornmended to investigate possible effects of these added process reagents. The investigation would include: 1) armmonia off-gas problems, or possible substitution of sodium for ammonium ions, 2) foaming in the 
concentrator, 3) degradation of DTPA in the concentrator, 4) reactivity and thermal energy balance in the calciner, and 5) processing capacity of specified equipment.

The ILLW waste solidification process does not specify calcination of the waste nor does it involve the very large quantities of radioactive materials. As a result the processing requirements are less stringent, but information similar to that described above will be required for the ILLW system.

The disposal of large quantities of contaminated and degraded resin is a new technical requirement. The effects of resin moisture content, mineral content, and incinerator thermal energy balance upon the design, operation and capacity of the incinerator should be investigated. The route of possible contaminating radionuclides through the process requires some investigation.

DEVELOPMENT WORK REQUIRED IN SUPPORT OF PLANT CONSTRUCTION AND OPERATION

The need and justification for supporting development work was identified in the previous section. These are summarized by task and given a cost value in this section.

Task $1(\$ 15,000)$

Investigate the formation of solids in the curium stream following the second centrifugation step as a function of hold-up time, solution temperature, and feed dilution with water to $0.5 \mathrm{M} \mathrm{HNO}{ }_{3}$. Identify the need for any hold-up storage at this point in the flowsheet to allow for solids formation that might otherwise take place inside the ion-exchange resin beds. Also identify the need for centrifuging this solution after, rather than before, the dilution to $0.5 \mathrm{M} \mathrm{HNO}_{3}$. Al1 work would be done with non-radioactive solutions which simulate the HLLW. 
Task $2(\$ 10,000)$

Study and determine the rate of sugar consumption in the acid destruction step using non-radioactive solutions which simulate the composition of the HLLW at that point in the reference flowsheet.

Task $3(\$ 3,000)$

Experimentally verify the capacity of Dowex 50W, X-8 (100 to 200 mesh) resin for curium (using appropriate stand-ins) when absorbed from a feed solution which properly simulates the feed composition specified in the reference flowsheet. The feed solution flowrate is $8 \mathrm{ml} / \mathrm{min}-\mathrm{cm}^{2}$ and the curium waste losses during the loading cycle should not exceed $5 \%$ of the total in the feed processed.

Task $4(\$ 150,000)$

Design and fabricate an eight-column ion-exchange facility with 5 to $10 \%$ of the capacity of the proposed unit for development work with non-radioactive materials. Investigate the separation efficiency that can be achieved using the reference flowsheet conditions and a feed solution which will properly simulate (except for radioactivity) the ion-exchange feed in the reference flowsheet. Investigate the effect upon separation efficiency of shortening the elution distance, increasing or decreasing the elution flow rate and of using NTA for part or all of the elution cycle.

Task $5(\$ 150,000)$

Investigate any perturbing influence of DTPA, ammonia ions, and zinc upon the HLLW concentrator/calciner and upon the ILLW concentrator/solidifier. Examine the factors which influence the incineration of contaminated degraded resin and the disposal of the ash. The results of these investigations would guide the design and operation of the waste disposal system. 


\section{IMPROVED FLOWSHEET FOR CURIUM RECOVERY AND}

PURIFICATION USING NEW TECHNOLOGY

A reference flowsheet for curium recovery, using a combination of demonstrated technology, has been described in Section III. However, an alternative process could probably be developed which could offer the potential for lower costs. The objective of this research and development effort would be:

- To reduce the amount of material sent to solidification facilities.

- To provide processes more similar to BNFP operations.

- To reduce the unit cost of the $\mathrm{Cm}$ product.

\section{IMPROVED FLOWSHEET}

The proposed improved flowsheet for the recovery and purification of curium from the HLLW is shown in Figure 8 . Since the individual processing steps consisting of feed clarification, PU-Np-U solvent extraction and sugar denitration are identical to that proposed in the reference flowsheet, they will not be discussed in this section. The areas that will require future research and development are:

- Isolation of the lanthanide/actinide fraction,

- Separation of the actinides from 1 anthanides, and

- Separation of curium from americium.

The reference flowsheet for curium recovery requires a clarified feed to the ion-exchange column containing all of the constituents of the original HLLW (excluding Pu, Np and $U$ ). In addition, the solution volume has been increased three-fold. After ion-exchange processing, the high-level waste volume (12-fold) and the intermediate-level liquid waste (6-fold) represent an 18-fold volume increase over the initial HLLW. Solvent-extraction flowsheets have been suggested which would eliminate the ion-exchange flowsheet, or at least reduce the feed volume to the ion-exchange system thus reducing the overall waste flows. 


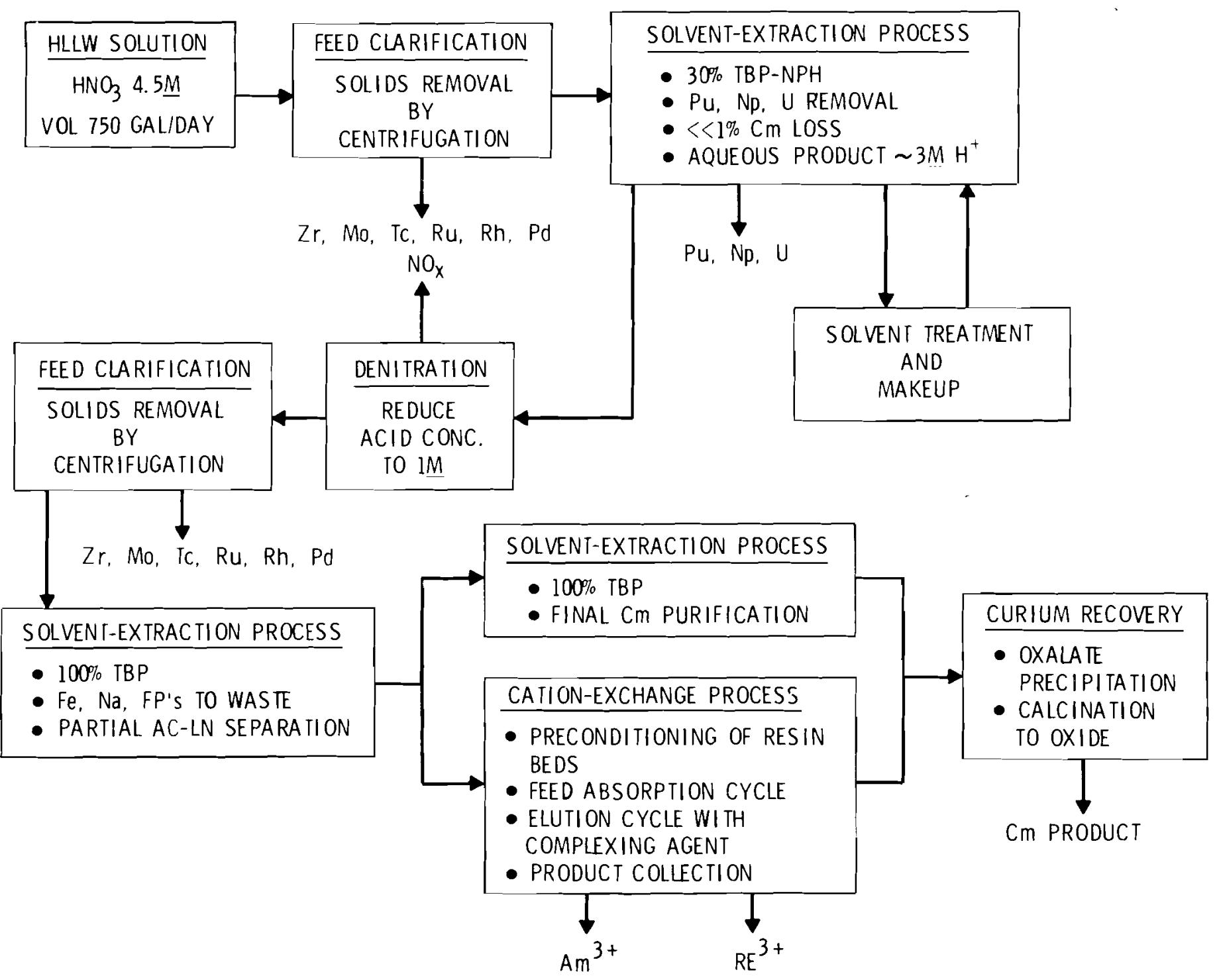

FIGURE 8. Advanced Flowsheet for Curium Recovery and Purification 


\section{ISOLATION OF THE LANTHANIDE/ACTINIDE FRACTION}

Solvent-extraction flowsheets have been developed $(2,3,5)$ and demonstrated $^{(5,13)}$ for the separation of $A m, C m$ and rare earths (RE) from the bulk of the other waste constituents. TBP solvent extraction has been demonstrated for several modes of initial extraction, such as:

\begin{tabular}{|c|c|c|c|}
\hline & Initial Aqueous & Organic & Aqueous \\
\hline $19-30 \%$ TBP & $4-10 \underline{M} \mathrm{HNO}_{3}$ & $\mathrm{U}, \mathrm{Zr}, \mathrm{Np}, \mathrm{Pu}$ & $\mathrm{Cm}, \mathrm{Am}, \mathrm{FP} \mathrm{P}^{\prime} \mathrm{s}$ \\
\hline $100 \%$ TBP & $15.6 \mathrm{M} \mathrm{HNO}_{3}$ & $\mathrm{Cm}, \mathrm{Am}, \mathrm{RE}$ & $F P^{\prime} s$ \\
\hline $100 \%$ TBP & $\mathrm{HLLW}, 1 \underline{\mathrm{M}} \mathrm{HNO}_{3}$ & $\mathrm{Cm}, \mathrm{Am}, \mathrm{RE}$ & $F P^{\prime} \mathrm{s}$ \\
\hline $50 \%$ TBP & $5-6 \underline{M} \mathrm{NO}_{3}^{-}, \mathrm{pH}$ & $\mathrm{Cm}, \mathrm{Am}, \mathrm{RE}$ & FP's \\
\hline
\end{tabular}

Each of these extraction systems is designed to separate $\mathrm{Cm}$, Am and RE's from the initial HLLW. Advantages of each system will require further in-depth study, however the 100\% TBP organic system and a $1 \mathrm{M} \mathrm{HNO}_{3} \mathrm{HLLW}$ feed appears most practica1. The resulting actinide/lanthanide fraction, which is free of monovalent ions and corrosion products, would then provide feed for a smaller ion-exchange facility or further separation by solvent extraction.

A TBP solvent-extraction step that would separate monovalent, divalent, and $\mathrm{FP}^{\prime} \mathrm{s}$ from the $\mathrm{Cm}$, Am, RE fraction was considered for the reference flowsheet (Section III and Table 4). Approximately 65\% of the feed absorption column (1700 gal) is required for absorption of $\mathrm{Cm}$, Am and RE's. The remaining elution columns are sized only for $\mathrm{Cm}, \mathrm{Am}$, and RE's. Therefore, only the feed absorption column could be reduced (1700 to $1100 \mathrm{gal}$ ) as a consequence of the isolation of the lanthanide/actinide fraction. Further separation of the actinides from the lanthanides is required to meet the R\&D objectives.

\section{SEPARATION OF THE ACTINIDES FROM LANTHANIDES}

Solvent-extraction techniques for the separation of Am-Cm from rare earths have been developed by several authors using, HDEHP [di-(2-ethy1hexy1) phosphoric acid], (2) $100 \%$ TBP, ${ }^{(3,12)}$ DBBP (dibutyl butyl phosphonate), TOP0 
(trioctyl phosphine oxide) and other mixed synergistic extractants. (14)

separation of individual rare earths from monazite in tonnage quantities (21-22) by the Molybdenum Corp. of America (Molycorp) using diethylhexyl phosphates and other proprietary methods is the best example of a similar industrial application to solvent extraction. However, practical application of any of these extractants to the HLLW will require extensive research.

The separation of $\mathrm{Am}-\mathrm{Cm}$ from the bulk of the lanthanides prior to $\mathrm{Am} / \mathrm{Cm}$ separation is the key to meeting the objectives for an ultimate flowsheet. As shown in Table 10, the Am-Cm represents $1.7 \%$ of the lanthanide/actinides present and if separated would permit a very large reduction in the size of the final Am/Cm separation facility. If $\mathrm{Gd}, Y$, and the light rare earths ( $\mathrm{Ce}, \operatorname{Pr}$ and $\mathrm{La}$ ) were separated from $\mathrm{Am} / \mathrm{Cm}$ and the other RE's the molar composition remaining for separation would be reduced by $72 \%$. Although an exhaustive study has not been completed for the separation of the actinides from lanthanides, the suggested high nitric acid flowsheet using TBP data (Table 11) of Best, Jackson, Hesford, and McKay $(15,16)$ or the rare earth nitrate - water $100 \%$ TBP system proposed by Bochinski, Smutz, and Spedding ${ }^{(23)}$ would provide a process similar to the BNFP operation, would eliminate the undesired use of aqueous complexants, $(2,5,12)$ and would complement the $\mathrm{Pu}, \mathrm{Np}, \mathrm{U}$ and lanthanide/actinide isolation flowsheets as suggested above.

\section{SEPARATION OF CURIUM FROM AMERICIUM}

Solvent-extraction studies to provide a separation of the actinides from the lanthanides will determine the flowsheet requirements for an $\mathrm{Am} / \mathrm{Cm}$ separation. Solvent-extraction separation and purification of $\mathrm{Cm}$ from Am has not been demonstrated. In general, the separation factor for the liquid-liquid system is less than 2. (17) 
TABLE 10. Concentration of Actinides and Lanthanides in HLLW

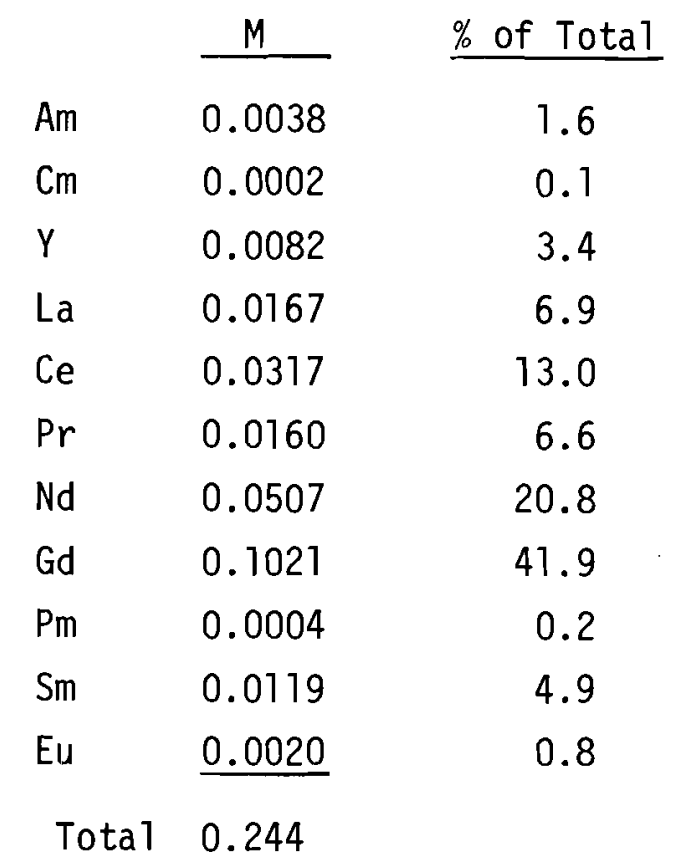

\section{RESEARCH AND DEVELOPMENT REQUIREMENTS}

An alternative flowsheet has been suggested for further research and development using new technology. This study would give more emphasis on solvent extraction similar to BNFP and to the reduction of the waste volume. On the order of $\$ 300,000$ to $\$ 500,000$ wi 11 be required for laboratory development, and $\$ 1$ - to 2,000,000 for engineering-scale evaluation. Savings through a more efficient facility and a plant with lower capital cost, could be enough to pay for this R\&D investment in 1 or 2 years of plant operation. A 2- to 3-year delay in plant construction would be likely. This delay will permit the plant to become operational when a high curium content is available in spent fuel, rather than starting up with a lower curium content. 
TABLE 11. TBP Partition Coefficients as a Function of $\mathrm{HNO}_{3}$ Concentration $(15,16)$

\begin{tabular}{|c|c|c|c|c|c|c|c|c|c|c|c|}
\hline $\begin{array}{l}(100 \% \text { TBP } \\
\mathrm{HNO}_{3} \text { Conc. } \\
\text { (Aqueous) } \\
(\mathrm{M})\end{array}$ & $\begin{array}{l}\text { hroughout) } \\
\text { Partition } \\
\text { Coefficient } \\
\text { (Organic/ } \\
\text { Aqueous) } \\
\end{array}$ & $\begin{array}{c}\text { HNO3 Conc. } \\
\text { (Aqueous) } \\
\text { (M) } \\
\end{array}$ & $\begin{array}{c}\text { Partition } \\
\text { Coefficient } \\
\text { (Organic/ } \\
\text { Aqueous) } \\
\end{array}$ & $\begin{array}{l}\mathrm{HNO}_{3} \text { Conc. } \\
\text { (Aqueous) } \\
\left(\mathrm{M}_{1}\right)\end{array}$ & $\begin{array}{c}\text { Partition } \\
\text { Coefficient } \\
\text { (Organic/ } \\
\text { Aqueous) } \\
\end{array}$ & $\begin{array}{l}\mathrm{HNO} 3 \text { Conc. } \\
\text { (Aqueous) } \\
(\underline{M})\end{array}$ & $\begin{array}{c}\text { Partition } \\
\text { Coefficient } \\
\text { (Organic/ } \\
\text { Aqueous) } \\
\end{array}$ & $\begin{array}{c}\mathrm{HNO}_{3} \text { Conc } \\
\text { (Aqueous) } \\
(\underline{\underline{M}})\end{array}$ & $\begin{array}{c}\text { Partition } \\
\text { Coefficient } \\
\text { (Organic/ } \\
\text { Aqueous) } \\
\end{array}$ & $\begin{array}{c}\mathrm{HNO}_{3} \text { Conc. } \\
\text { (Aqueous) } \\
(\underline{M})\end{array}$ & $\begin{array}{c}\text { Partition } \\
\text { Coefficient } \\
\text { (Organicl } \\
\text { Aqueous) } \\
\end{array}$ \\
\hline \multicolumn{2}{|c|}{ Americium } & \multicolumn{2}{|c|}{ Curium } & \multicolumn{2}{|c|}{ Gadolinium } & \multicolumn{2}{|c|}{ Praseodymium } & \multicolumn{2}{|c|}{ Neodymi um } & \multicolumn{2}{|c|}{ Samarium } \\
\hline 0.550 & 0.073 & 0.450 & 0.0486 & 0.72 & 0.108 & 0.34 & 0.041 & 0.53 & 0.050 & 0.59 & 0.077 \\
\hline 1.10 & 0.128 & 0.920 & 0.103 & 1.29 & 0.193 & 1.38 & 0.164 & 0.86 & 0.158 & 1.04 & 0.21 \\
\hline 1.71 & 0.182 & 2.40 & 0.198 & 2.31 & 0.31 & 2.58 & 0.20 & 1.40 & 0.23 & 2.24 & 0.38 \\
\hline 2.35 & 0.213 & 3.89 & 0.280 & 2.94 & 0.37 & 3.20 & 0.22 & 2.36 & 0.29 & 3.25 & 0.42 \\
\hline 2.70 & 0.227 & 4.96 & 0.249 & 3.56 & 0.42 & 4.13 & 0.20 & 3.12 & 0.32 & 4.48 & 0.44 \\
\hline 3.90 & 0.257 & 6.20 & 0.254 & 4.58 & 0.49 & 5.20 & 0.191 & 4.47 & 0.33 & 5.06 & 0.46 \\
\hline 4.70 & 0.262 & 7.30 & 0.231 & 5.47 & 0.52 & 6.16 & 0.167 & 5.31 & 0.28 & 5.96 & 0.45 \\
\hline 5.50 & 0.220 & 8.42 & 0.253 & 6.40 & 0.63 & 7.23 & 0.152 & 6.22 & 0.24 & 7.01 & 0.46 \\
\hline 7.65 & 0.192 & 10.1 & 0.407 & 7.54 & 0.70 & 8.54 & 0.146 & 7.16 & 0.24 & 7.97 & 0.50 \\
\hline 8.90 & 0.223 & 11.9 & 0.812 & 8.67 & 0.95 & 9.12 & 0.159 & 8.09 & 0.24 & 9.04 & 0.60 \\
\hline 10.1 & 0.261 & 13.7 & 1.97 & 9.40 & 1.14 & 10.0 & 0.175 & 9.53 & 0.27 & 10.3 & 0.83 \\
\hline 11.8 & 0.475 & 15.2 & 4.51 & 10.6 & 1.70 & 11.3 & 0.23 & 10.6 & 0.33 & 11.0 & 1.08 \\
\hline 12.7 & 0.642 & & & 11.2 & 2.8 & 12.4 & 0.33 & 11.4 & 0.42 & 11.3 & 1.16 \\
\hline 15.3 & 2.23 & & & 12.2 & 4.6 & 13.2 & 0.44 & 12.4 & 0.58 & 12.5 & 2.2 \\
\hline & & & & 13.0 & 7.6 & 13.8 & 0.56 & 13.2 & 0.85 & 13.3 & 2.8 \\
\hline & & & & 13.7 & 11.0 & 14.7 & 0.75 & 14.3 & 1.25 & 13.9 & 4.1 \\
\hline & & & & 14.5 & 18.5 & 15.1 & 0.83 & 15.1 & 1.70 & 14.7 & 5.9 \\
\hline & & & & 15.3 & 25 & & & 15.9 & 2.3 & 15.7 & 10.4 \\
\hline
\end{tabular}


Several tasks have been identified for the investigation. They include:

- Intensive Literature Search and Evaluation - Review and evaluate technical documentation for methods of actinide/lanthanide extraction, separation and purification. Obtain input from ORNL, Argonne and other sites to complete the evaluation.

- Solvent Extraction Studies - Determine distribution coefficients as a function of feed variables. Review viscosity and phase separation effects with organic concentration (50 to 100\% TBP) as a function of high salt loadings. Determine extraction and stripping distributions as a function of contact time and temperature.

- Contactor Studies - Review extraction efficiencies and separation capacities for the differential contactor, the mixer-settler, the centrifugal contactor, and the pulse column. Complete laboratory tests using the selected contactor to provide additional engineering flowsheet data. Develop separations data that will predict the efficiency of the overall curium recovery - purification cycle. 


\section{NEPTUNIUM RECOVERY}

A secondary objective to curium-244 recovery is to provide similar information for the recovery and purification of neptunium-237 from the BNFP high-level waste. The function of this system will be to recover and purify Np from the low acid strip solution resulting from the TBP extractionstrip of $\mathrm{Np}, \mathrm{Pu}$ and $\mathrm{U}$ from the initial waste (see Figure 1). A review of the state-of-the-art processes indicates that both anion exchange (Appen$\operatorname{dix} A)$ and solvent extraction $(18,19)$ proven technology are available.

\section{INTEGRATED FLOWSHEET}

The proposed BNFP reference solvent extraction flowsheet for the recovery and ion exchange purification of neptunium from the HLLW is given in Figures 9 through 12. The individual processing steps are based on the

Hanford Purex Plant solvent-extraction flowsheet ${ }^{(18)}$ for Np concentration, decontamination, and purification. Although an anion-exchange-only flowsheet may offer some advantages, the solvent extraction-ion exchange combination is based on more thoroughly demonstrated processes and offers the highest probability of technical feasibility.

NEPTUNIUM FEED

A solvent-extraction system using TBP is proposed as the $\mathrm{Pu}$ removal step for the initial HLLW. Details of the extraction and stripping cycles are included in Figure 2. Approximately, 99\% of the Pu, U, and Np will be removed from the HLLW without extracting the curium. Thus, the resulting aqueous acid strip of the TBP-NPH solvent becomes the feed solution for the Np concentration and purification cycles. The approximate $1600 \mathrm{gpd}$ of Np containing feed will contain 204, 10 and 2 g-moles of $\mathrm{U}, \mathrm{Np}$ and $\mathrm{Pu}$, respectively. In addition, other fission products should be expected. 
Concentration of Feed

The Np containing feed is first concentrated 7.5-fold and adjusted to $8 \mathrm{HNO}_{3}$. The overall 2.3-fold concentration results in a feed to the solvent-extraction facility containing $70,0.2$ and $0.9 \mathrm{~g} / \mathrm{gal}$ of $\mathrm{U}, \mathrm{Pu}$ and $\mathrm{Np}$, respectively (Figure 9 ).

Solvent Extraction, Concentration, and Decontamination

A solvent-extraction system, which uses pulse-column contactors and $30 \%$ TBP-NPH is proposed for the Np concentration and decontamination steps (Figures 9 through 11). Details of the solvent-extraction flowsheet are given in the References 18 through 20. Highlights in the overall solventextraction process are:

- The adjusted $\mathrm{Np}$ feed is fed to the 2N Column (Figure 9) which employs ferrous sulfamate in the scrub stream. Np is extracted as $\mathrm{Np}$ (IV) along with the uranium while $\mathrm{Pu}$ (III) remains in the aqueous raffinate and is sent to waste.

- In the stripping $2 \mathrm{P}$ Column, $\mathrm{Np}$ is partially stripped away from the uranium by dilute $\mathrm{HNO}_{3}$, the Np product (2NP) is recycled to the 2NF tank and the uranium goes to the waste. In this manner the Np builds up to $12 \mathrm{~g} / \mathrm{gal}$ after 7 to 9 days of operation in the concentration - accumulation cycle and U-Pu are sent to waste.

- After sufficient $\mathrm{Np}$ has been accumulated (Figure 10), $\mathrm{HNO}_{3}$ is substituted for the $2 \mathrm{~N}$ flow and $\mathrm{Np}$ is decontaminated. Decontamination factors of greater than $10^{8}$ for $\mathrm{Zr}-\mathrm{Nb}-95$ and $\mathrm{Ru}-\mathrm{Rh}-103,106$ have been accomplished.

- When the Np is sufficiently purified (Figure 11), the Np product is removed from the solvent-extraction system.

- Ion-exchange purification (Figure 12) will be required to provide sufficient clean-up and concentration of the neptunium so that fission product specifications for the final neptunium oxide can be met. Typical Np decontamination factors ${ }^{(14)}$ resulting from the ion-exchange system have been measured. 


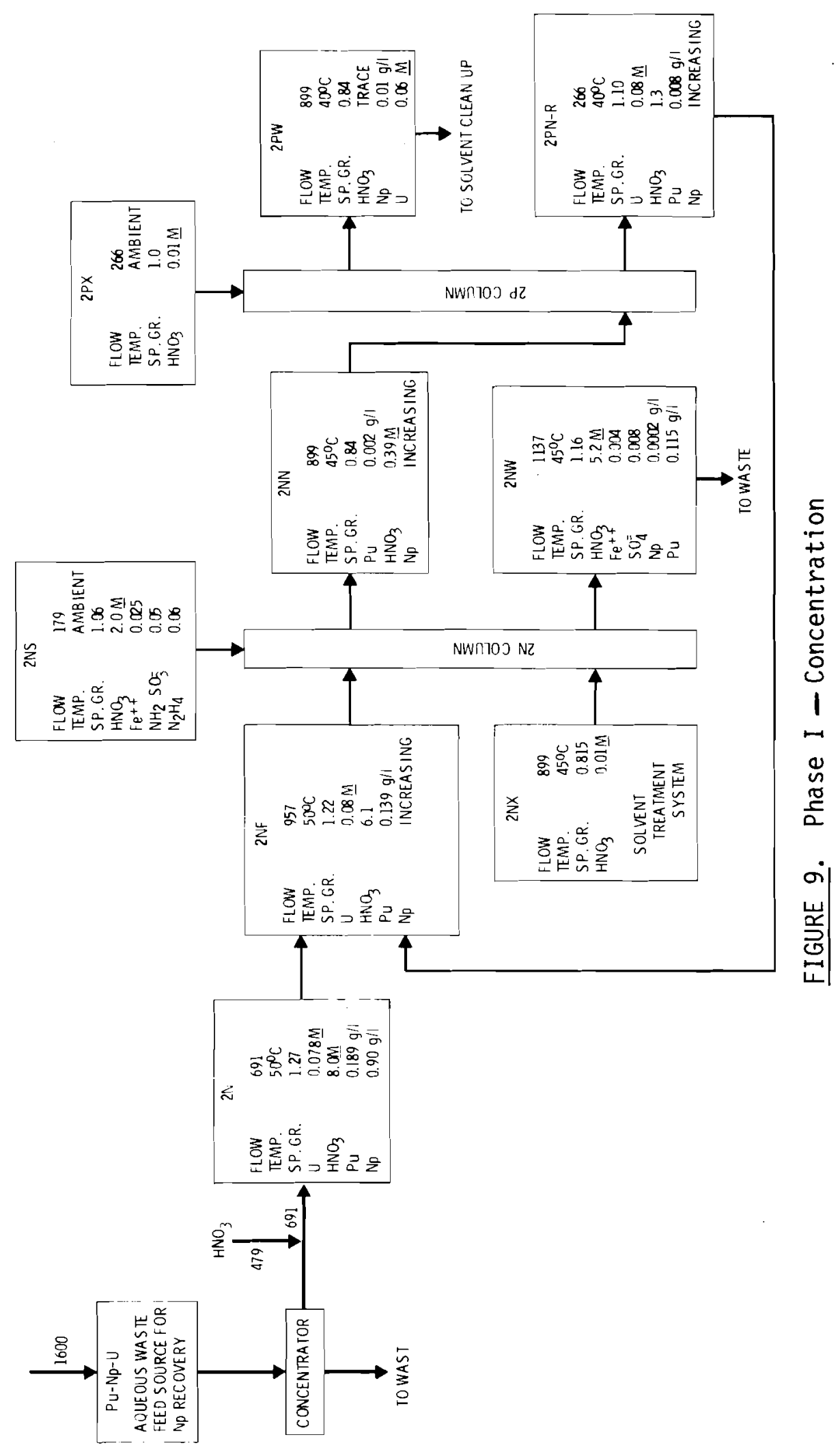




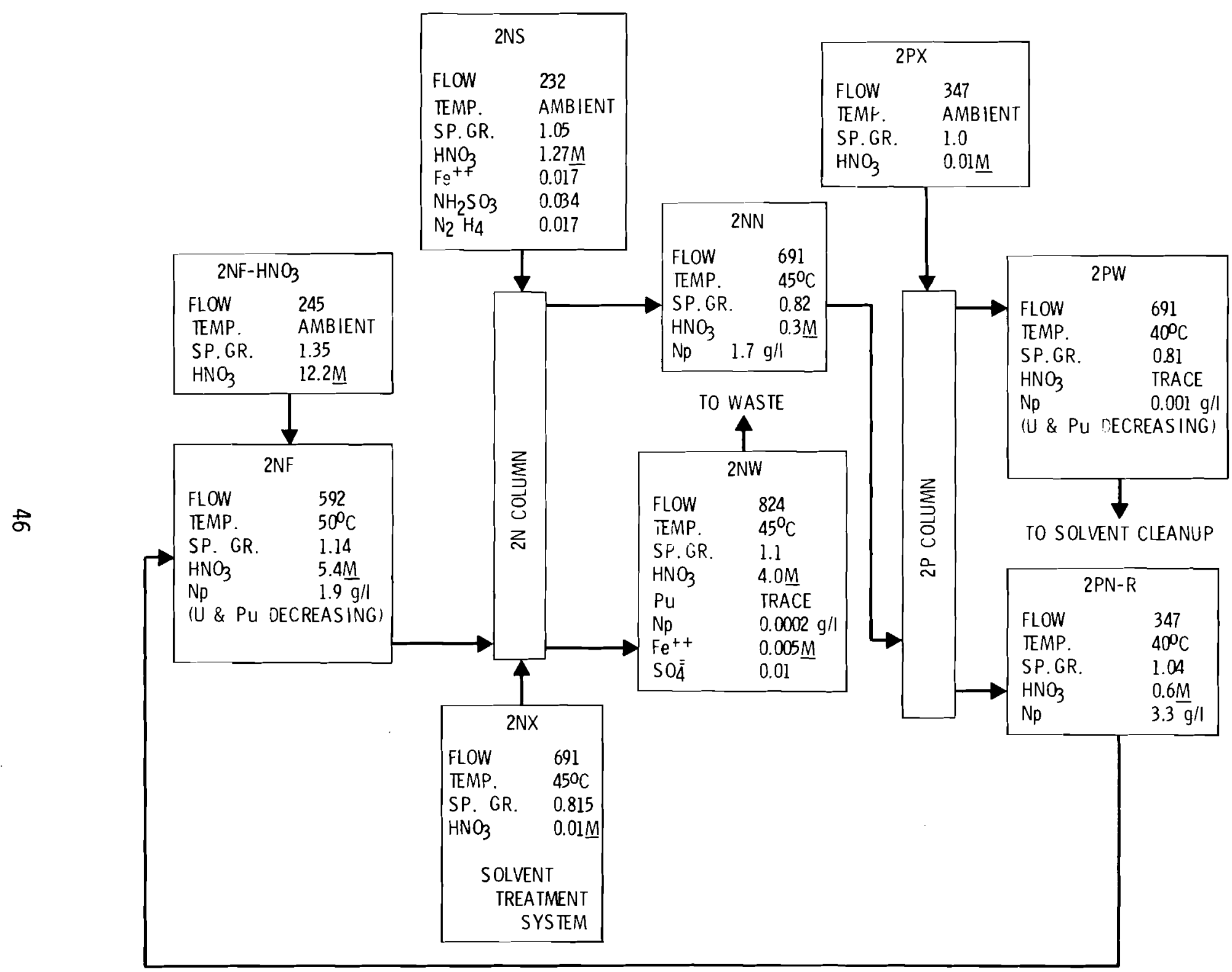

FIGURE 10. Phase II - Decontamination 


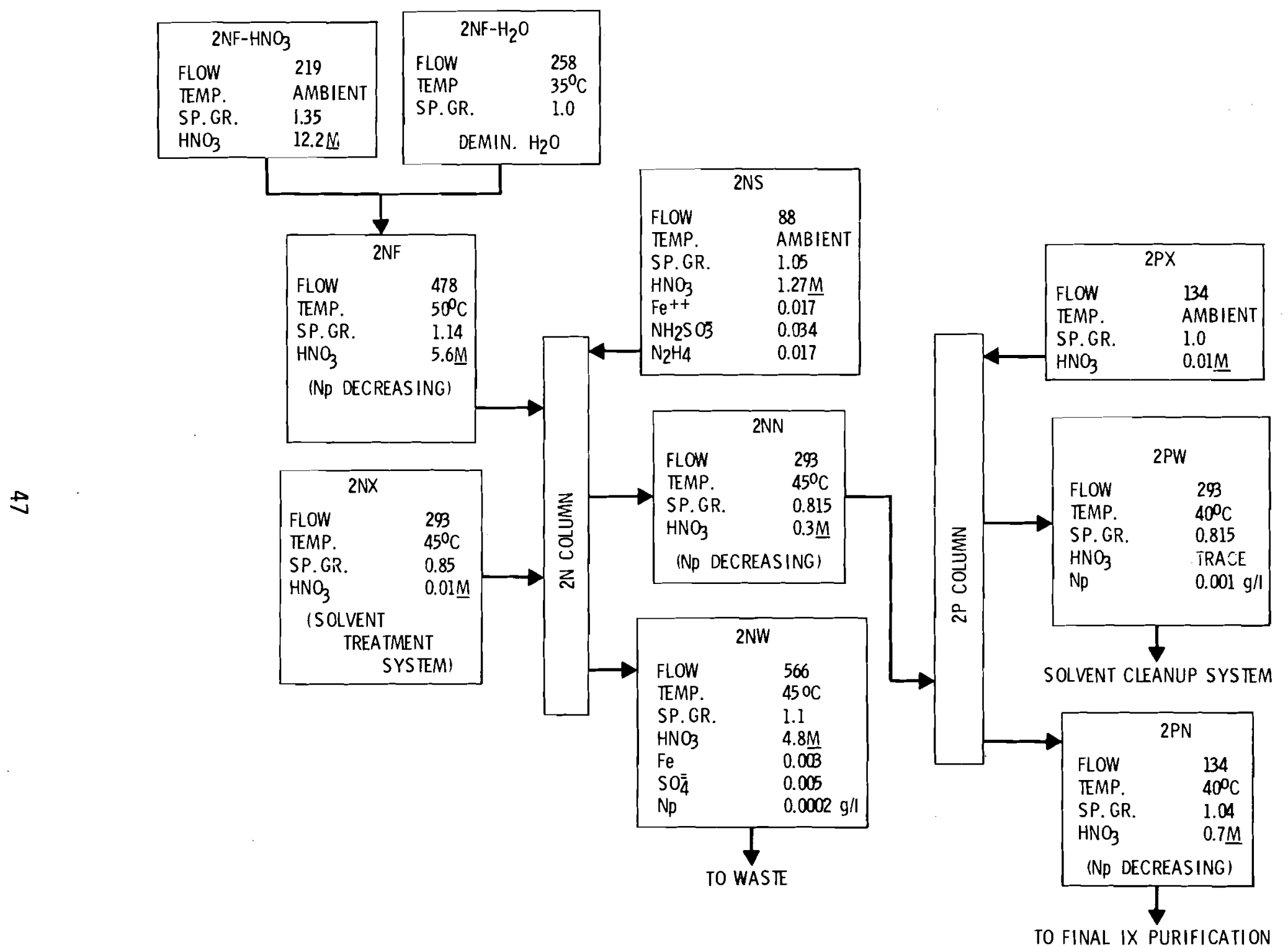

FIGURE 11. Phase III - Neptunium Removal Cycle 


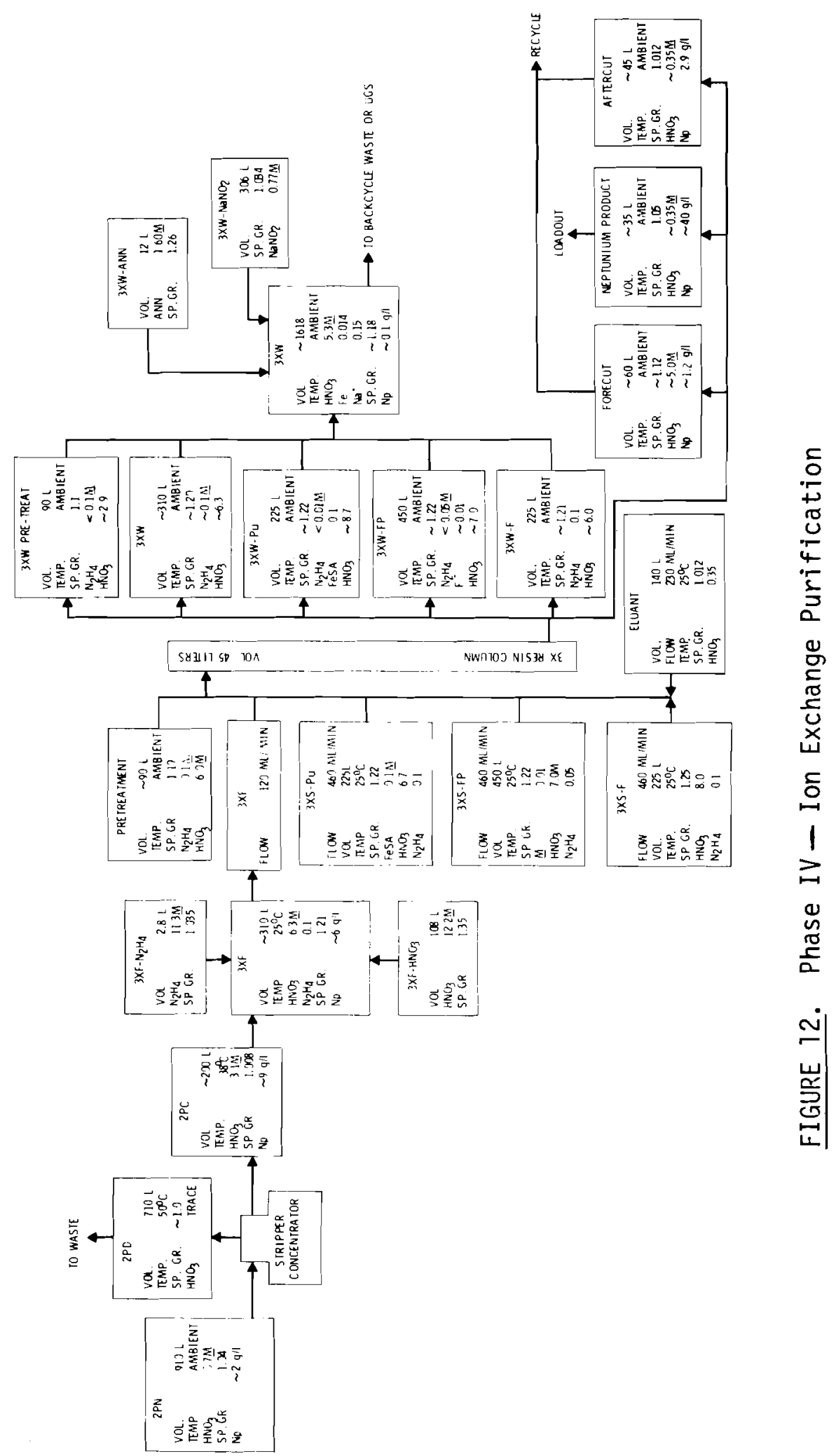




\section{REFERENCES}

1. P. E. Brown and J. A. Garate, Report on the Availability and Cost of Curium-244 from Reactor Fuel Reprocessing Waste, General Electric/USAEC Report No. 74SD4209, February 15, 1974.

2. G. Koch, Z. Kolarik, H. Haug, W. Hild, and S. Drobnik, Recovery of Transplutonium Elements from Fue 1 Reprocessing High-Leve T Waste Solutions, Kernforschungszentrum Karlsruhe, Document No. KFK-1651, November 1972.

3. Flowsheet Proposals Curium-244 Recovery, informal undocumented report provided by C. L. Ottinger, Isotopes Development Center, Oak Ridge National Laboratory, at the review meeting held in Richland, Washington, September 20, 1973.

4. R. D. Baybarz, "Recovery and Application of the Transuranium Elements $237 \mathrm{~Np}, 238 \mathrm{Pu}, 241 \mathrm{Am}, 242 \mathrm{~cm}, 244 \mathrm{~cm}$, and $252 \mathrm{Cf}, "$ At. Energy Rev., No. 8, pp. 327-360 (1970).

5. A. L. Boldt and G. L. Ritter, Recovery of $\mathrm{Am}, \mathrm{Cm}$, and Pm from Shippingport Reactor Fue 1 Reprocessing Wastes by Successive TBP and D2EHPA Extractions, USAEC Report No. ARH-1354, October 1969.

6. E. J. Wheelwright and F. P. Roberts, The Use of Alternating DTPA and NTA Cation-Exchange Flowsheets for the Simultaneous Recovery and Purification of Pm, Am, and Cm, USAEC Report No. BNWL-1072, JuTy 1969.

7. R. M. Harbour, W. H. Ha le, G. A. Burney, and J. T. Lowe, "Large-Scale Separation of Transplutonium Actinides by Pressurized Cation Exchange," At. Energy Rev., No. 10, pp. 379-399, 1972.

8. J. A. Kelley, Ion Exchange Process for Separating Americium and Curium from Irradiated Plutonium, USAEC Report No. DP-1308, November 1972.

9. L. A. Bray, Denitration of Purex Wastes with Sugar, USAEC Report No. HW-76973 REV, Aprí 1963.

10. L. A. Bray and E. C. Martin, Method of Treating Radioactive Waste, U.S. Patent No. 3,158,577, November 21, 1964 .

11. E. A. Coppinger, Pilot Plant Denitration of Purex Waste with Sugar, USAEC Report No. HW-77080, March 1963.

12. John C. Posey, Curium-244 Isotopic Power Fuel - Chemical Recovery from Commercial Power Reactor Fuels, presented at ANS Meeting in Detroit, June 1973.

13. F. P. Roberts and L. A. Bray, Solvent Extraction (50\% TBP) of Transplutonium Elements for Redox Shippingport Waste - BNWL-CC-956, December 20, 1966. 
14. J. J. Fardy and J. M. Pearson, "Solvent Extraction of Trivalent Actinides and Lanthanides from a Mixture of Carboxy1ic and Aminopolyacetoc Acids," J. Inorg. Nucl. Chem., no. 35, pp. 2513-2524, 1973.

15. E. Hesford, E. E. Jackson and H. A. C. McKay, "Tri-n-Butyl Phosphate as an Extracting Agent for Inorganic Nitrates - VI," J. Inorg. Nucl. Chem., no. 9, pp. 279-289, 1959.

16. G. F. Best, E. Hesford, and H. A. C. McKay, "Tri-n-Butyl Phosphate as an Extracting Agent for Inorganic Nitrates - VII," J. Inorg. Nucl. Chem., no. 12, pp. 136-140, 1959.

17. D. F. Peppard, "Liquid-Liquid Extraction of Metal Ions," Advances in Organic Chemistry and Radiochemistry, no. 9, pp. 1-80, 1966.

18. Purex Chemical Flowsheet for Processing iv-Reactor Fue 1, ARH-2362, (Unclassified, not cleared for non-AEC publication), June 1972.

19. R. E. Isaacson and B. F. Judson, "Neptunium Recovery and Purification at Hanford," I\&EC Process Design and Development, vol. 3, no. 4, October 1964.

20. W. W. Schultz and G. E. Benedict, "Neptunium-237 Productivity and Recovery," AEC Critical Review Series, TID-25955, 1976.

21. "More Rare Earths by the Ton," Chemical Week, December 2, 1967.

22. E. K. Hulet and D. D. Bode, "Separation Chemistry of the Lanthanides and Transplutonium Actinides," MTP International Review of Science, Inorganic Chemistry, Series One, vol. 7, Butterworth University Park Press, 1972, Vo1. Editor - K. W. Bagna11.

23. J. Bochinski, M. Smutz, and F. H. Spedding, "Separation of Monazite Rare Earths by Solvent Extraction," Industrial and Engineering Chemistry, vol. 50, no. 2, February 1958. 


\section{ACKNOWLEDGMENTS}

The authors express their appreciation to the several people who contributed to this study and to the final report. A. P. Litman (AEC/SNS) provided helpful direction as guidelines were established, encouraged a realistic approach to the project and made several good suggestions during the preparation of the final report. H. C. Carney and J. J. Shefcik (General Atomic) established a useful and productive relationship between the subcontractors, provided guidance on acceptability of proposed processes, encouraged our work and carefully reviewed the report prior to printing.

D. D. Campbe11, J. C. Posey, C. L. Ottinger, E. Lamb, and B. S. Weaver (ORNL) provided input into the flowsheet development during the preliminary literature survey and at the mid-term review. J. A. Kelley, H. P. Holcomb, G. A. Burney, J. A. Porter, Frank Field, Charles Holsted, and W. H. Hale (SRL) described their experience in purifying curium and provided a tour of their facility.

Special thanks are given to Jan Simmons and Darla Kennedy for editorial work, typing, and exercising great patience in working with four authors during the preparation of the final report. 
APPENDIX A

ALTERNATE METHODS FOR CURIUM PURIFICATION 


\section{APPENDIX A}

\section{ALTERNATE METHODS FOR CURIUM PURIFICATION}

Prior to selection of the processing steps in the reference flowsheet, each separation process that has been proposed for curium recovery and purification was reviewed on the basis of the flowsheet criteria given in Section II. The processes which were examined and rejected are each outlined in this appendix with the rationale for their rejection.

\section{THE KARLSRUHE SEPARATION PROCESS}

One of the processes with great potential application is the solvent extraction process proposed by Koch, Kolarik, Haug, Hild and Drobnik at KarTsruhe. (2) This process involves denitration and feed clarification steps similar to the reference flowsheet and then a 2-cycle solvent extraction employing the mixed solvent 0.3M HDEHP-0.2M TBP in an $n-a$ lcane diluent to separate americium and curium from other impurities. The back extraction of americium and curium is accomplished with a buffered solution of DTPA and lactic acid. A simple cation-exchange absorption-desorption process is used to concentrate the solvent extraction product. The flowsheet is shown in Figure $A-1$; the proposed stream flows and compositions are given in Table $A-1$.

The Karlsruhe flowsheet is based on tracer-scale laboratory data. The decontamination factors from cerium (>4000) and europium (500) indicate good separation of americium and curium from the lanthanide fission products. A final separation of curium from americium by cation exchange would be required, but this would be a relatively small-scale operation.

The Karlsruhe flowsheet was rejected because it has never been applied to full-level waste. The authors acknowledge that a pilot-plant demonstration is required before a full-scale plant could be built. The route of plutonium and neptunium through the process has not been investigated. 


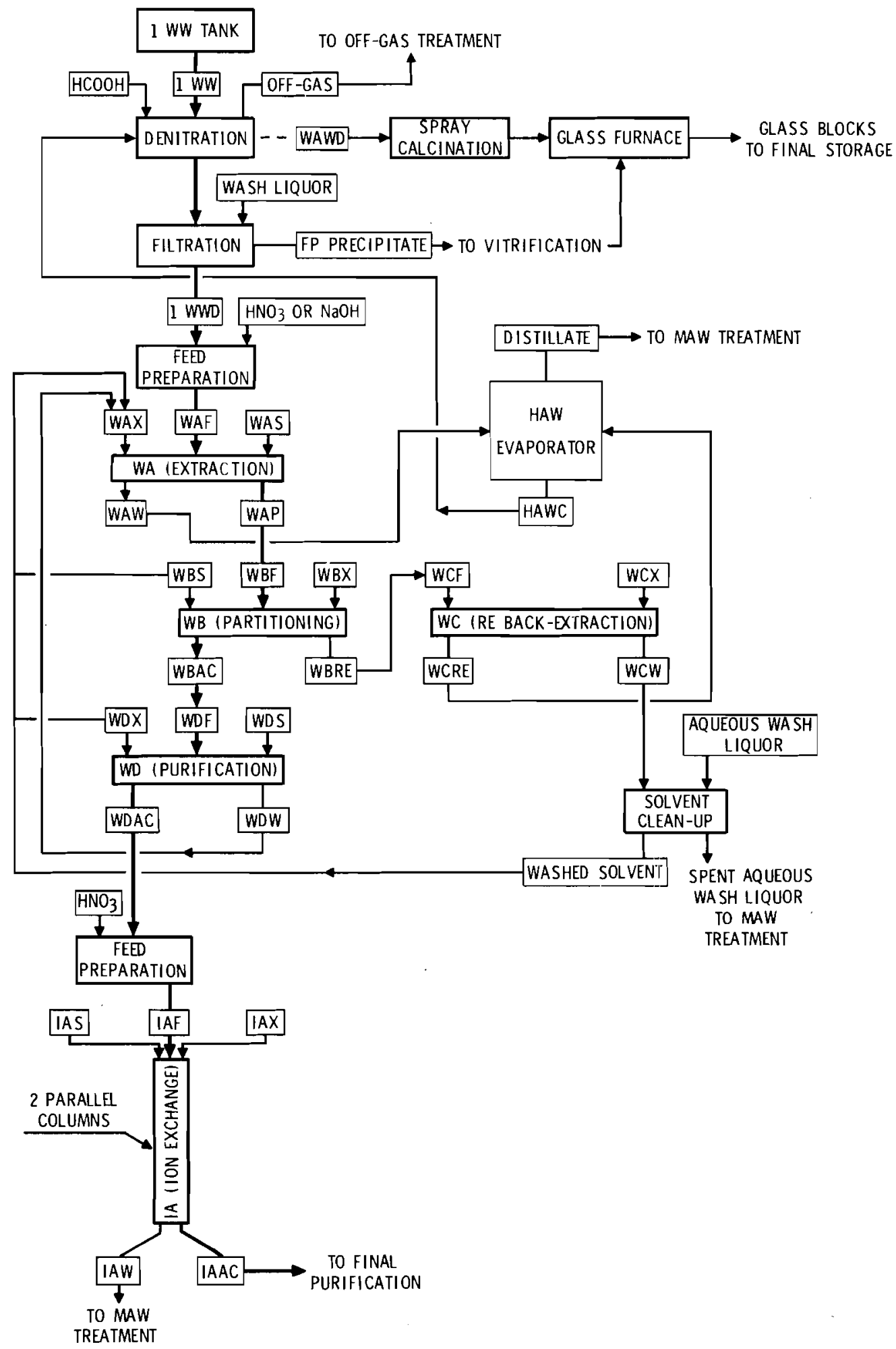

FIGURE A-1. The Karlsruhe Flowsheet ${ }^{(2)}$ 
TABLE A-1. Karlsruhe Flowsheet - Stream Flows and Compositions (2)

1WW:

$27 \mathrm{~g} / 1 \mathrm{FPs}, 4 \mathrm{~g} / 1 \mathrm{CPs}, 0.12 \mathrm{~g} / 1 \mathrm{Am}$, $0.01 \mathrm{~g} / 1 \mathrm{Cm}, 5 \mathrm{~g} / 1 \mathrm{Na}, 4 \underline{\mathrm{M}} \mathrm{HNO}_{3}$, $f=100$

FP Precipitate: Contains essentially the fission and corrosion products without $\mathrm{REs}, \mathrm{Rb}, \mathrm{Sr}, \mathrm{Cs}, \mathrm{Ba}, \mathrm{Ni}$.

Estimated amount: $\mathrm{ca} .11 \mathrm{~kg}$ of metals per 1000 1 of 1 WW.

WAF:

$5 \mathrm{~g} / 1$ REs, $3 \mathrm{~g} / 1$ other FPs (essentially Rb, $\mathrm{Sr}, \mathrm{Cs}, \mathrm{Ba}), 0.06 \mathrm{~g} / 1 \mathrm{Am}, 0.005 \mathrm{~g} / 1 \mathrm{Cm}, 0.02 \mathrm{~g} / 1$ $\mathrm{Ni}, 2.5 \mathrm{~g} / 1 \mathrm{Na}$ (a11 metals as nitrates), $\mathrm{pH}=$ $2 \pm 0.5, f=200$.

WAX:

0.3 MDEHP, 0.2 M TBP, $0.002 \mathrm{~g} / 1$ REs, di $1, f=500$.

WAS: $0.02 \mathrm{M} \mathrm{HNO} 3, f=134$

WAW:

$1.8 \mathrm{~g} / 1 \mathrm{FPs}, 0.12 \mathrm{~g} / 1 \mathrm{Ni}, 1.5 \mathrm{~g} / 1 \mathrm{Na}$ (a11 as nitrates), $\mathrm{pH}=1.1 \pm 0.2, \mathrm{f}=334$.

$\underline{W A P}=\mathrm{WBF}:$

$2 \mathrm{~g} / 1$ REs, $0.024 \mathrm{~g} / 1 \mathrm{Am}, 0.002 \mathrm{~g} / 1 \mathrm{Cm}, 0.3 \mathrm{M}$ HDEHP, $0.2 \underline{M}$ TBP, di $1, f=500$.

WBX:

$0.05 \underline{M} \mathrm{Na}_{5} \mathrm{DTPA}, 1 \mathrm{M} \mathrm{HLac}, \mathrm{pH}=3.0 \pm 0.1, f=166$

WBS:

0.3 M HDEHP, 0.2M TBP, di1, $f=166$.

$\underline{W A C}=\underline{W D F}:$

$0.072 \mathrm{~g} / 1 \mathrm{Am}, 0.006 \mathrm{~g} / 1 \mathrm{Cm}, 0.006 \mathrm{~g} / 1 \mathrm{REs}$, $0.05 \mathrm{M} \mathrm{Na}_{5} \mathrm{DTPA}, 1 \underline{\mathrm{M}} \mathrm{HLac}, \mathrm{pH}=3.0 \pm 0.1, f=166$.

$\underline{\text { WBRE}}=\underline{\mathrm{WCF}}:$

$1.5 \mathrm{~g} / 1$ REs, 0.3M HDEHP, 0.2ㅆ TBP, di1, $f=666$.

WCX: $5 \underline{M} \mathrm{HNO}_{3}, f=166$

WCRE:

$6 \mathrm{~g} / 1 \mathrm{RES}, 4.9 \mathrm{M} \mathrm{HNO}_{3}, \mathrm{f}=166$

WCW:

0.3M HDEHP, 0.2M TBP, di1, $f=666$.

WDX:

0.3M HDEHP, 0.2M TBP, di1, $f=125$. 
TABLE A-1. (contd)

WDS:

$0.05 \underline{M} \mathrm{Na}_{5}$ DTPA, 1M HLac, pH $=3.0 \pm 0.1, f=42$

WDAC:

$0.058 \mathrm{~g} / 1 \mathrm{Am}, 0.0048 \mathrm{~g} / 1 \mathrm{Cm}, 0.05 \underline{\mathrm{M}} \mathrm{Na}_{5} \mathrm{DTPA}$, 1 M HLac, pH $=3.0 \pm 0.1, f=208$.

WDW:

$0.008 \mathrm{~g} / 1$ REs, 0.3M HDEHP, 0.2M TBP, di $1, f=125$.

IAF:

$0.056 \mathrm{~g} / 1 \mathrm{Am}, 0.0047 \mathrm{~g} / 1 \mathrm{Cm}, 0.049 \mathrm{M} \mathrm{H}_{5}$ DTPA, $0.98 \mathrm{MLaC}, 0.24 \mathrm{M} \mathrm{NaNO}{ }_{3}, \mathrm{pH}=0.9 \pm 0.1, f=213$.

IAS:

$0.1 \underline{M} \mathrm{HNO}_{3}, f=10$.

IAW:

$0.047 \underline{\mathrm{M}} \mathrm{H}_{5} \mathrm{DTPA}, 0.98 \underline{\mathrm{M}} \mathrm{HLac}, 0.23 \underline{\mathrm{M}} \mathrm{NaNO}_{3}$, $\mathrm{pH}=\mathrm{ca}$. $0.9, f=223$.

IAX: $3 \underline{M} \mathrm{HNO}_{3}, f=5$.

IAAC:

$2.4 \mathrm{~g} / 1 \mathrm{Am}, 0.2 \mathrm{~g} / 1 \mathrm{Cm}, 0.5 \mathrm{~g} / 1 \mathrm{Na}, 0.012 \mathrm{M}$ $\mathrm{H}_{5} \mathrm{DTPA}, 2.9 \mathrm{M} \mathrm{HNO}_{3}, \mathrm{f}=5$.

Because of the good tracer-scale DF from europium, a good separation of americium/curium from gadolinium could be implied, but there is not even tracer-level data to substantiate this implication.

\section{OAK RIDGE PROCESS}

A solvent extraction process with alternate low-acid and high-acid preliminary steps for the separation of curium and americium from all other impurities has been proposed by John Posey ${ }^{(12)}$ at ORNL. This process is outlined in Figure $A-2$ and the process details are given in Figures $A-3$, A-4 and A-5. This flowsheet yields a mixed americium/curium product like the Karlsruhe flowsheet.

The low-acid precipitation process requires careful pH control. Experience at Hanford has repeatedly shown that this is difficult to do on a large scale in a remote, shielded facility. 
LOW-ACID PROCESS

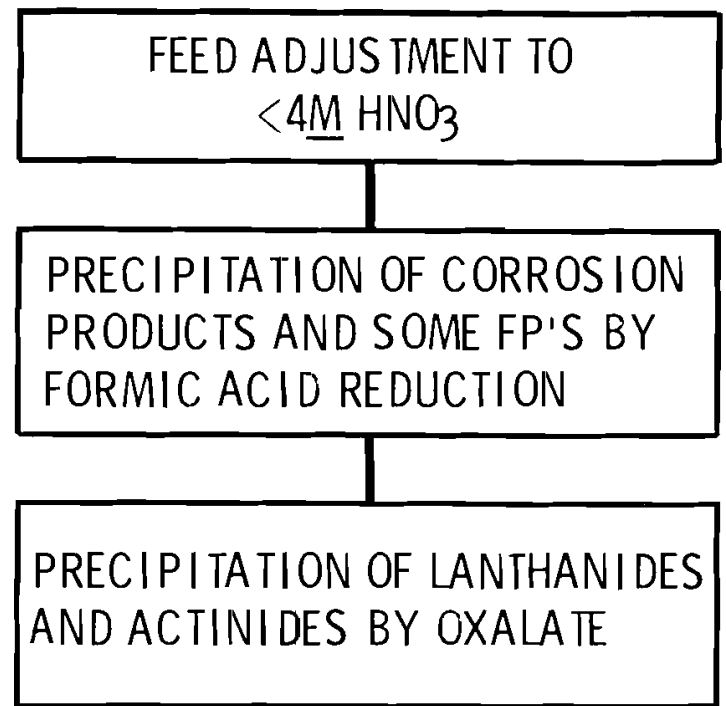

HIGH-ACID PROCESS

CLARIFICATION AND FEED ADJUSTMENT TO $10 \mathrm{M} \mathrm{HNO}_{3}$

DIFFERENTIAL EXTRACTION OF U, Pu, Np, Zn (TBP-1OM HNOB)

DIFFERENTIAL EXTRACTION OF LANTHANIDES AND ACTINIDES (TBP-15.6M HNO3)

\section{FEED ADJUS TMENT}

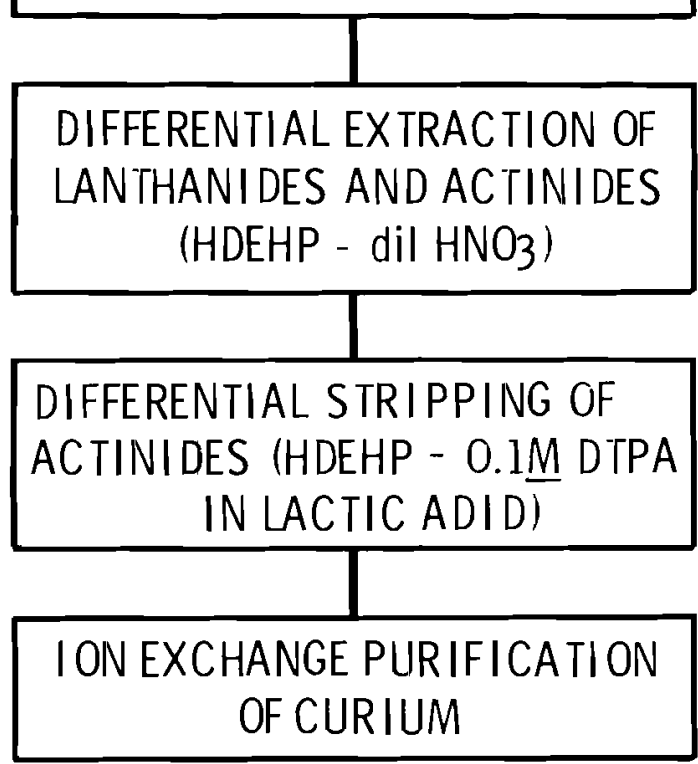

FIGURE A-2. The ORNL Flowsheet $(3,12)$ 
Corrected pine …n

FEED FROM WAS IE STORAGE

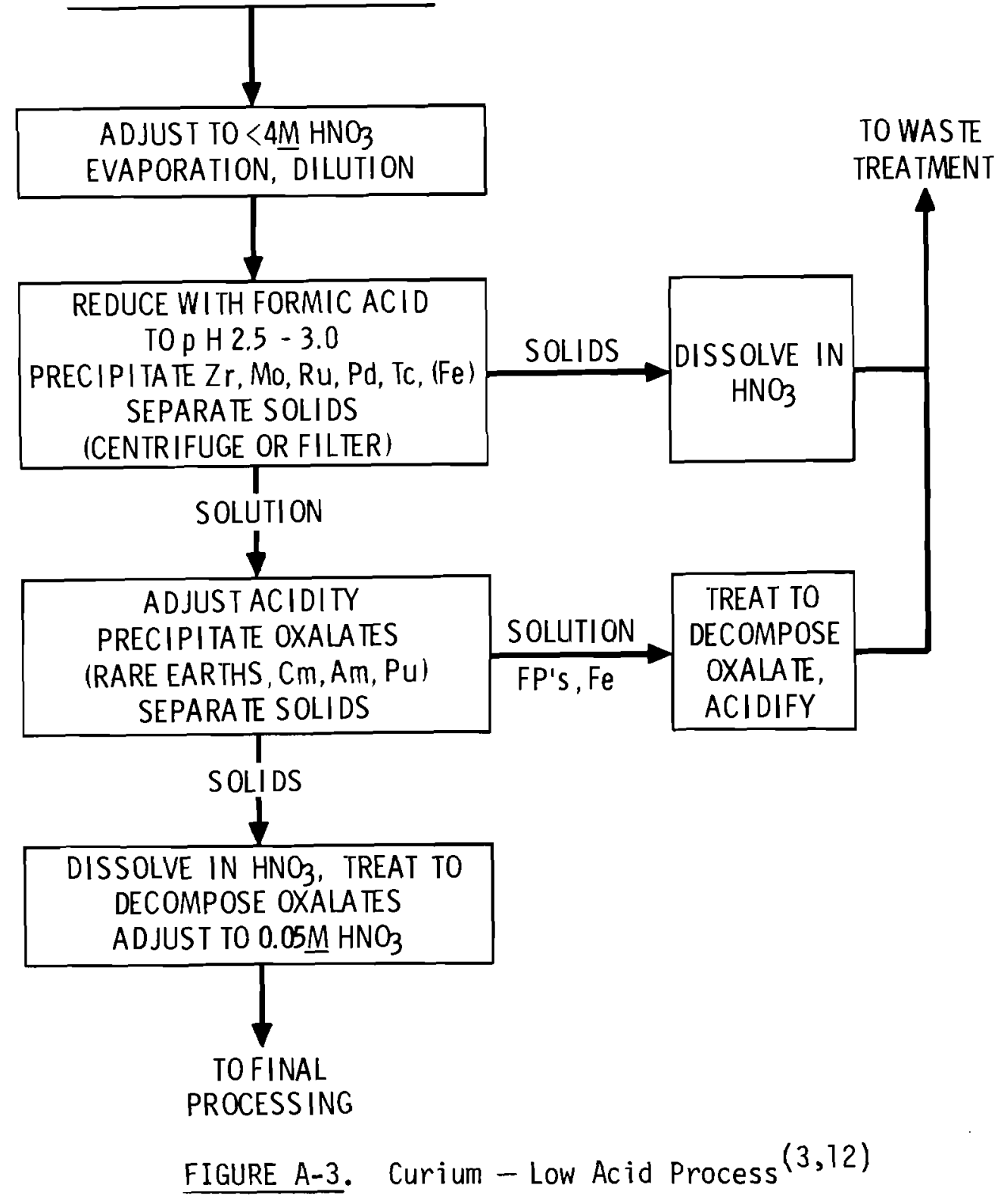


FEED FROM WAS TE STORAGE

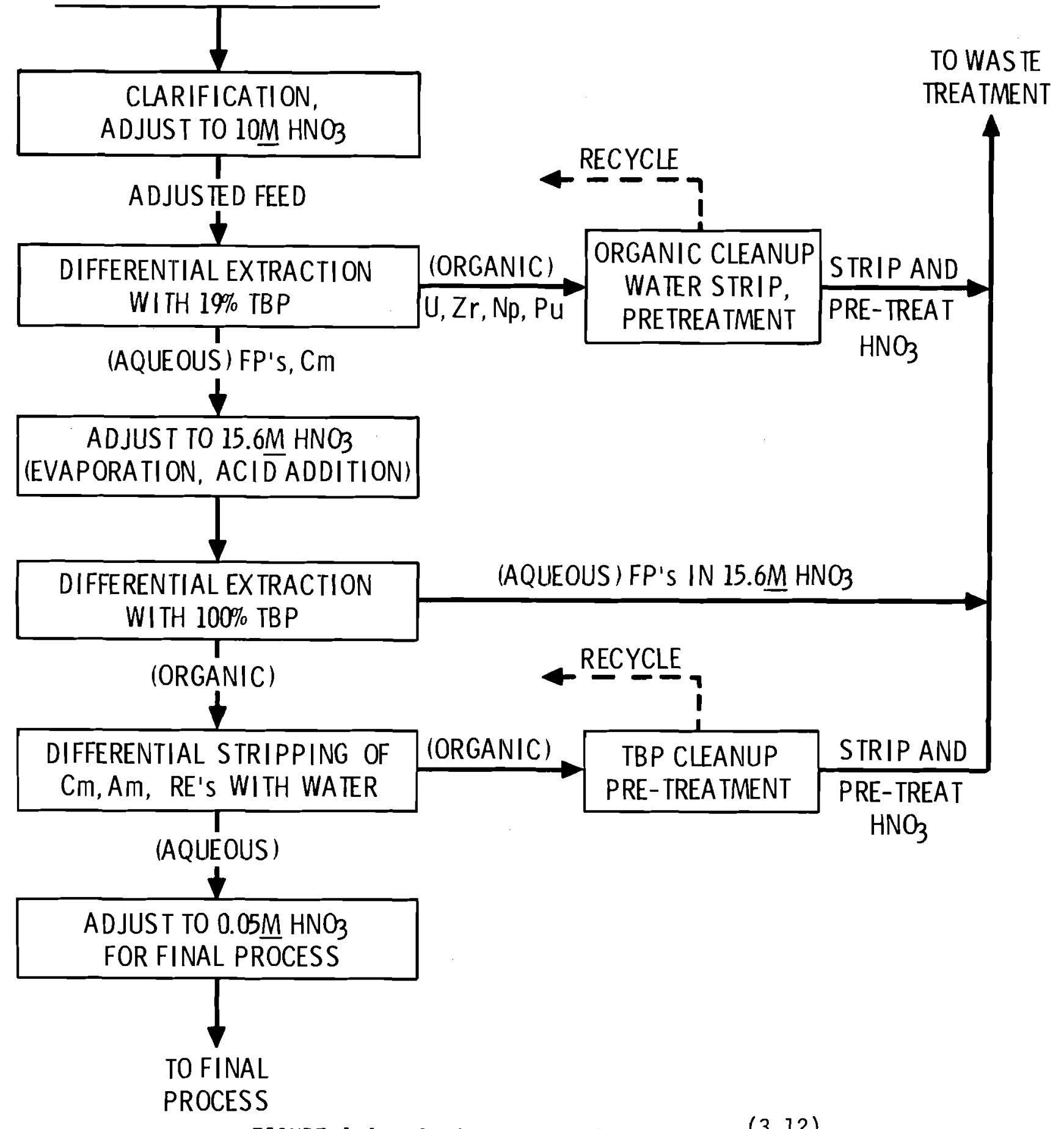

FIGURE A-4. Curium - High Acid Process $(3,12)$ 
FEED FROM PRELIMINARY PROCESS

RARE EARTHS, ACTINIDES, SOME FP'S

IN $0.05 \mathrm{M}$ HNO3

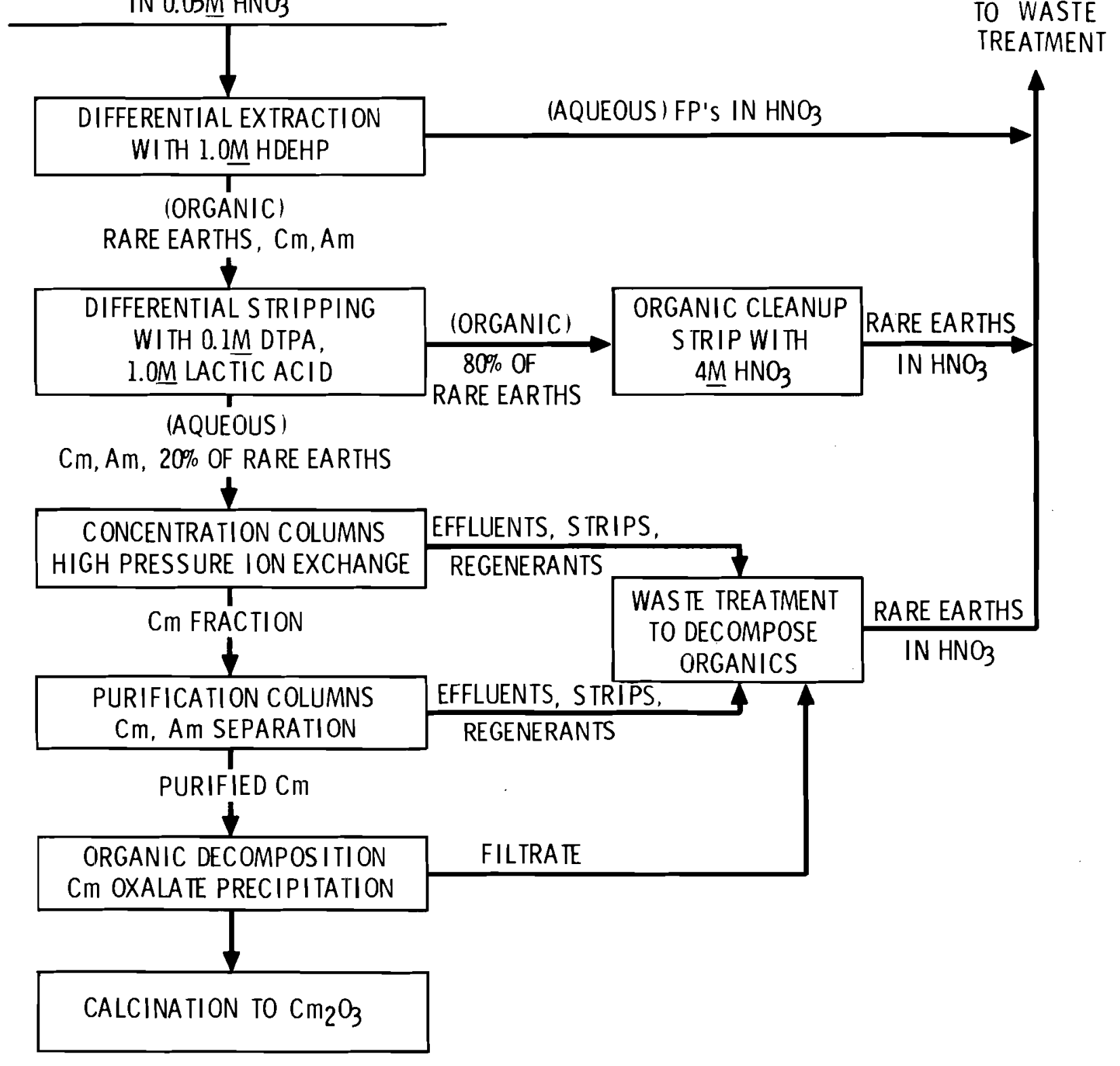

FIGURE A-5. Curium - Final Processing $(3,12)$ 
The high-acid preliminary process requires separate TBP extractions from 10 and then $15.6 \mathrm{M} \mathrm{HNO}_{3}$ to remove $\mathrm{U}, \mathrm{Pu}$, Np and then the non-lanthanide fission products. The first extraction is similar to that proposed in the reference flowsheet to accomplish the same objective but at a much higher acid concentration. The second TBP extraction has not been demonstrated and it would be very difficult to increase the acid concentration of this salt solution from $10 \mathrm{M}$ to $15.6 \mathrm{M} \mathrm{HNO}_{3}$ by concentration or acid addition.

The separation of americium/curium from the rare earths by HDEHP extraction and DTPA-lactic acid stripping has not been demonstrated with full-activity solutions. The separation from gadolinium is particularly important because it represents $47 \%$ of the rare earth mixture. The method of differential extraction proposed by Posey does not appear to provide distinct advantages over other methods of contacting aqueous and organic phases in a large-scale plant.

\section{PURIFICATION USING ALL SOLVENT EXTRACTION}

Several flowsheets were examined which utilize only feed clarification, acid adjustment, and solvent extraction steps. Each of these were rejected because no solvent-extraction process for the separation of americium and curium from the lanthanide fission products or from each other has been demonstrated with full-activity solutions.

\section{PURIFICATION USING ALL ION EXCHANGE}

A flowsheet similar to the reference flowsheet but using anion exchange rather than solvent extraction for the removal of neptunium and plutonium from the HLLW has been examined. The anion-exchange flowsheet is given in Figure A-6 and the time cycle in Figure A-7. This process has been demonstrated for the recovery of ${ }^{237} \mathrm{~Np}$ and ${ }^{238} \mathrm{Pu}$ from irradiated and then dissolved neptunium oxide targets. The process was rejected because there is more plant-scale experience with the TBP solvent-extraction process and the solvent extraction process also removes uranium from the HLLW. 


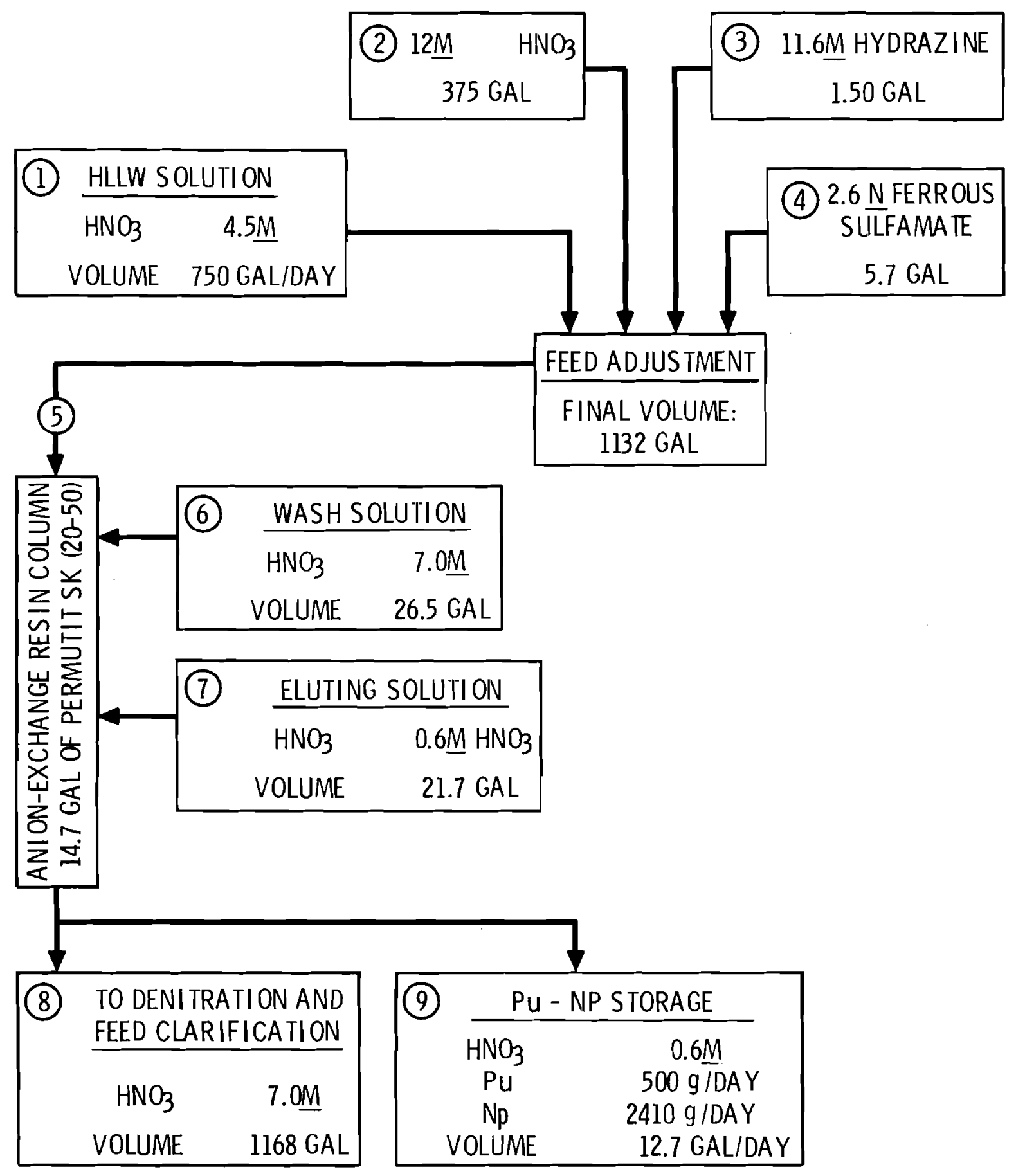

FIGURE A-6. Anion-Exchange Flowsheet for $\mathrm{Pu}$ and $\mathrm{Np}$ Separation 

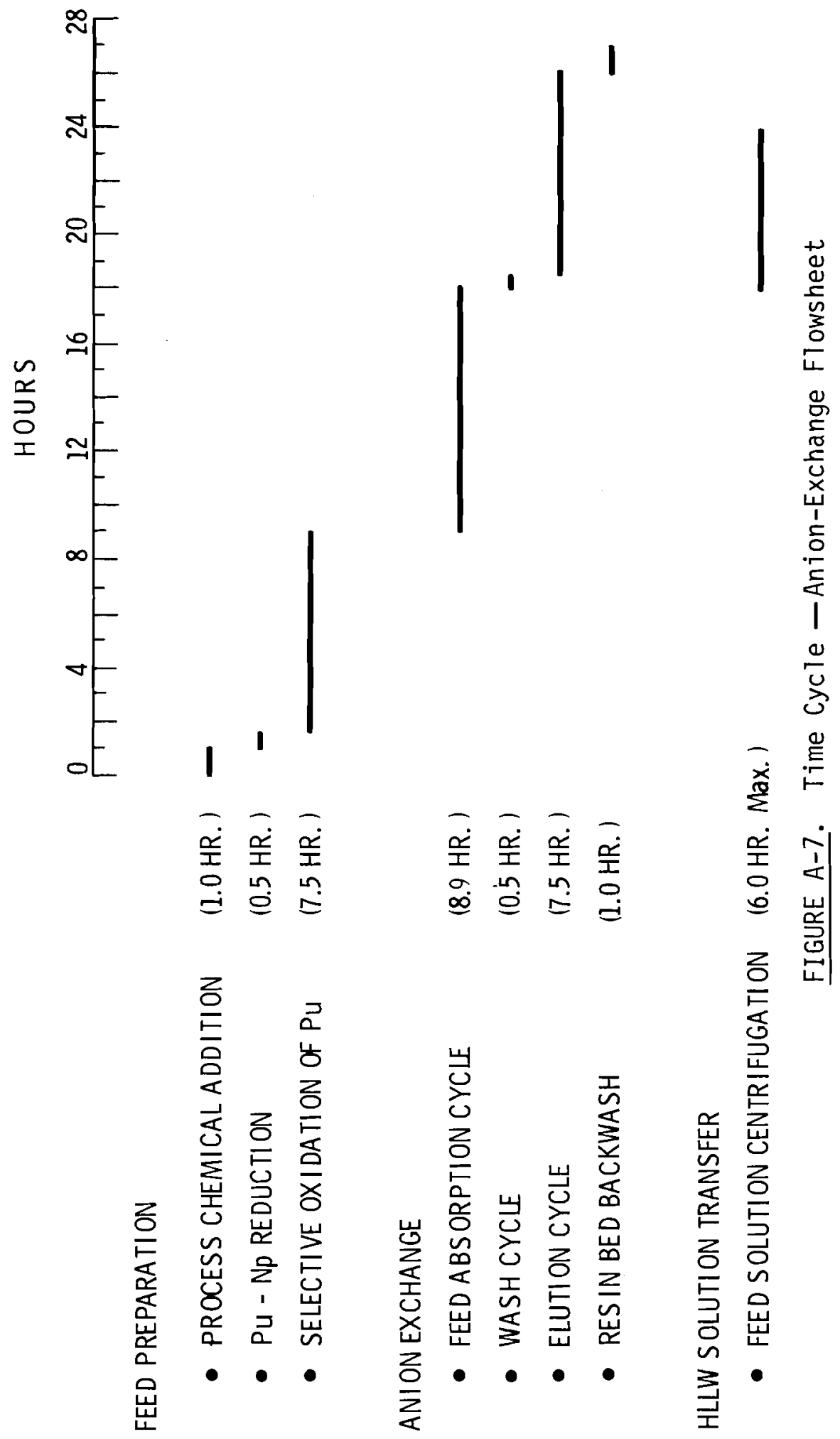


\section{APPENDIX B}

PROCESS STREAM FLOWS AND COMPOSITIONS 
APPENDIX B

\section{PROCESS STREAM FLOWS AND COMPOSITIONS}

The primary flowsheets used for recovery of ${ }^{244} \mathrm{Cm}$ from Barnwel1 HLLW solution were developed on the basis that only state-of-the-art technology could be used. The reference flowsheet uses solvent extraction for Pu-U-Np removal, sugar denitration for acid destruction, and ion exchange for curium recovery and purification. Al1 of the operations have been well demonstrated with radioactive feed solutions. Process flows for ${ }^{244} \mathrm{Cm}$ recovery from a 5 tonne/day reprocessing plant HLLW were calculated using the flowsheets developed, published data on solvent-extraction distribution coefficients and ion-exchange decontamination factors, and data developed at Hanford on processing high-level waste. The Barnwell HLLW feed solution was assumed to have the composition described in Section III. The waste solution was further assumed to have aged for 3 years prior to processing for curium recovery.

The principal heat emitters in the aged HLLW solution are also described in Section III. Five isotopes, ${ }^{90} \mathrm{Sr},{ }^{106} \mathrm{Ru},{ }^{134} \mathrm{Cs},{ }^{137} \mathrm{Cs}$ and ${ }^{144} \mathrm{Ce}$, account for more than $90 \%$ of the heat output of the aged solution.

The overall flow diagram for the ${ }^{244} \mathrm{Cm}$ recovery process is shown in Figure 1. Stream flows are indicated in gallons per day. The ion-exchange purification of curium is a batch operation. Each batch of feed for the ion-exchange operation is equivalent to 3.5 days flow (17.5 tonne of fuel). Certain assumptions were made in calculating the stream flows: 1) no allowances were made for volume changes which result from composition changes; and 2) no allowances were made for solvent degradation in calculating organic phase flow rates in the solvent extraction section.

Based on the flowsheet presented in Figure 1 it is possible to estimate the waste load which would result from a ${ }^{244} \mathrm{Cm}$ recovery operation. This has been done and results are given in Table 8 . The curium processing waste consists of three streams: a high level liquid waste, an intermediate level 
liquid waste, and spent ion-exchange resin. Comparing these streams with the original waste stream (Table 8 ), it is apparent that curium recovery increases the waste volume to be processed substantially and adds significant amounts of zinc, $\mathrm{NH}_{4}^{+}$and DTPA, as well as spent resin, to the waste load. The other waste constituents are not changed to any great degree by the curium recovery process.

As stated previously, the curium recovery process, as developed, is divided into three major operations: 1) $\mathrm{Pu}, \mathrm{Np}$ and $U$ removal from the feed solution using solvent extraction; 2) destruction of the excess nitric acid using sugar denitration; and 3) curium recovery and purification using ion exchange. Each of the operations are discussed in detail in the following sections.

SOLVENT EXTRACTION OF PU, Np AND U FROM THE CM FEED SOLUTION

To facilitate subsequent operations and eliminate the need for using all critically safe equipment, the $\mathrm{Pu}, \mathrm{Np}$ and $\mathrm{U}$ are removed from the curium feed solution using solvent extraction. The solvent used is $30 \%$ TBP in normal paraffin hydrocarbon (NPH). The flow diagram for the solvent extraction section is shown in Figure B-1. Stream flows are in gallons per day. Design of the extraction and stripping columns is based on the data presented in Table $B-1$. The compositions of the various process streams are given on pages $B-5$ through $B-13$.

The HLLW feed solution will undoubtedly contain some solids which will have to be removed prior to solvent extraction. This is best done by centrifugation. Work at PNL has shown that the solids will probably be on the order of 1 vol\% (settled). The settled solids will be approximately $35 \%$ solids and $65 \%$ entrained 1 iquor. The solids are principally noble metals $(\mathrm{Ru}, \mathrm{Rh}, \mathrm{Pd}$, etc.) and will contain about 0.6 to $0.7 \%$ of the curium.

The spent solvent will be cleaned up using a process similar to that used at the Hanford Purex Plant. The used solvent is washed with an aqueous phase containing about $0.2 \mathrm{M} \mathrm{Na}{ }_{2} \mathrm{CO}_{3}$ and possibly some $\mathrm{KMnO}_{4}$. Aqueous make-up is added as needed to maintain the carbonate concentration. The treated solvent is returned to the extraction circuit. 


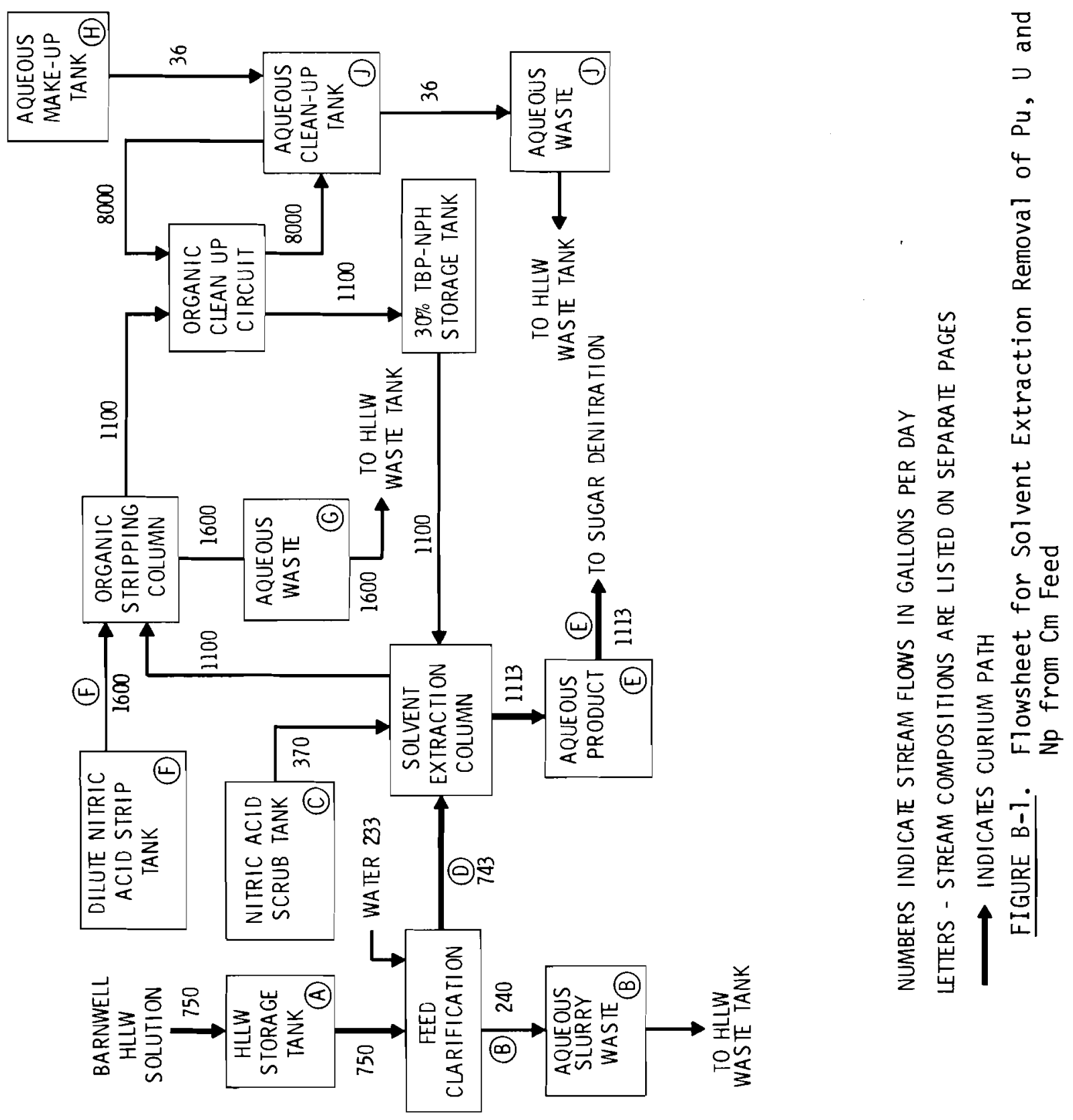


TABLE B-1. Basis for Design of Extraction and Stripping Columns

\section{EXTRACTION COLUMN}

Basis: $99 \%$ Pu extraction

98\% $U$ and Np extraction

$<<1 \% \mathrm{Cm}$ extraction

Temperature: 30 to $40^{\circ} \mathrm{C}$

Flows: Aqueous Feed $\sim 743 \mathrm{gpd}$

Aqueous Scrub $2370 \mathrm{gpm}$

$30 \%$ TBP-NPH $\sim 1100 \mathrm{gpm}$

Distribution Coefficients (estimated):

\begin{tabular}{|c|c|}
\hline & $E_{a}^{0}$ \\
\hline $\mathrm{Pu}$ (IV) & 215 \\
\hline$N p(V I)(a)$ & 25 \\
\hline$U(V I)$ & ح30 \\
\hline $\mathrm{Cm}$ & 0.1 \\
\hline $\mathrm{H}^{+}$ & 0.2 \\
\hline
\end{tabular}

STRIPPING COLUMN

Basis: Essentially complete removal of $\mathrm{Pu}, \mathrm{Np}$ and $\mathrm{U}$ from the loaded organic phase. $U$ will be most difficult to remove.

Temperature: 30 to $40^{\circ} \mathrm{C}$

Flows: Organic Phase $21100 \mathrm{gpd}$

Aqueous Strip $1600 \mathrm{gpd}$ $\left(0.01 \underline{\mathrm{MNO}} \mathrm{HN}_{3}\right)$

(a) Valence adjustment with $\mathrm{NaNO}_{2}$ may be necessary to assure $\mathrm{Np}$ is in (VI) state. 


\begin{tabular}{|c|c|c|c|}
\hline STREAM: & A & & \\
\hline FLOW: & $750 \mathrm{gpd}$ & & \\
\hline HEAT LOAD: & $18.3 \mathrm{~W} / \mathrm{gal}$ & & \\
\hline ACTIVITY: & $22600 \mathrm{Ci} / \mathrm{gal}$ & & \\
\hline COMPOSITION: & & M & g-mol/day \\
\hline $\mathrm{H}^{+}$ & & 4.58 & 13,000 \\
\hline $\mathrm{Na}$ & & 0.383 & 1,087 \\
\hline $\mathrm{NO}_{3}$ & & 8.21 & 23,302 \\
\hline $\mathrm{Fe}-\mathrm{Ni}-\mathrm{Cr}$ & & 0.64 & 1,816 \\
\hline$P$ & & 0.037 & 106 \\
\hline$R E^{\prime} S^{(a)}$ & & 0.232 & 658 \\
\hline$F P^{\prime} s^{(b)}$ & & 0.323 & 918 \\
\hline$U$ & & 0.074 & 210 \\
\hline $\mathrm{Np}$ & & 0.0036 & 10.2 \\
\hline $\mathrm{Pu}$ & & 0.00074 & 2.1 \\
\hline $\mathrm{Am}$ & & 0.0038 & 10.85 \\
\hline $\mathrm{Cm}$ & & 0.00018 & 0.51 \\
\hline
\end{tabular}

(a) Rare Earths

(b) Fission products other than the rare earths and actinides 


\begin{tabular}{|c|c|c|c|}
\hline STREAM: & B & & \\
\hline FLOW: & $240 \mathrm{gpd}$ & & \\
\hline HEAT LOAD: & $3.18 \mathrm{~W} / \mathrm{gal}$ & & \\
\hline ACTIVITY: & $2350 \mathrm{Ci} / \mathrm{gal}$ & & \\
\hline COMPOSITION: & & $M$ & g-mol/day \\
\hline $\mathrm{H}^{+}$ & & 0.096 & 87 \\
\hline $\mathrm{Na}$ & & 0.0077 & 7 \\
\hline $\mathrm{NO}_{3}$ & & 0.171 & 155 \\
\hline $\mathrm{Fe}-\mathrm{Ni}-\mathrm{Cr}$ & & 0.013 & 12 \\
\hline$P$ & & 0.00077 & 0.7 \\
\hline$R E^{\prime} s$ & & 0.0048 & 4.4 \\
\hline F P's & & 0.132 (including & 120 \\
\hline$U$ & & 0.0015 & 1.4 \\
\hline Np & & & 0.07 \\
\hline $\mathrm{Pu}$ & & & 0.01 \\
\hline $\mathrm{Am}$ & & & 0.07 \\
\hline $\mathrm{Cm}$ & & & 0.003 \\
\hline
\end{tabular}




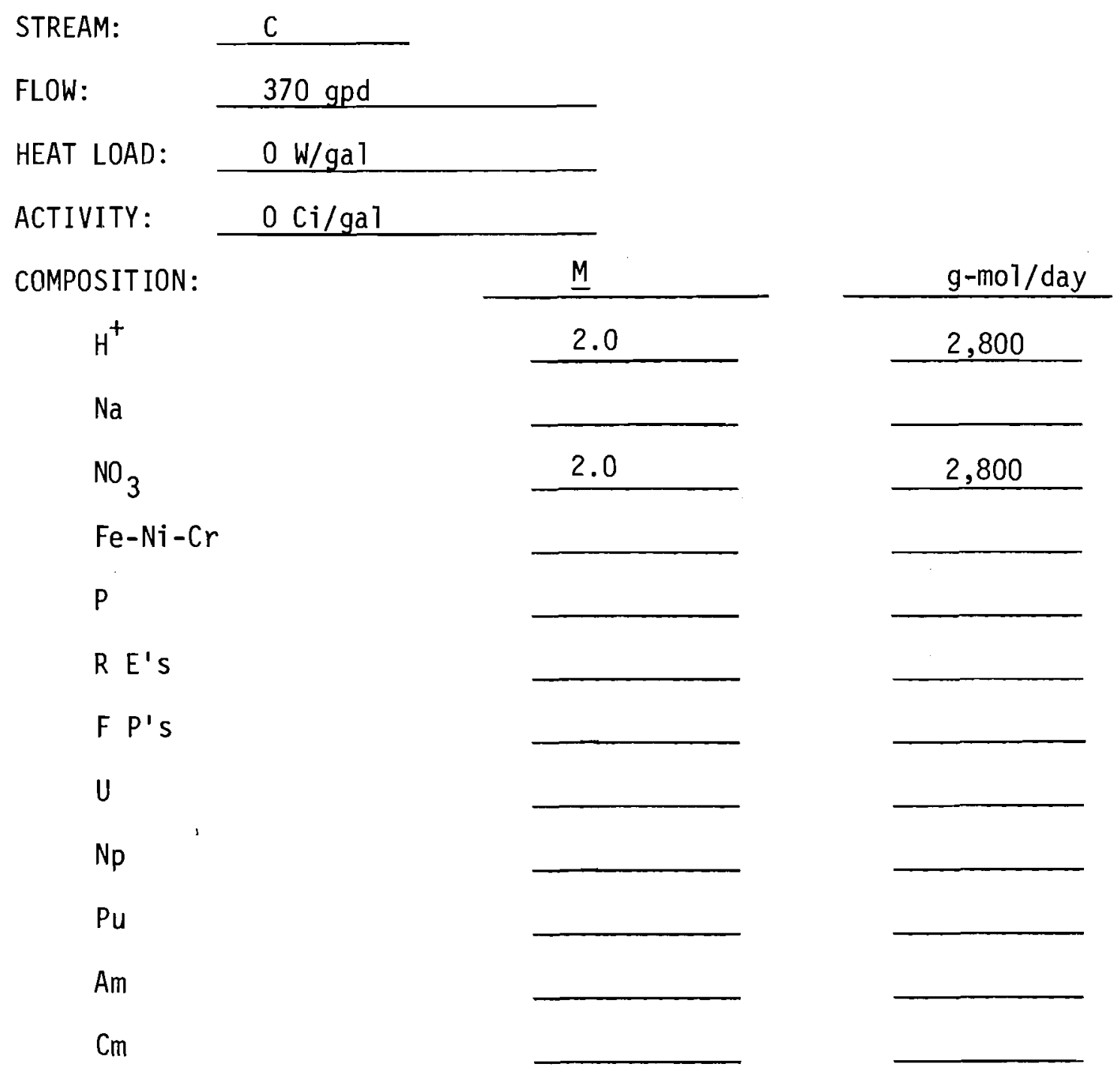




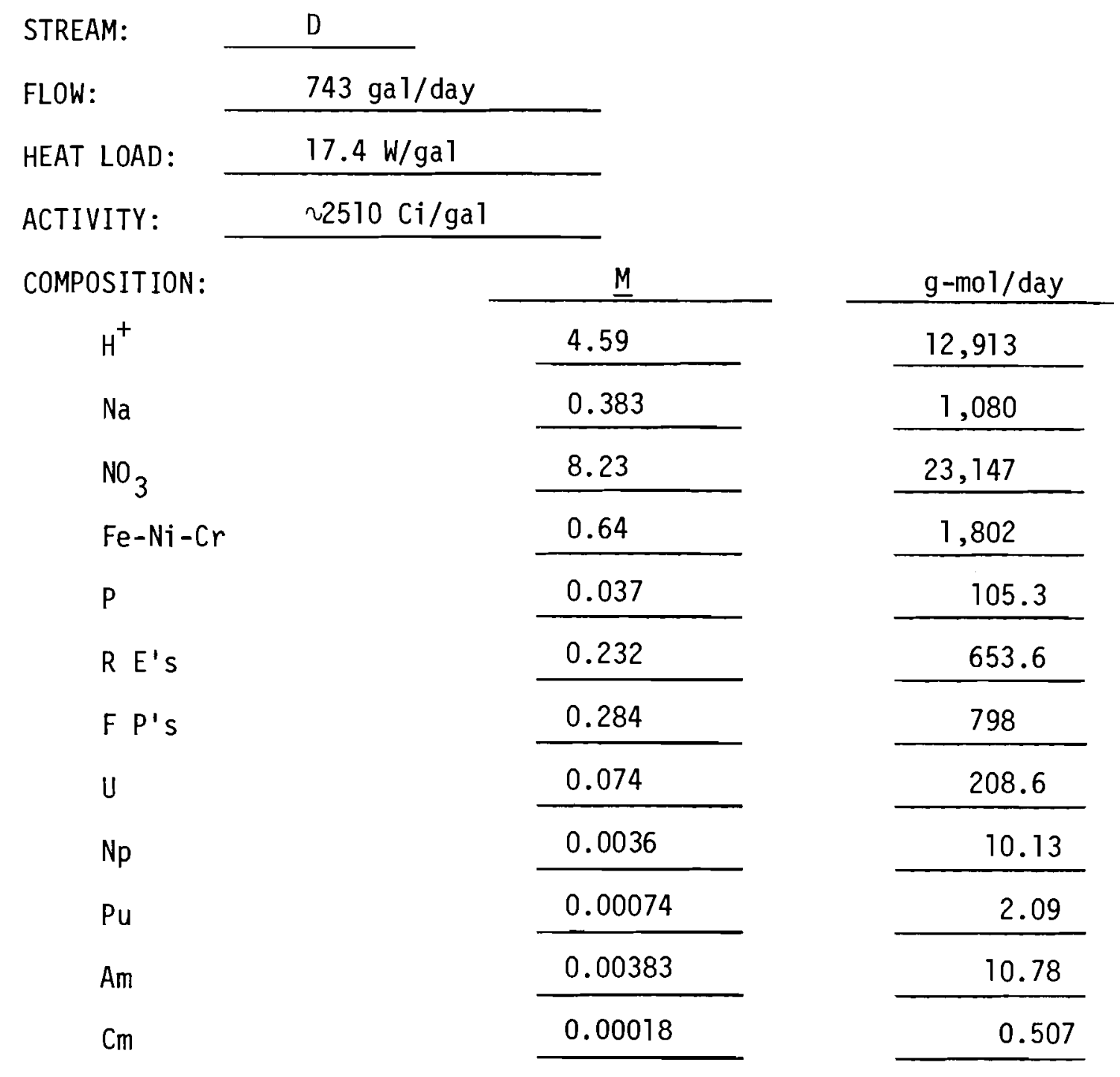




\begin{tabular}{|c|c|c|c|}
\hline STREAM: & $E$ & & \\
\hline FLOW: & $1113 \mathrm{gpd}$ & & \\
\hline HEAT LOAD: & $11.6 \mathrm{~W} / \mathrm{gal}$ & & \\
\hline ACTIVITY: & $\sim 1670 \mathrm{Ci} / \mathrm{ga} 1$ & & \\
\hline COMPOSITION: & & $\underline{M}$ & g-mol/day \\
\hline $\mathrm{H}^{+}$ & & 3.08 & 12,965 \\
\hline $\mathrm{Na}$ & & 0.256 & 1,080 \\
\hline $\mathrm{NO}_{3}$ & & 5.42 & 22,722 \\
\hline $\mathrm{Fe}-\mathrm{Ni}-\mathrm{Cr}$ & & 0.428 & 1,802 \\
\hline$P$ & & 0.025 & 105.3 \\
\hline$R E^{\prime} S$ & & 0.155 & 653.6 \\
\hline$F P^{\prime} S$ & & 0.189 & 798.0 \\
\hline$U$ & & 0.001 & 4.2 \\
\hline $\mathrm{Np}$ & & $4.7 \times 10^{-4}$ & 0.2 \\
\hline $\mathrm{Pu}$ & & $4.7 \times 10^{-5}$ & 0.02 \\
\hline $\mathrm{Am}$ & & 0.0026 & 10.78 \\
\hline $\mathrm{Cm}$ & & 0.00012 & 0.507 \\
\hline
\end{tabular}




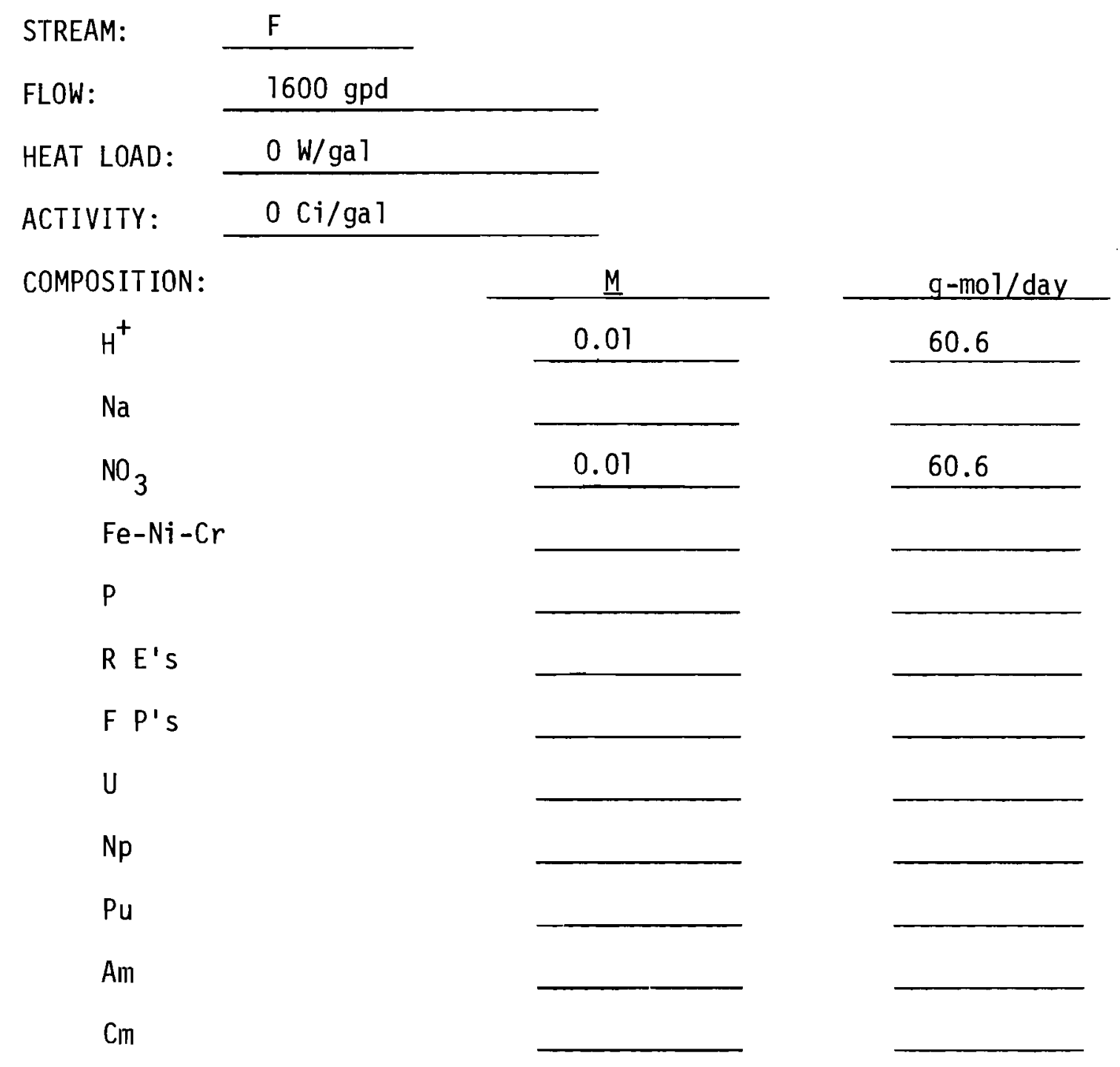




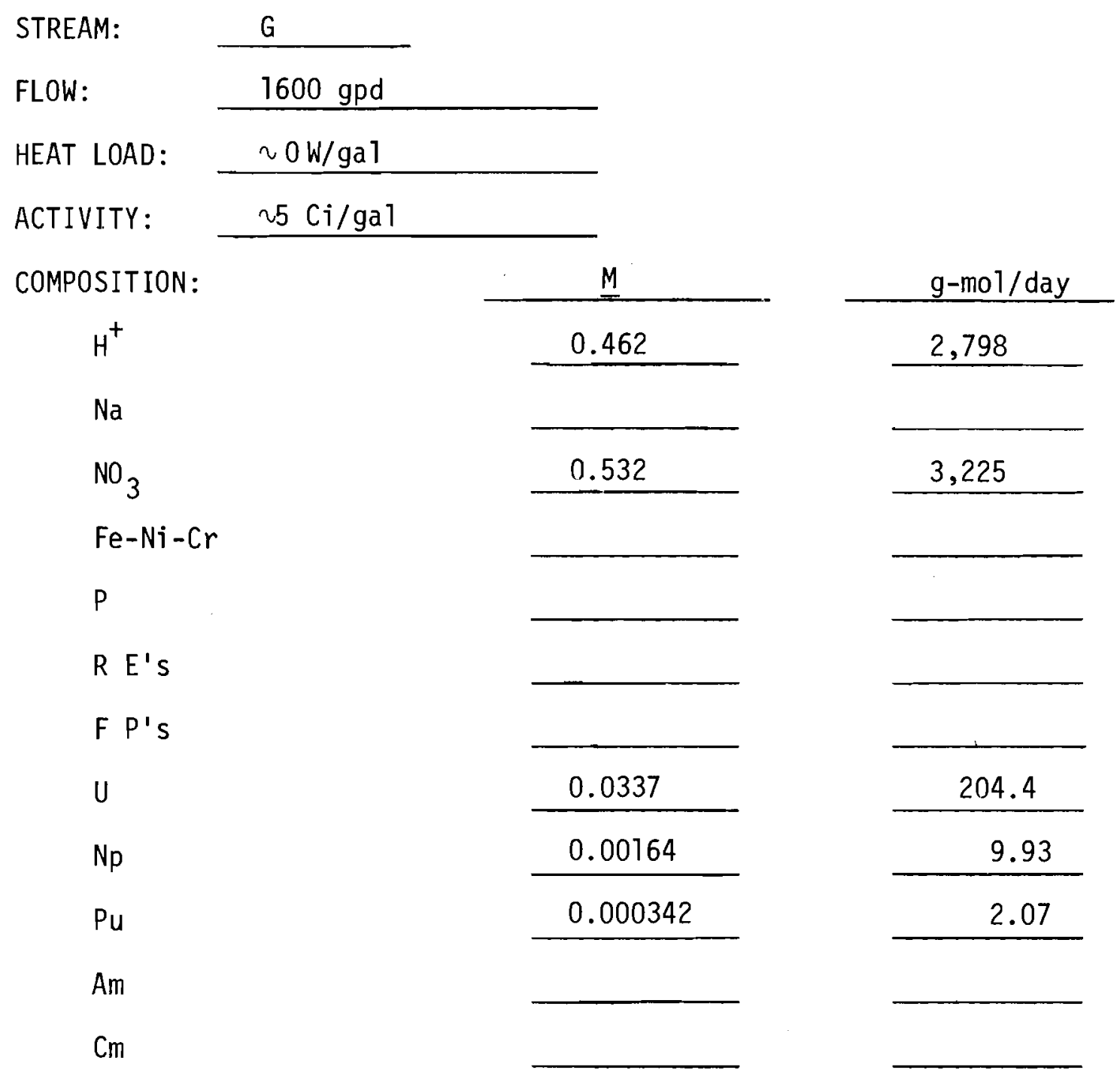




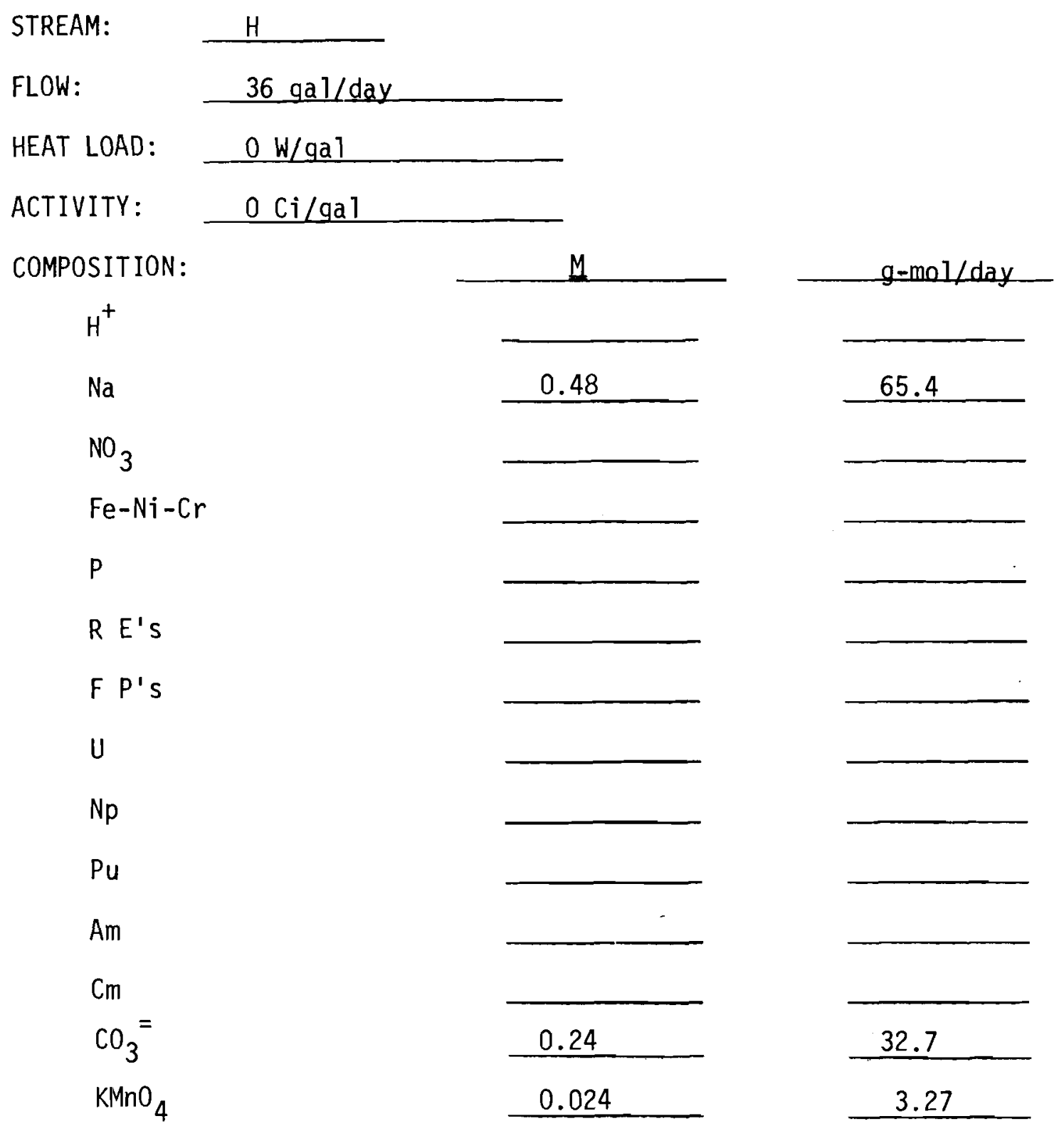




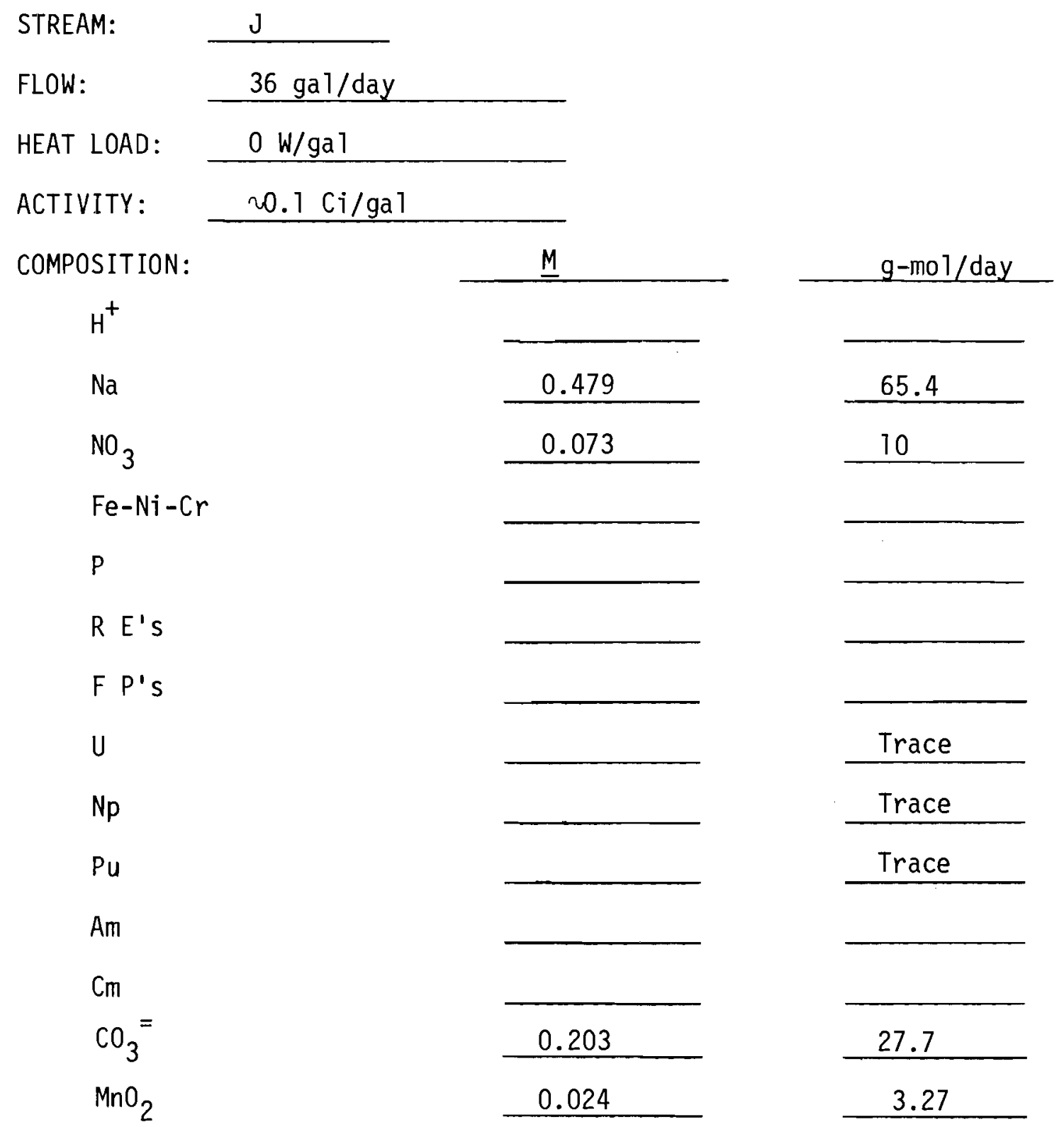




\section{ACID DESTRUCTION USING SUGAR DENITRATION}

The aqueous curium stream leaving the solvent extraction section has an acid concentration of approximately 3 molar. This must be reduced to about one molar before the ion-exchange operation. Reduction of the acid concentration is best accomplished by sugar denitration using a 1 M sucrose solution. The reaction of the batch is carried out at a temperature of about $100^{\circ} \mathrm{C}$. Each mole of sucrose destroys approximately 16 moles of nitric acid while approximately $10 \%$ of the water entering the denitration reactor is evaporated due to the heat of reaction.

When the acid concentration of the aqueous curium solution is reduced to 1 molar additional precipitation of solids occurs. These solids amount to about 1.5 vol\% (settled), and consist principally of $\mathrm{Zr}$, Mo and the noble metals. About 1\% of the curium is lost with the solids which are separated from the aqueous phase by centrifugation.

The diagram for the sugar denitration section is shown in Figure B-2. Stream flows are given in gallons per day (gpd). The compositions of the various streams are given in pages $\mathrm{B}-17$ through $\mathrm{B}-22$. 


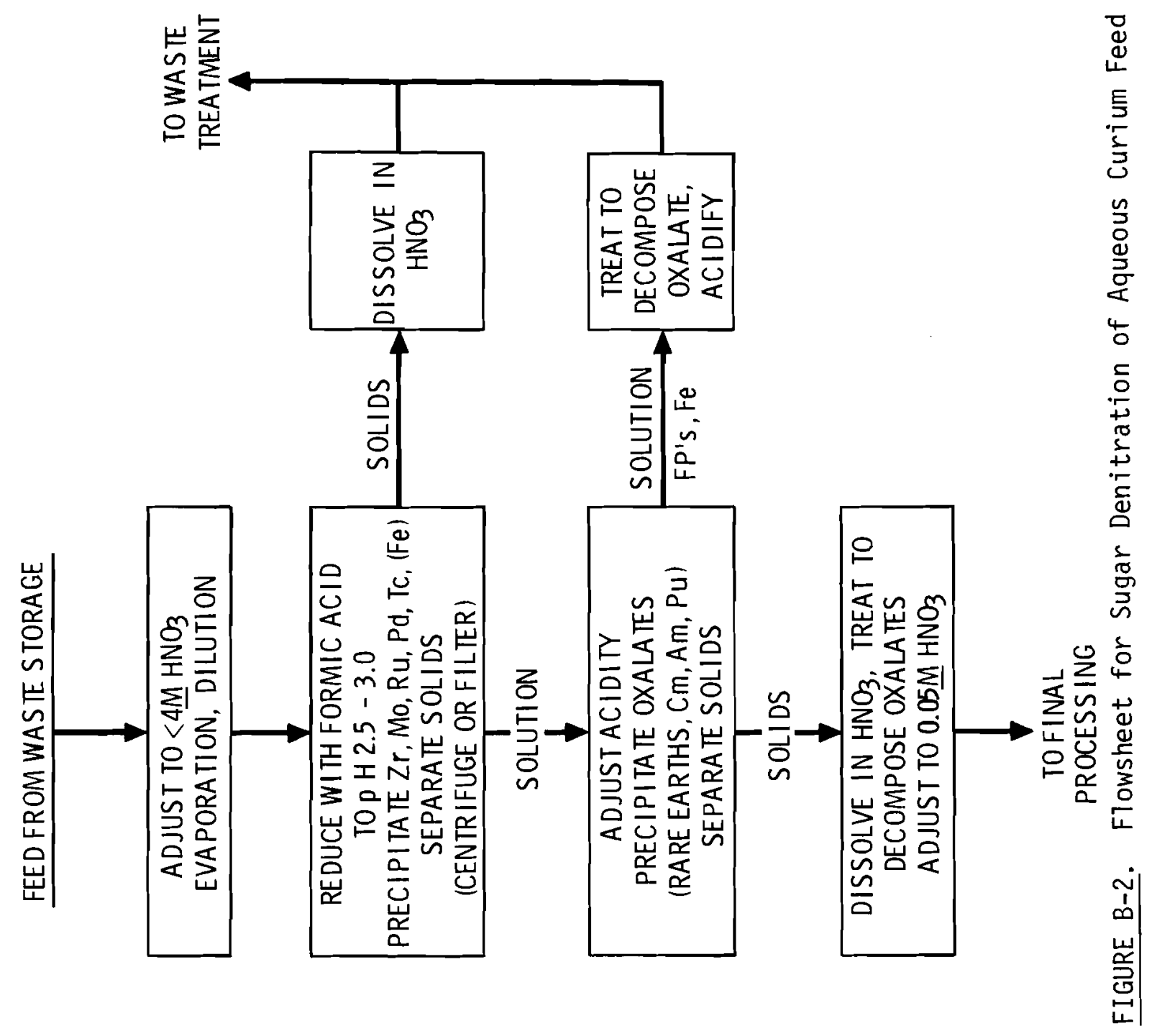




\begin{tabular}{|c|c|c|c|}
\hline STREAM: & $E$ & & \\
\hline FLOW: & $1113 \mathrm{gpd}$ & & \\
\hline HEAT LOAD: & $11.6 \mathrm{~W} / \mathrm{gal}$ & & \\
\hline ACTIVITY: & 21670 Ci/gal & & \\
\hline COMPOSITION: & & $\underline{M}$ & g-mol/day \\
\hline $\mathrm{H}^{+}$ & & 3.08 & 12,965 \\
\hline $\mathrm{Na}$ & & 0.256 & 1,080 \\
\hline $\mathrm{NO}_{3}$ & & 5.42 & 22,772 \\
\hline $\mathrm{Fe}-\mathrm{Ni}-\mathrm{Cr}$ & & 0.428 & 1,802 \\
\hline$P$ & & 0.025 & 105.3 \\
\hline$R E^{\prime} S$ & & 0.155 & 653.6 \\
\hline$F P^{\prime} S$ & & 0.189 & 798.0 \\
\hline $\mathrm{U}$ & & 0.001 & 4.2 \\
\hline $\mathrm{Np}$ & & $4.7 \times 10^{-4}$ & 0.2 \\
\hline $\mathrm{Pu}$ & & $4.7 \times 10^{-5}$ & 0.02 \\
\hline $\mathrm{Am}$ & & 0.0026 & 10.78 \\
\hline $\mathrm{Cm}$ & & 0.00012 & 0.507 \\
\hline
\end{tabular}





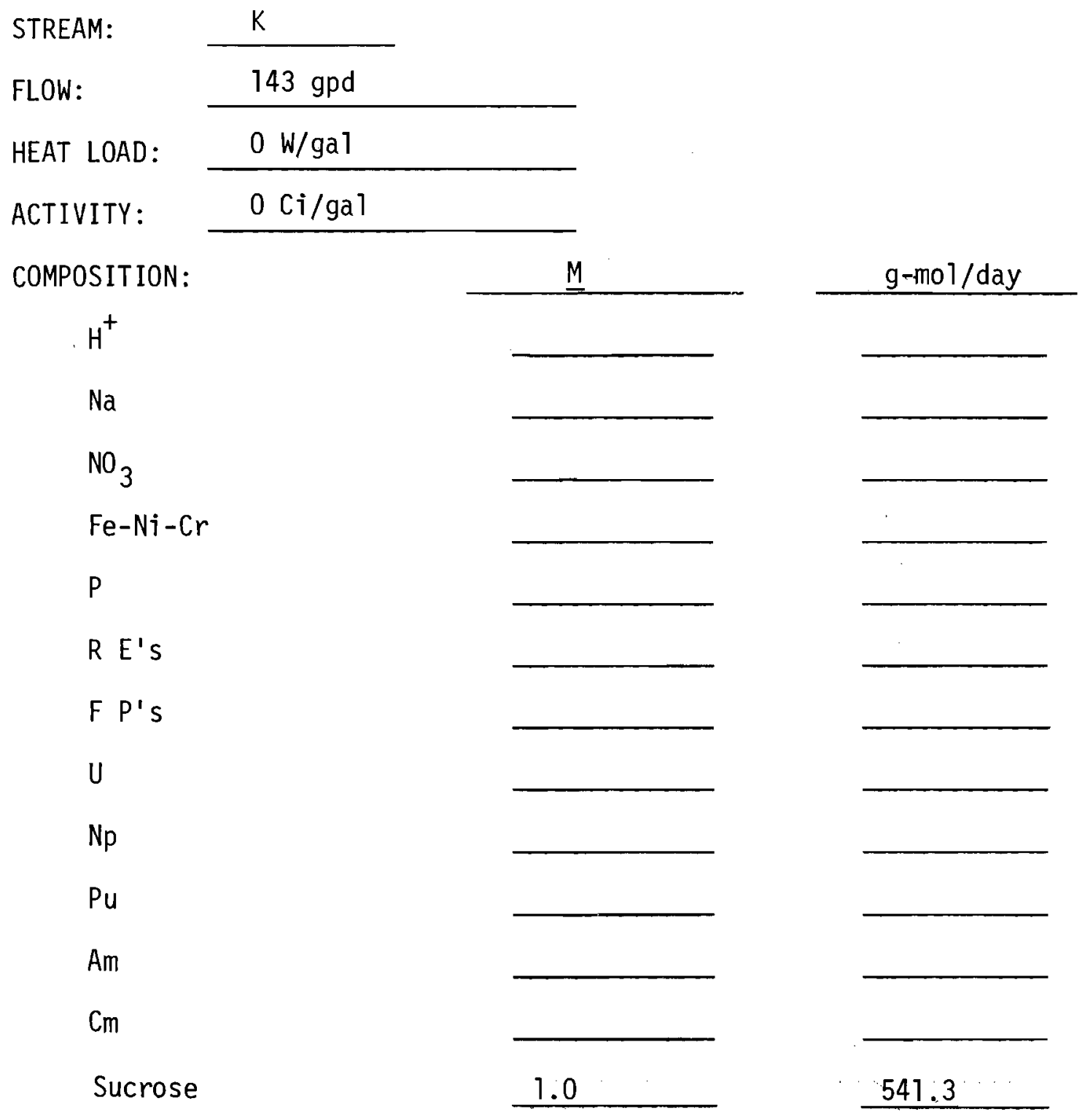




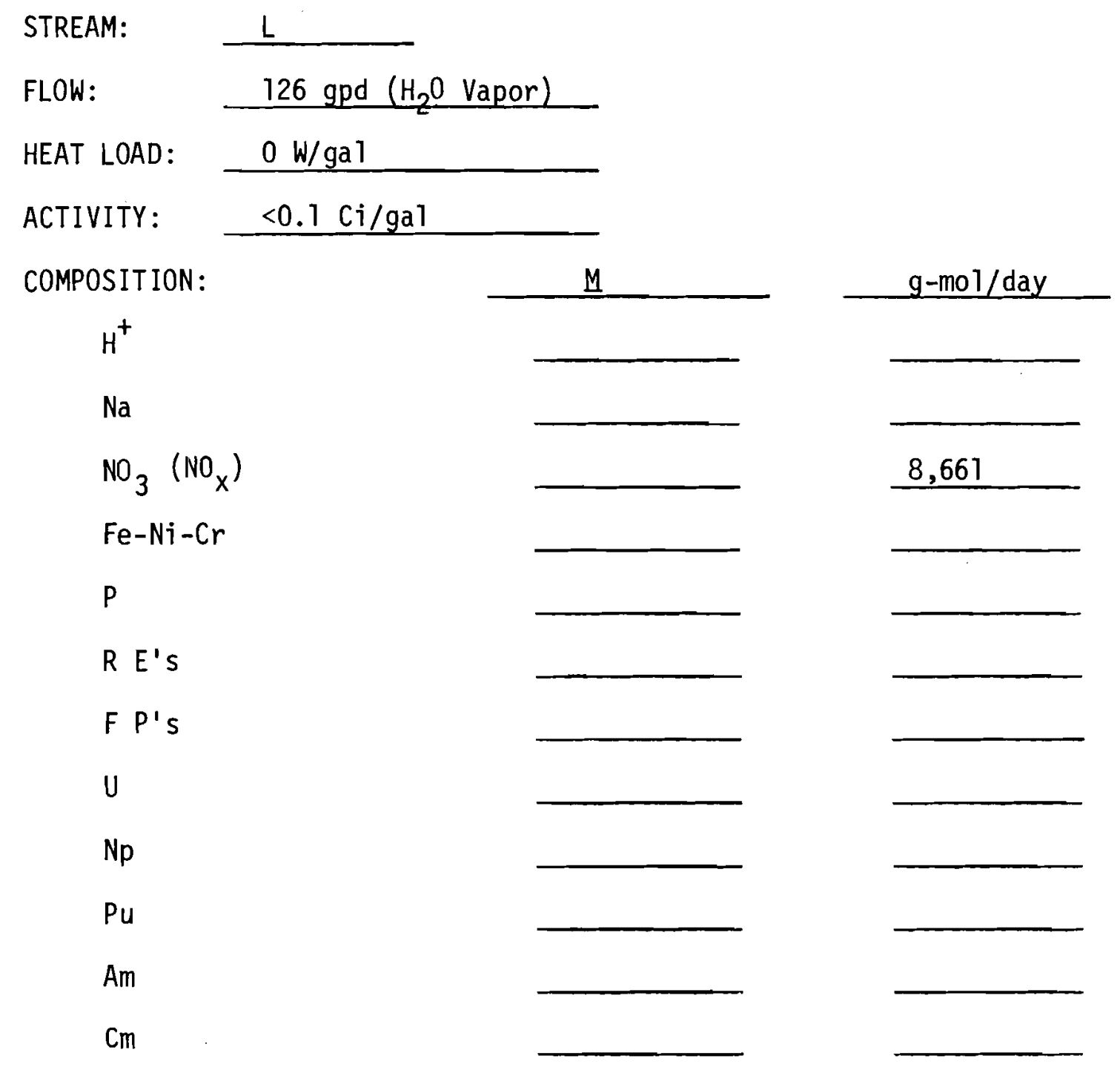




\begin{tabular}{|c|c|c|c|}
\hline STREAM: & $M$ & & \\
\hline FLOW: & $1130 \mathrm{gpd}$ & & \\
\hline HEAT LOAD: & $11.43 \mathrm{~W} / \mathrm{gal}$ & & \\
\hline ACTIVITY: & ح1645 Ci/gal & & \\
\hline COMPOSITION: & & $M$ & g-mol/day \\
\hline $\mathrm{H}^{+}$ & & 1.006 & 4,304 \\
\hline $\mathrm{Na}$ & & 0.246 & 1,080 \\
\hline $\mathrm{NO}_{3}$ & & 3.30 & 14,111 \\
\hline $\mathrm{Fe}-\mathrm{Ni}-\mathrm{Cr}$ & & 0.411 & 1,802 \\
\hline$P$ & & 0.025 & 105.3 \\
\hline$R E^{\prime} S$ & & 0.149 & 653.6 \\
\hline$F P^{\prime} s$ & & 0.182 & 798 \\
\hline $\mathrm{U}$ & & & 4.2 \\
\hline $\mathrm{Np}$ & & & 0.2 \\
\hline $\mathrm{Pu}$ & & & 0.2 \\
\hline Am & & & 10.78 \\
\hline $\mathrm{Cm}$ & & 0.000116 & 0.507 \\
\hline
\end{tabular}




\begin{tabular}{|c|c|c|c|}
\hline STREAM: & $N$ & & \\
\hline FLOW: & $517 \mathrm{gpd}$ & & \\
\hline HEAT LOAD: & $2.86 \mathrm{~W} / \mathrm{ga} 1$ & & \\
\hline ACTIVITY: & $2300 \mathrm{Ci} / \mathrm{gal}$ & & \\
\hline COMPOSITION: & & $M$ & g-mol/day \\
\hline $\mathrm{H}^{+}$ & & 0.022 & 43 \\
\hline $\mathrm{Na}$ & & 0.0056 & 11 \\
\hline $\mathrm{NO}_{3}$ & & 0.072 & 141 \\
\hline $\mathrm{Fe}-\mathrm{Ni}-\mathrm{Cr}$ & & 0.0092 & 18 \\
\hline$P$ & & 0.0511 & 100 \\
\hline$R E^{\prime} S$ & & 0.0036 & 7 \\
\hline$F P^{\prime} s$ & & 0.202 (including & 395 \\
\hline $\mathrm{U}$ & & & 0.04 \\
\hline $\mathrm{Np}$ & & & 0.002 \\
\hline $\mathrm{Pu}$ & & & 0.0002 \\
\hline Am & & & 0.108 \\
\hline $\mathrm{Cm}$ & & & 0.0051 \\
\hline
\end{tabular}




\begin{tabular}{|c|c|c|c|}
\hline STREAM: & 0 & & \\
\hline FLOW: & $1113 \mathrm{gpd}$ & & \\
\hline HEAT LOAD: & $10.28 \mathrm{~W} / \mathrm{gal}$ & & \\
\hline ACTIVITY: & $7530 \mathrm{Ci} / \mathrm{gal}$ & & \\
\hline COMPOSITION: & & $\underline{M}$ & g-mol/day \\
\hline $\mathrm{H}^{+}$ & & 1.01 & 4,261 \\
\hline $\mathrm{Na}$ & & 0.254 & 1,069 \\
\hline $\mathrm{NO}_{3}$ & & 3.32 & 13,970 \\
\hline $\mathrm{Fe}-\mathrm{Ni}-\mathrm{Cr}$ & & 0.42 & 1,784 \\
\hline $\mathrm{P}$ & & 0.0012 & 5.3 \\
\hline$R E^{\prime} s$ & & 0.153 & 646.6 \\
\hline$F P^{\prime} s$ & & 0.096 & 403 \\
\hline$U$ & & 0.00099 & 4.76 \\
\hline $\mathrm{Np}$ & & $4.7 \times 10^{-4}$ & 0.198 \\
\hline $\mathrm{Pu}$ & & $4.7 \times 10^{-5}$ & 0.0198 \\
\hline $\mathrm{Am}$ & & 0.0025 & 10.67 \\
\hline $\mathrm{Cm}$ & & 0.00012 & 0.502 \\
\hline
\end{tabular}


Ion-Exchange Recovery of Curium

The aqueous stream from the denitration section contains curium at a concentration of about $0.0001 \mathrm{M}$. The curium is recovered from the stream and purified by an ion-exchange process. The ion-exchange process is carried out batchwise and solution equivalent to 17.5 tonne of fuel is processed per batch. It requires about 3.5 days to process each batch of feed. The feed solution is diluted approximately $50 \%$ with water to reduce the acid concentration to about $0.5 \mathrm{M}$ prior to processing. The time cycle for the ion-exchange process is shown in Figure 6 , and the flow diagram is given in Figure B-3; the flows indicated in Figure B-3 are gallons per batch. The compositions of the various streams are given on pages $B-24$ through B-38.

\section{RESIN DESTRUCTION}

The resin used in the ion-exchange process will have to be replaced periodically. The average volume of waste resin is estimated to be about 400 gallons per batch of feed processed. The resin, which will be contaminated, will have to be destroyed in some manner. Incineration appears to be the most practical method available. This means an incineration and off-gas filter system will have to be provided. The filter system will have to provide sufficient contaminant removal to allow release of the incinerator off-gas to the atmosphere.

Since resin removal from the columns will be on a periodic rather than a continuous basis, the resin can be stockpiled. The incinerator can then be operated periodically as needed to control the spent resin inventory.

The resin is a strong base cation resin of the Dowex 50 type. It is a sulfonated copolymer of styrene and divinylbenzene. The resin has an $8 \%$ cross-linkage and a particle size range of 100 to 200 mesh. Bulk density of the dry resin is about 0.36 grams per cubic centimeter $(3.0 \mathrm{lb} / \mathrm{ga} 1)$. Heat of combustion should be 12 to $15,000 \mathrm{Btu} / 1 \mathrm{~b}$. 


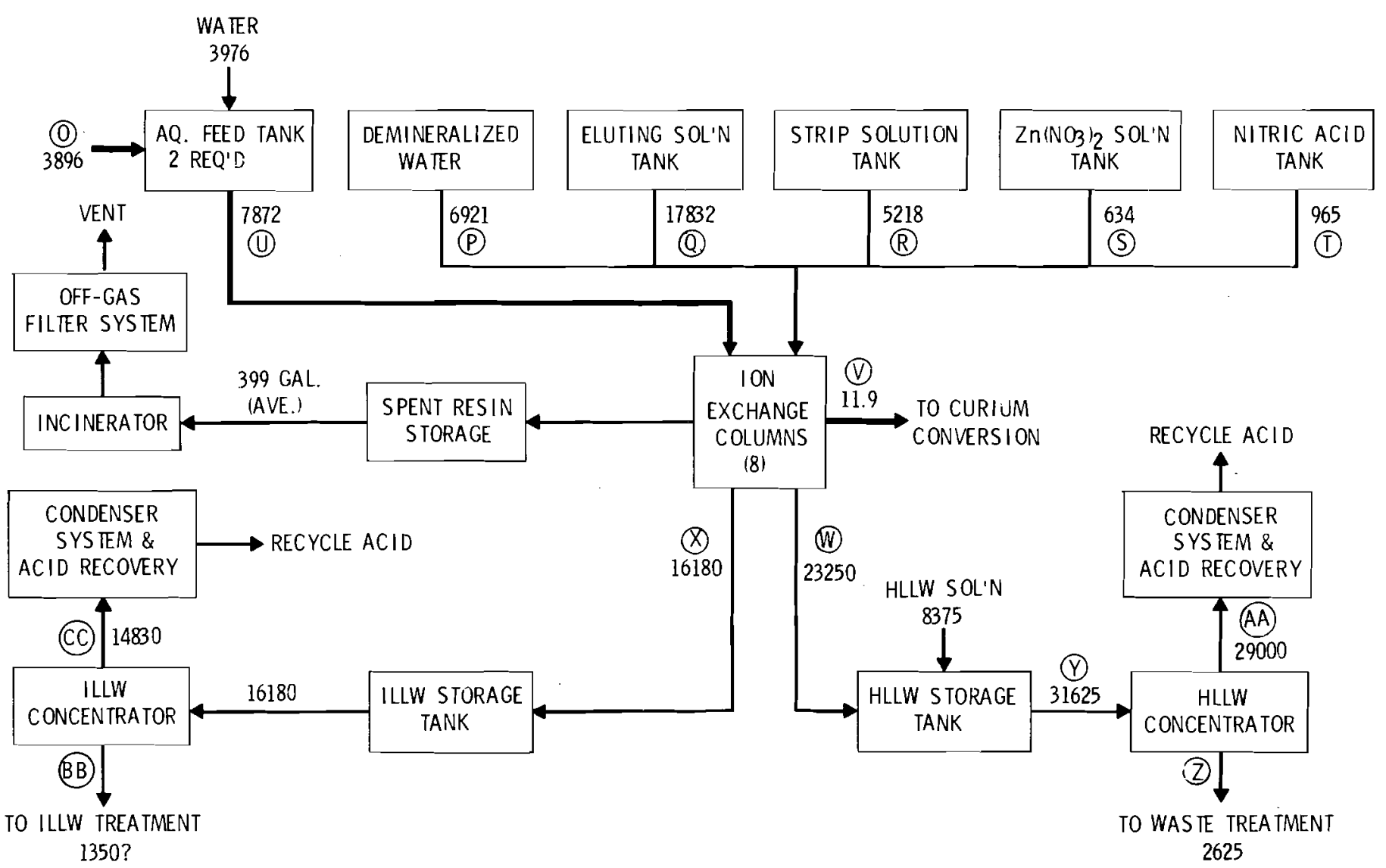

NUMBERS INDICATE FLOWS IN GALLONS PER BATCH (17.5 MT FUEL/BATCH LETTERS-STREAM COMPOSITIONS ARE GIVEN ON SEPARATE PAGES

$\rightarrow$ INDICATES CURIUM PATH

FIGURE B-3. Flow Diagram for Ion Exchange Recovery and Purification of Curium 


\begin{tabular}{|c|c|c|c|}
\hline STREAM: & 0 & & \\
\hline FLOW: & $3896 \mathrm{gal} / \mathrm{batch}$ & & \\
\hline HEAT LOAD: & $10.28 \mathrm{~W} / \mathrm{gal}$ & & \\
\hline ACTIVITY: & ح1530 Ci/gal & & \\
\hline COMPOSITION: & & $\underline{M}$ & g-mol/batch \\
\hline $\mathrm{H}^{+}$ & & 1.01 & 14,914 \\
\hline $\mathrm{Na}$ & & 0.254 & 3,742 \\
\hline $\mathrm{NH}_{4}^{+}$ & & & \\
\hline $\mathrm{NO}_{3}^{-}$ & & 3.32 & 48,895 \\
\hline DTPA & & & \\
\hline $\mathrm{Zn}$ & & & \\
\hline $\mathrm{Fe}-\mathrm{Cr}-\mathrm{Ni}$ & & 0.42 & 6,244 \\
\hline$P$ & & 0.0012 & 18.6 \\
\hline$R E^{\prime} s$ & & 0.153 & 2,263 \\
\hline$F P^{\prime} s$ & & 0.096 & 1,411 \\
\hline $\mathrm{U}$ & & 0.00099 & 14.6 \\
\hline $\mathrm{Np}$ & & $4.7 \times 10^{-4}$ & 0.7 \\
\hline $\mathrm{Pu}$ & & $4.7 \times 10^{-5}$ & 0.07 \\
\hline Am & & 0.0025 & 37.4 \\
\hline $\mathrm{Cm}$ & & 0.00012 & 1.76 \\
\hline
\end{tabular}




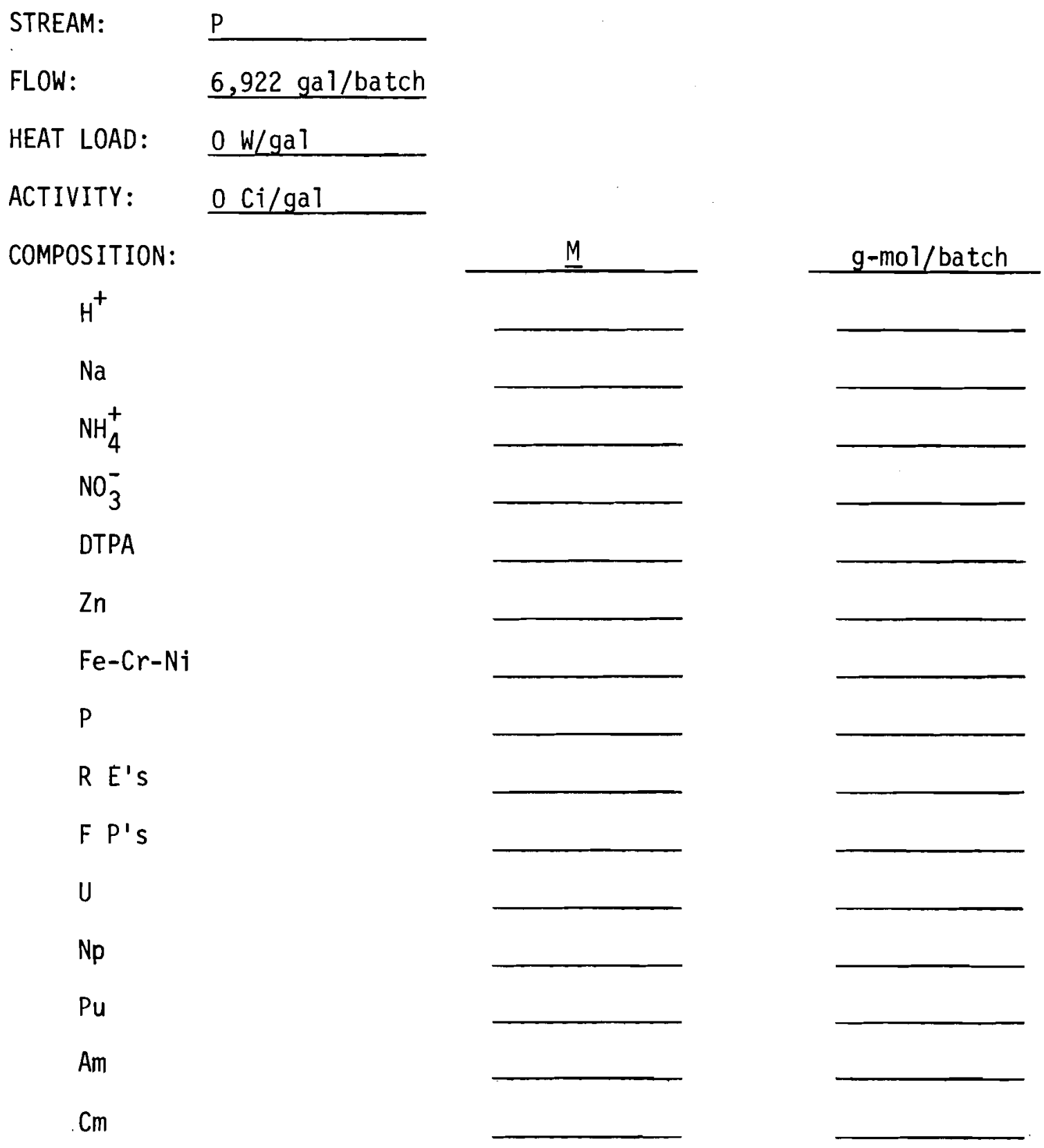




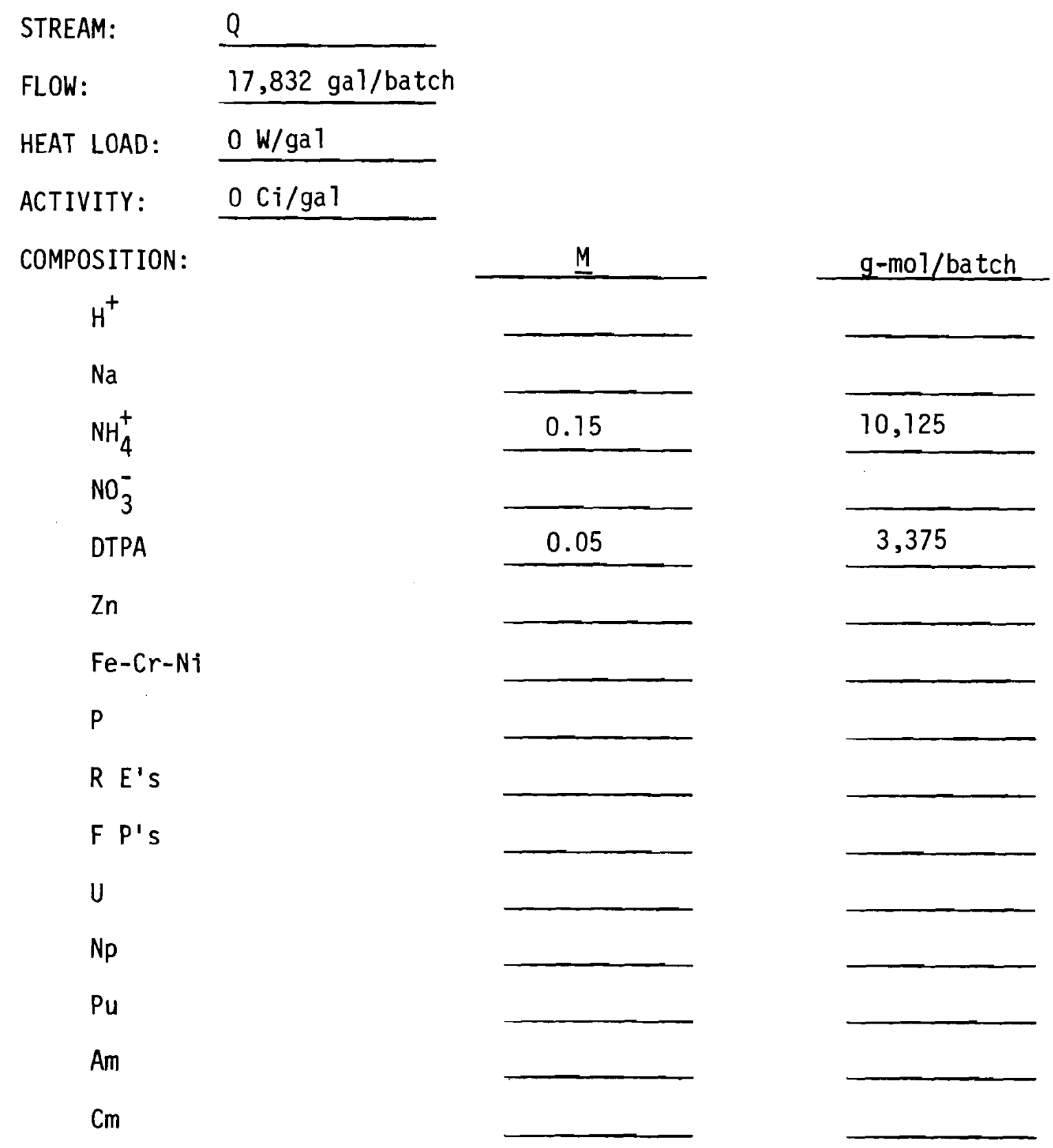




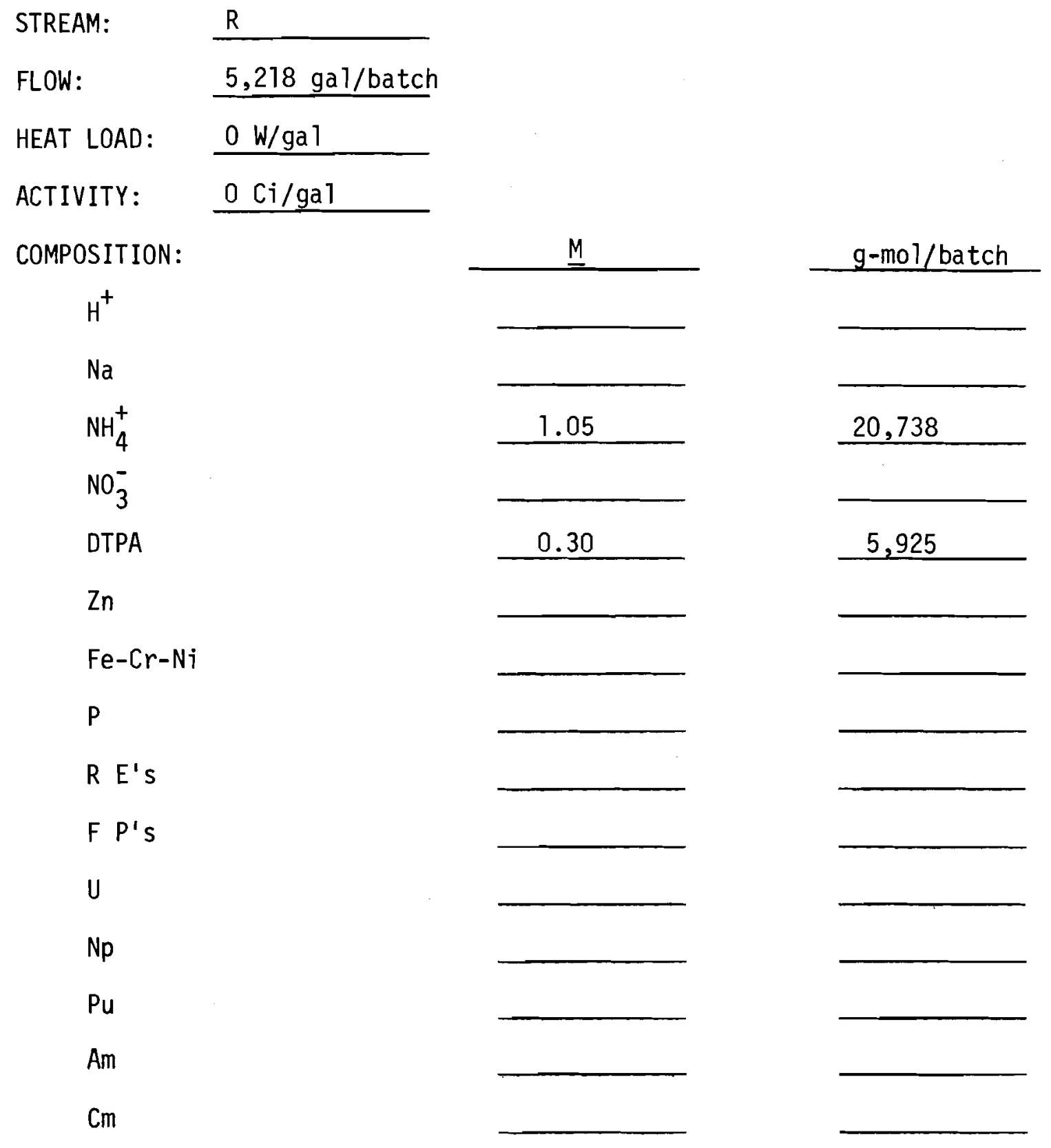




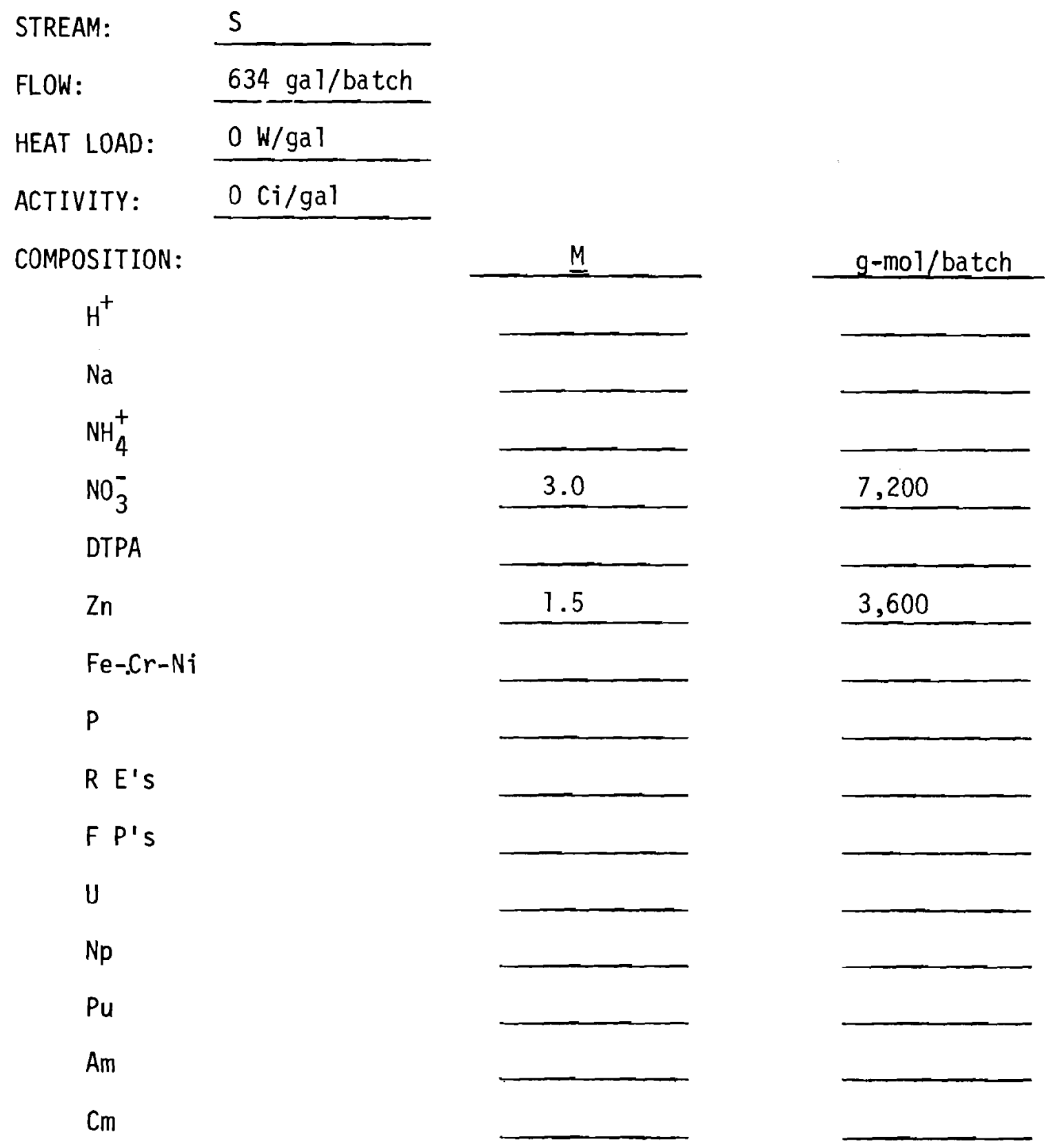




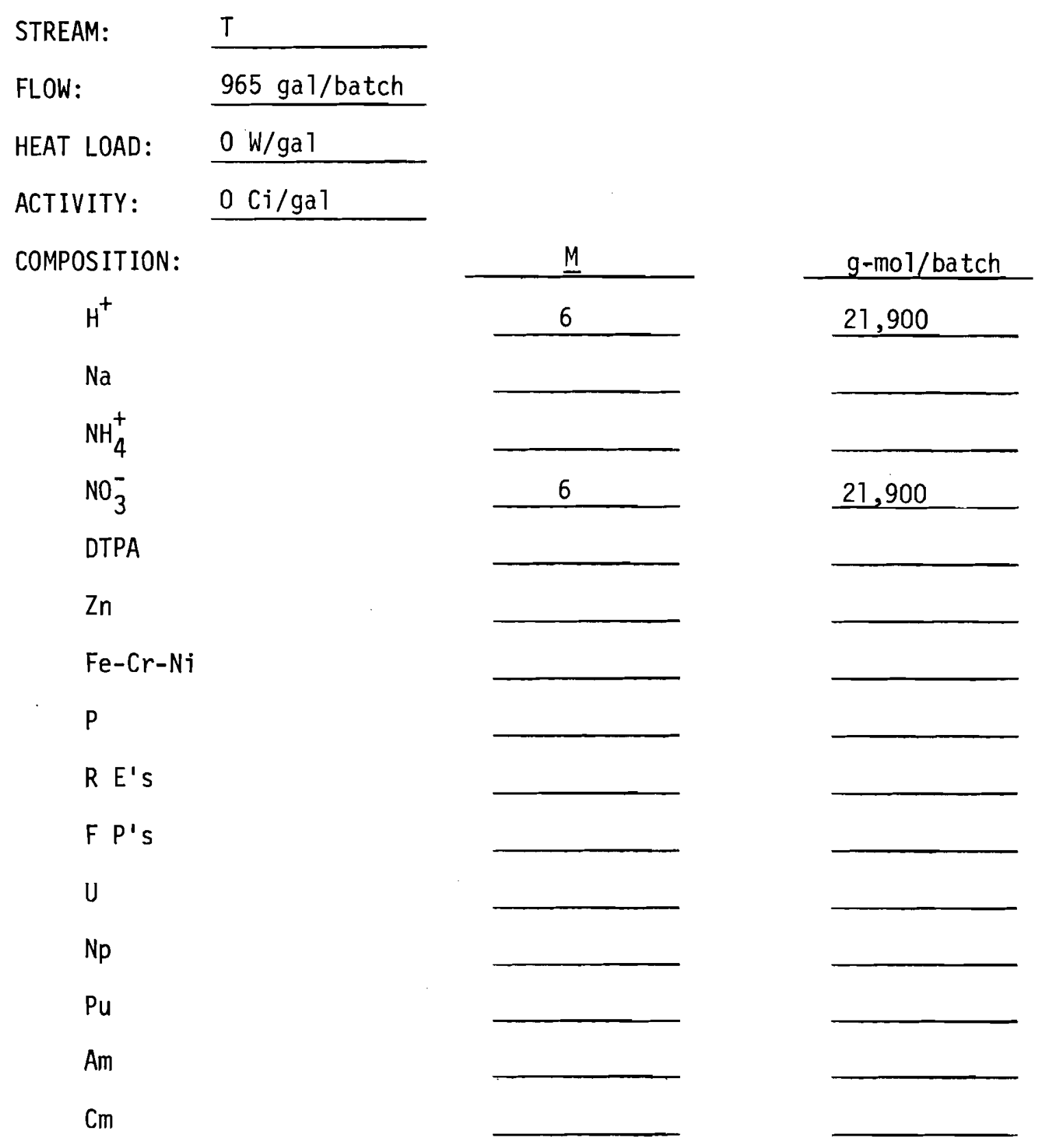




\begin{tabular}{|c|c|c|c|}
\hline STREAM: & U & & \\
\hline FLOW: & $7,872 \mathrm{ga} 1 /$ batch & & \\
\hline HEAT LOAD: & $5.09 \mathrm{~W} / \mathrm{gal}$ & & \\
\hline ACTIVITY: & $2757 \mathrm{Ci} / \mathrm{gal}$ & & \\
\hline COMPOSITION: & & $\underline{M}$ & g-mol/batch \\
\hline $\mathrm{H}^{+}$ & & 0.50 & 14,898 \\
\hline $\mathrm{Na}$ & & 0.126 & 3,742 \\
\hline $\mathrm{NH}_{4}^{+}$ & & & \\
\hline $\mathrm{NO}_{3}^{-}$ & & 1.64 & 48,895 \\
\hline DTPA & & & \\
\hline $\mathrm{Zn}$ & & & \\
\hline $\mathrm{Fe}-\mathrm{Cr}-\mathrm{Ni}$ & & 0.210 & 6.244 \\
\hline$P$ & & 0.0006 & 18.5 \\
\hline$R E^{\prime} s$ & & 0.076 & 2.263 \\
\hline$F P^{\prime} S$ & & 0.047 & 1,411 \\
\hline$U$ & & 0.0005 & 14.6 \\
\hline $\mathrm{Np}$ & & 0.00002 & 0.7 \\
\hline $\mathrm{Pu}$ & & 0.000002 & 0.07 \\
\hline$A m$ & & 0.00125 & 37.4 \\
\hline $\mathrm{Cm}$ & & 0.000059 & 1.76 \\
\hline
\end{tabular}




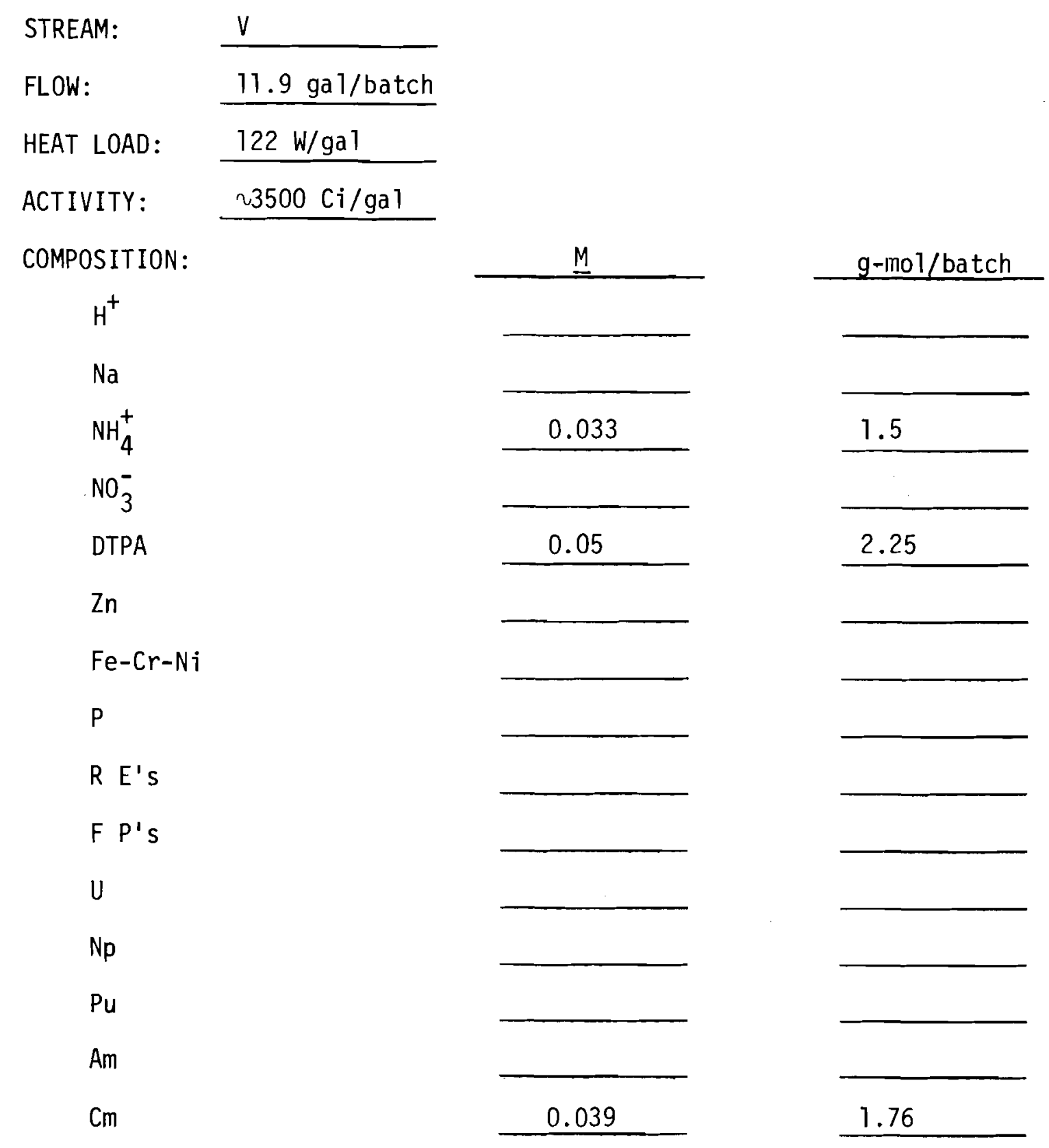




\begin{tabular}{|c|c|c|c|}
\hline STREAM: & $W$ & & \\
\hline FLOW: & $23,250 \mathrm{gal} / \mathrm{batch}$ & & \\
\hline HEAT LOAD: & $1.66 \mathrm{~W} / \mathrm{ga} 1$ & & \\
\hline ACTIVITY: & $2254 \mathrm{Ci} / \mathrm{gal}$ & & \\
\hline COMPOSITION: & & M & g-mol/batch \\
\hline $\mathrm{H}^{+}$ & & 0.293 & 25,873 \\
\hline $\mathrm{Na}$ & & 0.0425 & 3,742 \\
\hline $\mathrm{NH}_{4}^{+}$ & & 0.159 & 14,015 \\
\hline $\mathrm{NO}_{3}^{-}$ & & 0.556 & 48,895 \\
\hline DTPA & & 0.083 & 7,338 \\
\hline $\mathrm{Zn}$ & & & \\
\hline $\mathrm{Fe}-\mathrm{Cr}-\mathrm{Ni}$ & & 0.071 & 6,249 \\
\hline P & & 0.0002 & 18.5 \\
\hline$R E^{\prime} S$ & & 0.0257 & 2,263 \\
\hline$F P^{\prime} s$ & & 0.016 & 1,411 \\
\hline$U$ & & 0.00016 & 14.6 \\
\hline $\mathrm{Np}$ & & & 0.7 \\
\hline $\mathrm{Pu}$ & & & 0.07 \\
\hline$A m$ & & 0.00042 & 37.4 \\
\hline $\mathrm{Cm}$ & & & \\
\hline
\end{tabular}




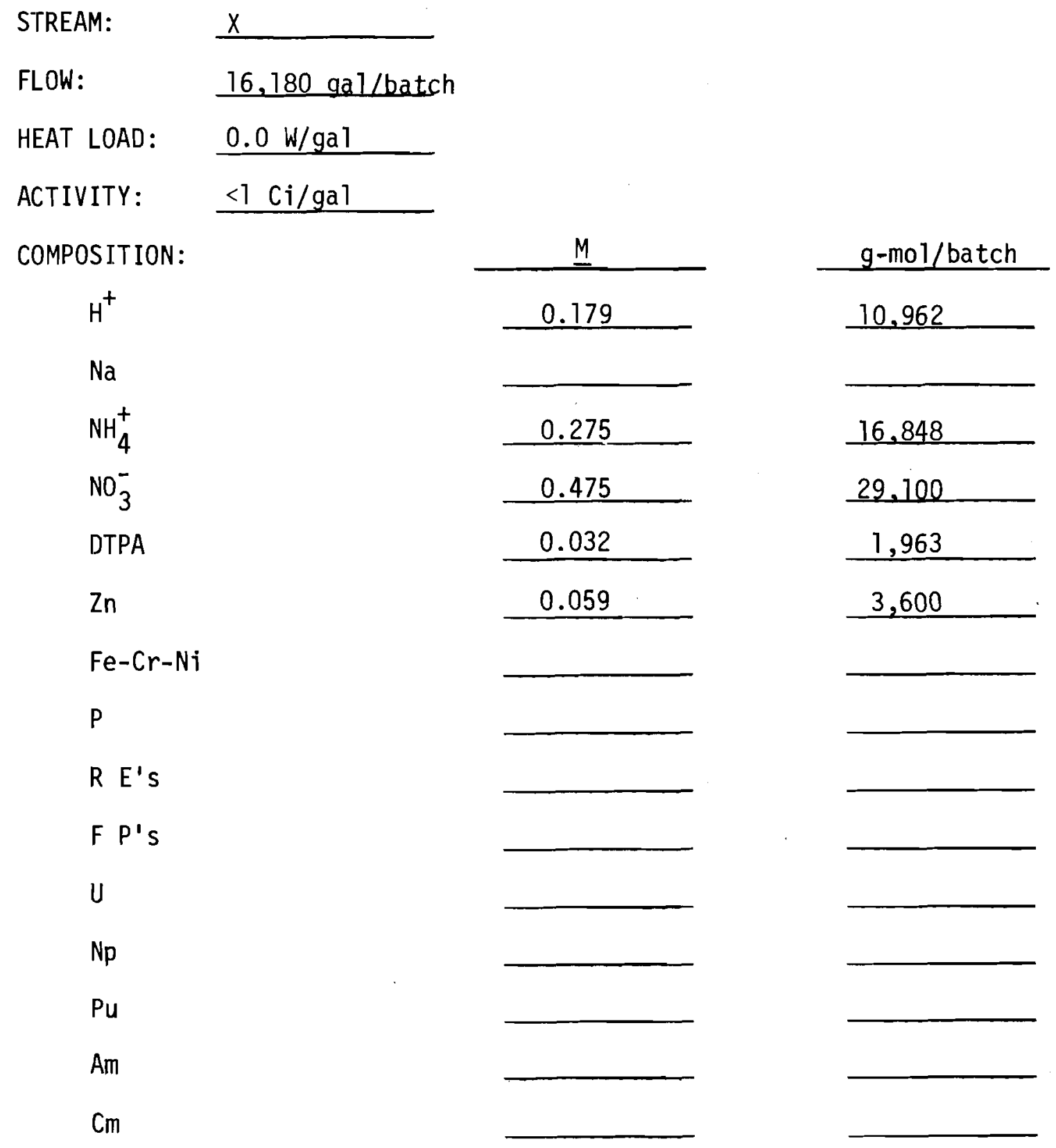




\begin{tabular}{|c|c|c|c|}
\hline \multirow{2}{*}{$\begin{array}{l}\text { STREAM: } \\
\text { FLOW: }\end{array}$} & $Y$ & \multirow[b]{5}{*}{$\underline{M}$} & \multirow[b]{5}{*}{ g-mol/batch } \\
\hline & $31,625 \mathrm{gal} / \mathrm{batch}$ & & \\
\hline HEAT LOAD: & $1.47 \mathrm{~W} / \mathrm{gal}$ & & \\
\hline ACTIVITY: & $2214 \mathrm{Ci} / \mathrm{gal}$ & & \\
\hline COMPOSITION: & & & \\
\hline $\mathrm{H}^{+}$ & & 0.30 & 35,910 \\
\hline $\mathrm{Na}$ & & 0.034 & 4,032 \\
\hline $\mathrm{NH}_{4}^{+}$ & & 0.117 & 14,015 \\
\hline $\mathrm{NO}_{3}^{-}$ & & 0.51 & 61.250 \\
\hline DTPA & & 0.061 & 7,338 \\
\hline $\mathrm{Zn}$ & & & \\
\hline $\mathrm{Fe}-\mathrm{Cr}-\mathrm{Ni}$ & & $>0.053$ & $>6,356$ \\
\hline$P$ & & $>0.003$ & $>371$ \\
\hline$R E^{\prime} S$ & & 0.019 & 2,303 \\
\hline$F P^{\prime} S$ & & 0.027 & 3,213 \\
\hline U & & 0.006 & 735 \\
\hline $\mathrm{Np}$ & & 0.0003 & 35.7 \\
\hline $\mathrm{Pu}$ & & 0.00006 & 7.35 \\
\hline Am & & 0.00032 & 38.0 \\
\hline $\mathrm{Cm}$ & & $3 \times 10^{-7}$ & 0.04 \\
\hline
\end{tabular}




\begin{tabular}{|c|c|c|c|}
\hline STREAM: & Z & & \\
\hline FLOW: & $2,625 \mathrm{ga} / \mathrm{batch}^{(\mathrm{a})}$ & & \\
\hline HEAT LOAD: & $17.4 \mathrm{~W} / \mathrm{ga} 1$ & & \\
\hline ACTIVITY: & $22,540 \mathrm{Ci} / \mathrm{gal}$ & & \\
\hline COMPOSITION: & & $\underline{\underline{M}}$ & g-mol/batch \\
\hline $\mathrm{H}^{+}$ & & (b) & $(b)$ \\
\hline $\mathrm{Na}$ & & 0.406 & 4,032 \\
\hline $\mathrm{NH}_{4}^{+}$ & & 1.41 & 14,015 \\
\hline $\mathrm{NO}_{3}^{-}$ & & (b) & $(b)$ \\
\hline DTPA & & & 0 \\
\hline $\mathrm{Zn}$ & & & \\
\hline $\mathrm{Fe}-\mathrm{Cr}-\mathrm{Ni}$ & & $>0.64$ & $>6,356$ \\
\hline $\mathrm{P}$ & & 0.037 & $>371$ \\
\hline$R E^{\prime} S$ & & 0.232 & 2,303 \\
\hline$F P^{\prime} S$ & & 0.323 & 2,142 \\
\hline$U$ & & 0.074 & 735 \\
\hline Np & & 0.0036 & 35.7 \\
\hline $\mathrm{Pu}$ & & 0.00074 & 7.35 \\
\hline $\mathrm{Am}$ & & 0.0038 & 38.0 \\
\hline $\mathrm{Cm}$ & & $3.5 \times 10^{-7}$ & 0.04 \\
\hline
\end{tabular}

(a) Variable - will depend on the level of evaporation desired in the concentrator.

(b) Exact amount is unknown, will depend several factors, values given are best estimates. 


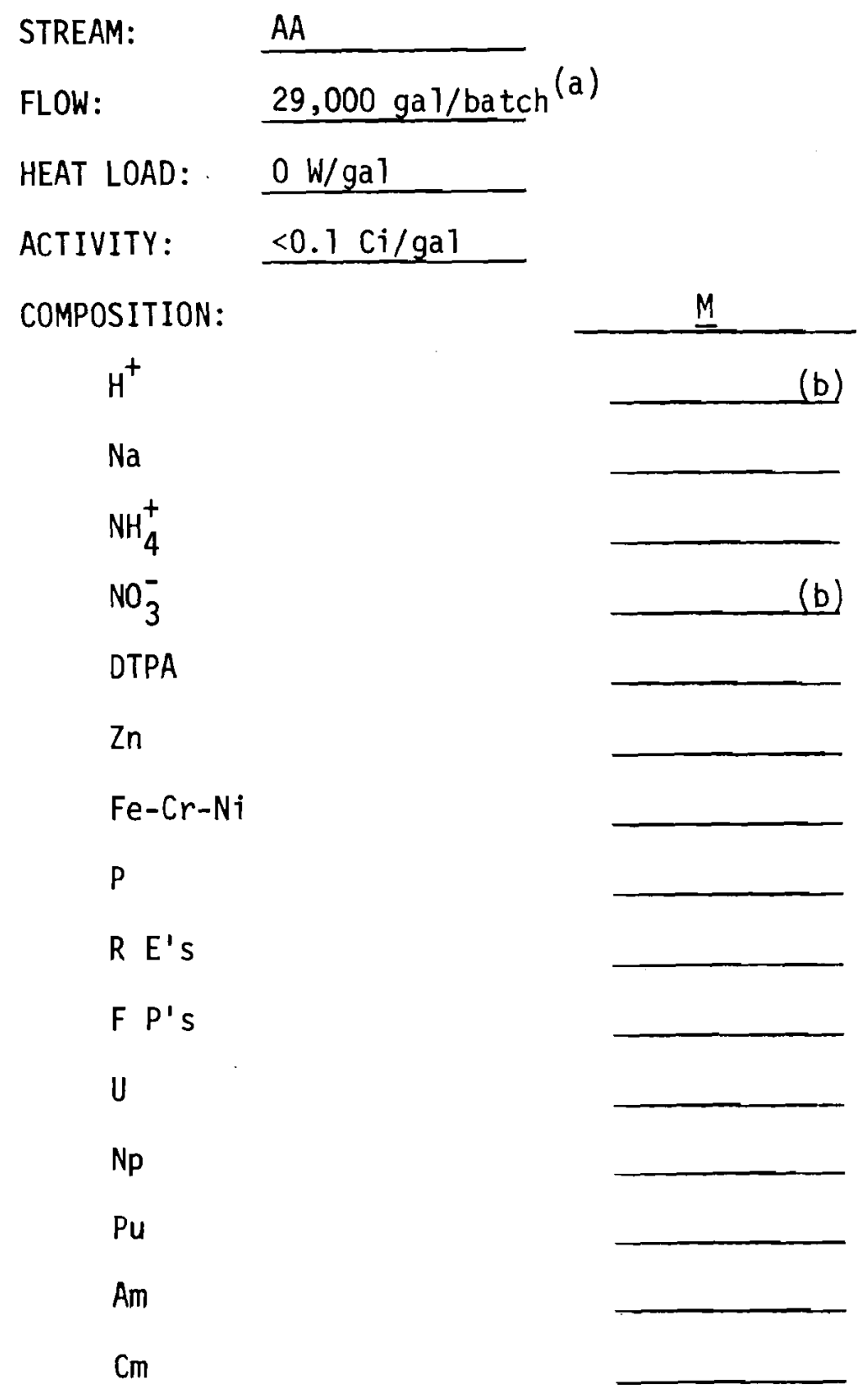

(b)

(b)
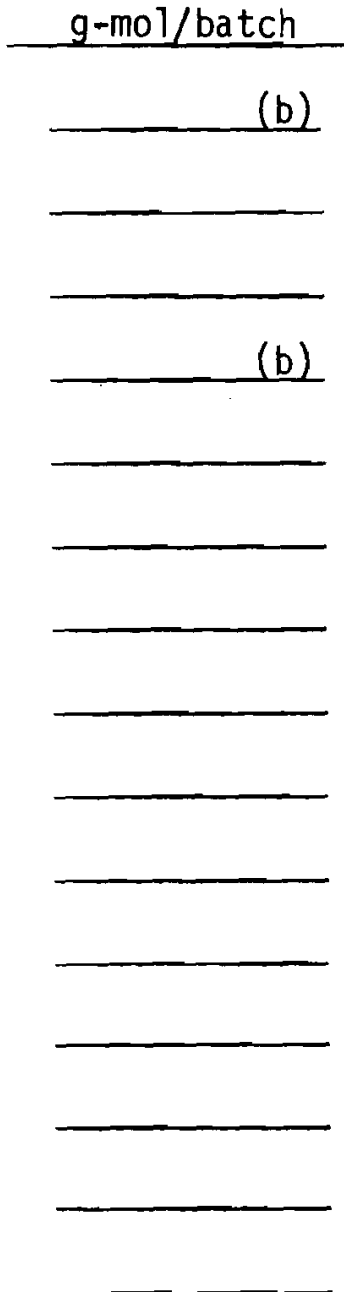

(a) Variable - will depend on the level of evaporation desired in the concentrator.

(b) Exact amount is unknown, will depend on several factors, values given are best estimates. 


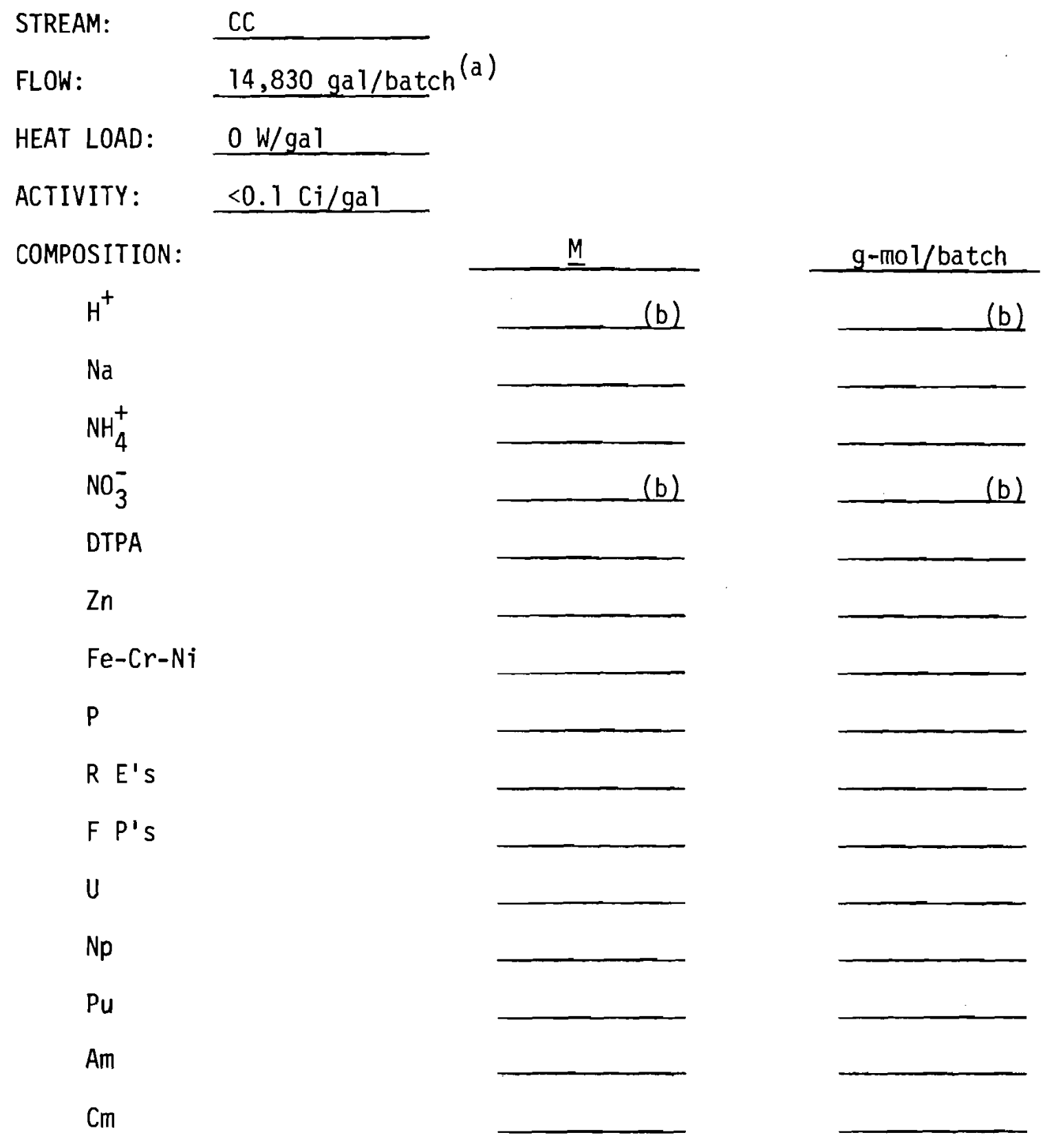

(a) Variable - will depend on the level of evaporation desired in the concentrator.

(b) Exact amount is unknown, will depend on several factors, values given are best estimates. 


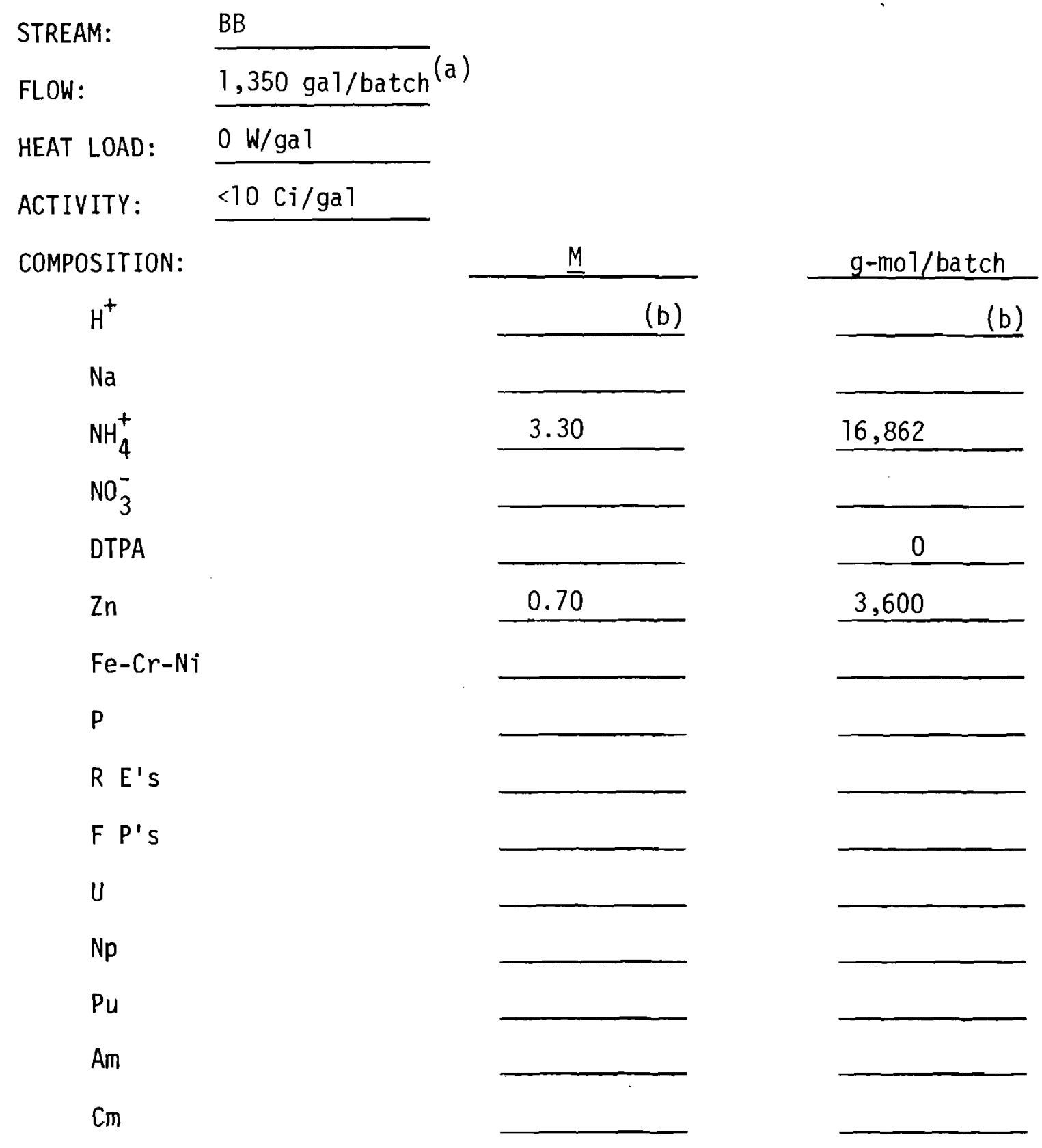

(a) Variable - wi11 depend on the level of evaporation desired in the concentrator.

(b) Exact amount is unknown, will depend on several factors, values given are best estimates. 
BNWL-1831

UC-4

\author{
ERRATA \\ for \\ Flowsheet for Recovery \\ of Curium from Power Reactor Fuel \\ Reprocessing Plant Waste \\ May 1974
}

Please replace pages $A-6$ and $B-15$ with the attached pages.

$$
\text { DONE! }
$$




\section{DISTRIBUTION}

No. of

Copies

OFFSITE

1

AEC Chicago Patent Group

U.S. Atomic Energy Commission

Chicago Operations Office

9800 South Cass Avenue

Argonne, IL 60439

A. A. Churm

AEC Division of Space Nuclear Systems

U.S. Atomic Energy Commission

Century Office Building

Washington, D.C. 20545

R. T. Carpenter

A. P. Litman (10)

G. A. Newby

1 AEC Division of Space Nuclear Systems

Germantown Headquarters B7dg.

Washington, D.C. 20545

N. Goldenberg

AEC Division of Waste Management and Transportation

U.S. Atomic Energy Commission Germantown Headquarters B1dg.

Washington, D.C. 20545

R. W. Ramsey, Jr.

AEC Division of Physical Research

U.S. Atomic Energy Commission Germantown Headquarters Bldg.

Washington, D.C. 20545

A. R. Van Dyken

AEC Division Biomedical and Environmental Research U.S. Atomic Energy Commission Germantown Headquarters

Washington, D.C. 20545

J. N. Maddox

AEC Technical Information Center 
No. of

Copies

$9 \quad$ General Atomic Company

P.0. Box 81608

San Diego, CA 92138

H. C. Carney (6)

J. J. Shefcik

$5 \quad$ Bechte1 Inc.

50 Beale Street

San Francisco, CA 94119

T. Breitmayer

F. N. Jones (4)

7 Union Carbide Corporation (ORNL)

Oak Ridge National Laboratory

P.0. Box X

Oak Ridge, TN 37830

T. A. Butler

D. 0. Campbe 11

J. H. Gillette

E. Lamb

C. L. Ottinger

J. C. Posey

B. W. Weaver

1

General Electric Company Space Division

Valley Forge Space Center

P.0. Box 8555

Philadelphia, PA 19101

P. E. Brown

ONSITE-HANFORD

$7 \quad$ AEC Richland Operations Office

P. A. Craig

0. J. Elgert

P. W. Gottschalk

H. A. House

N. T. Karagianes

B. J. Melton

M. J. Rasmussen 
No. of

Copies

2

Donald W. Douglas Laboratory 2955 George Washington Way Richland, WA 99352

E. E. Warner

J. D. Watrous

92

Batte1le

L. A. Bray

R. E. Burns

H. T. Fullam

J. H. Jarrett

R. E. Nightingale

A. M. Platt

F. P. Roberts

H. H. Van Tuyl

E. J. Wheelwright

(84)

Distr-3 